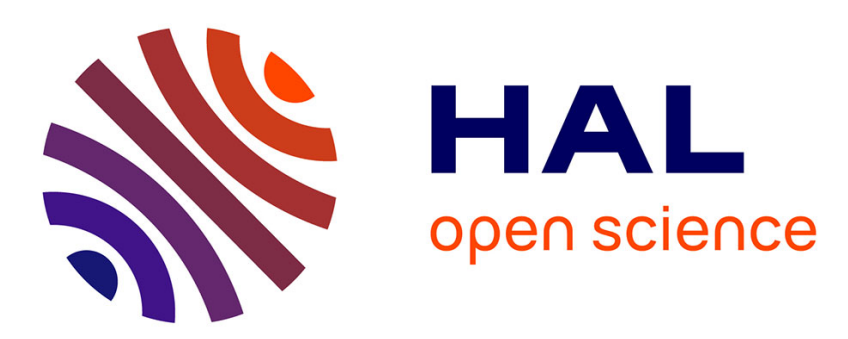

\title{
Le mont Wakasugi, son sanctuaire et le shugen dans l'histoire de Kyūshū et de l'Asie de l'Est
}

\author{
Anne Bouchy, Hiroko Mori
}

\section{To cite this version:}

Anne Bouchy, Hiroko Mori. Le mont Wakasugi, son sanctuaire et le shugen dans l'histoire de Kyūshū et de l'Asie de l'Est. Cahiers d'Extrême-Asie, 2013, no. 22, p. 203-267. halshs-03134692

\section{HAL Id: halshs-03134692 \\ https://shs.hal.science/halshs-03134692}

Submitted on 8 Feb 2021

HAL is a multi-disciplinary open access archive for the deposit and dissemination of scientific research documents, whether they are published or not. The documents may come from teaching and research institutions in France or abroad, or from public or private research centers.
L'archive ouverte pluridisciplinaire HAL, est destinée au dépôt et à la diffusion de documents scientifiques de niveau recherche, publiés ou non, émanant des établissements d'enseignement et de recherche français ou étrangers, des laboratoires publics ou privés. 


\section{Le mont Wakasugi, son sanctuaire et le shugen dans l'histoire de} Kyūshū et de l'Asie de l'Est

Hiroko Mori, Anne Bouchy

\section{Citer ce document / Cite this document :}

Mori Hiroko, Bouchy Anne. Le mont Wakasugi, son sanctuaire et le shugen dans l'histoire de Kyūshū et de l'Asie de l'Est. In: Cahiers d'Extrême-Asie, vol. 22, 2013. Le vivre ensemble à Sasaguri, une communauté de Kyūshū. Dans l'entrelacs des dynamiques du dedans et du dehors. pp. 203-267;

doi : https://doi.org/10.3406/asie.2013.1419

https://www.persee.fr/doc/asie_0766-1177_2013_num_22_1_1419

Fichier pdf généré le 06/02/2019 


\begin{abstract}
From the geographical standpoint, the northern region of Kyūshū is closer to the Korean peninsula and China, so that in antiquity, a governmental office taking charge of foreign affairs called Dazaifu was established there. The greatest megalopolis of Kyūshū nowadays, Fukuoka, developed on the basis of the port of Dazaifu, Hakata. Mount Wakasugi is one of the peaks belonging to the mountain range of Sangun extending to the north from Mount Hōman of Dazaifu, that is seen at the front as a beautiful mountain when ships are entering in Hakata port from the open sea. The kami of this mountain, named "Taiso gongen", is not an indigenous god of the inside, but one which came from the outside, across the sea. When, in the later 13th century, Mongols attempted to invade Japan, facing this "greater outside", this god, allied with the protecting god of Japan, Hachiman, and transformed itself as an original form of the god Izanagi, under the name of Taiso gongen. Diverse powers

of the inside, facing the outside, intermingled with each other, and formed a new entity of greater power.

Impoverished by the wars toward the end of Middle Ages, Mount Wakasugi was restored at the beginning of the Early Modern period by the new settlement of Sekisen-ji Ishii-bō, by Kame.ishi-bō from Mount Hōman. In the Shugen organization of Mount Hōman, Ishii-bō was a simple subaltern under the Twenty-five bō of Hōman (Hōman niju-go bō), but at the same time, he was responsible (furegashira) for the eastern region of Hōman Shugen, having under its order all the yamabushi of the counties of Munakata and Kasuya. He was thus an object of respect for villages of these counties, as was the priest (and administrator, bettō) of the regional god (sōbyō) of Kasuya county, Taiso gū. The dynamics between inside and outside that surrounded Ishii-bō were very complex.

The present article attempts to analyze according to the sources the dynamics of inside and outside that governed the Shugen who were evolving in Mount Wakasugi.
\end{abstract}




\title{
LE MONT WAKASUGI, SON SANCTUAIRE ET LE SHUGEN DANS L'HISTOIRE DE KYŪSHŪ ET DE L'ASIE DE L'EST
}

\author{
MorI Hiroko 森弘子
}

\begin{abstract}
From the geographical standpoint, the northern region of Kyūshü is closer to the Korean peninsula and China, so that in antiquity, a governmental office taking charge of foreign affairs called Dazaifu 太幸付 was established there. The greatest megalopolis of Kyüshü nowadays, Fukuoka 福岡市, developed on the basis of the port of Dazaifu, Hakata 博多. Mount Wakasugi 若杉山 is one of the peaks belonging to the mountain range of Sangun 三郡山系 extending to the north from Mount Homan 宝満山 of Dazaifu, that is seen at the front as a beautiful mountain when ships are entering in Hakata port from the open sea. The kami of this mountain, named “Taiso gongen" 太祖権現, is not an indigenous god of the inside, but one which came from the outside, across the sea. When, in the later $13^{\text {th }}$ century, Mongols attempted to invade Japan, facing this "greater outside," this god, allied with the protecting god of Japan, Hachiman 八幡神, and transformed itself as an original form of the god Izanagi 伊兹諾尊, under the name of Taiso gongen. Diverse powers of the inside, facing the outside, intermingled with each other, and formed a new entity of greater power.

Impoverished by the wars toward the end of Middle Ages, Mount Wakasugi was restored at the beginning of the Early Modern period by the new settlement of Sekisen-ji Isbii-bō 石泉寺石井坊, by Kame.ishi-bō 龟石坊 from Mount Höman. In the Shugen 修験 organization of Mount Höman, Ishii-bō was a simple subaltern under the Twenty-five bō of Höman (Höman nijū go bō 宝満一十五坊), but at the same time, be was responsible (furegashira 触頭) for the eastern region of Homan Shugen, baving under its order all the yamabushi 山伏 of the counties of Munakata 宗像郡 and Kasuya 糟屋郡. He was thus an object of respect for villages of these counties, as was the priest (and administrator, bettō 別当) of the regional god (sōbyō 宗潮) of Kasuya county, Taiso gū 太祖宮. The dynamics between inside and outside that surrounded Ishii-bo were very complex.

The present article attempts to analyze according to the sources the dynamics of inside and outside that governed the Shugen who were evolving in Mount Wakasugi.
\end{abstract}

Dans le cadre du programme de recherche "Entre "dedans" et "debors" : les dynamiques socioculturelles au Japon », conduit de 2004 à 2010 par notre équipe franco-japonaise dans la commune de Sasaguri, mon travail s'est concentré sur l'étude du mont Wakasugi 若杉山, montagne qui se dresse au sud de cette commune. Cette montagne a fait partie jusqu'à Meiji d'un réseau régional du shugendō dont les deux principaux pôles à Kyūshū étaient les monts Hōman 宝満山 et Hiko 英彦山. Le mont Hōman, situé au nord-est de Daizaifu 太宰府, est, par cette position géographique, le 
gardien de la «porte des puissances néfastes 》(kimon 鬼門) protégeant cette ville qui joua le rôle de capitale de Kyūshū dans l'Antiquité et au Moyen Age. L'organisation shugen* du mont Hōman, à laquelle était affilié le shugen du mont Wakasugi, était elle-même sous l'obédience du mont Hiko, le centre le plus puissant du shugendō de Kyūshū. Habitant à Dazaifu 太萃府市, au sud-est de Fukuoka et au sud de la commune de Sasaguri, je mène depuis de longues années des recherches sur le shugen du mont Hōman'. Dans ce contexte, j'ai abordé la question des rapports entre les monts Hōman et Wakasugi, mais à ce jour, il n'existe aucune étude complète sur le mont Wakasugi lui-même. C'est donc en m'inscrivant dans cette continuité, et, en tout premier lieu, pour tenter de combler ce manque, que j'ai entrepris mon approche de l'histoire et des structures religieuses du mont Wakasugi.

Sur le mont Wakasugi, il n'y a pas d'autres travaux que l'étude partielle de Yahiro Izumi 八尋和泉 ${ }^{2}$ ainsi que les quelques éléments intégrés à la monographie de la commune de Sasaguri ${ }^{3}$. L'étude de Yahiro présente, en transcription contemporaine, l'ensemble des documents historiques relatant l'histoire des origines (engi 縁起) et les historiographies locales, mais son point de vue est celui de l'histoire de l'art. Quant aux archives de l'Ishii-bō 石井坊, qui était à la fois le prêtre du sanctuaire du mont Wakasugi, le Taiso-gū 太祖宮4, et le responsable (furegasbira 触頭) des affiliés shugen du mont Hōman pour la partie orientale du canton de Kasuya 糟屋郡 ${ }^{5}$, cet

* Comme les autres chercheurs japonais aujourd'hui, Mori Hiroko utilise ici préférentiellement le terme shugen 修験 à shugendō 修験道 pour désigner à la fois ce courant religieux et ses adeptes, qui sont plus couramment appelés yamabushi 山伏 («celui qui dort dans les montagnes »). Shugen est donc utilisé ici, d'une part comme nom commun pour désigner soit l'une des organisations du shugendō (ainsi, shugen du mont Hōman), soit, parallèlement au terme yamabushi, un affilié du shugen, et d'autre part, comme adjectif. Dans ce cas seulement, il est en italique. Le shugendō, "voie des pouvoirs par l'ascèse ", est un courant rcligicux, bien vivant aujourd'hui, qui est né au Japon, dans l'Antiquité, de la fusion de croyances locales centrées sur les divinités des montagnes, de pratiques qui leur étaient associées, et d'éléments du bouddhisme et du taoïsme venus de Chine. Composé d'organisations régionales implantées dans les montagnes et d'un réseau de temples dont les sommets hiérarchiques étaient liés aux pouvoirs centraux, le shugendō a constitué une puissance socioreligieuse, politique et économique importante jusqu'à Meiji. L'histoire et les multiples dimensions du shugendō n'ont été progressivement mises au jour qu'à partir de la seconde moitié du $\mathrm{XX}^{e}$ siècle par les historiens et les ethnologues japonais. Sur le shugendō et l'historique des études, voir la présentation d'Anne Bouchy, «La cascade et l'écritoire. Dynamique de l'histoire du fait religieux et de l'ethnologie du Japon : le cas du shugendō ", BEFEO 87/I (2000), p. 341-366. (N.D.T.)

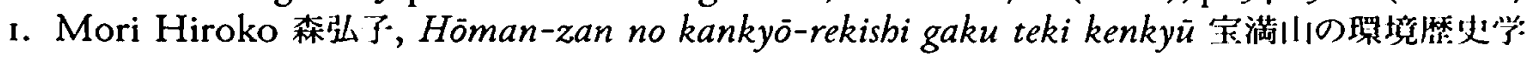
的研究, 2008.

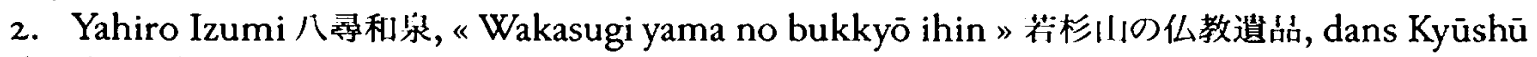
rekishi shiryōkan 九州歷史資料館, éd., Chikuzen Kasuya. Wakasugi yama no bukkyō iseki 筑湔䊀। 屋: 若杉11の仏教遺跡, 1986, p. 26-30.

3. Sasaguri-chō bunkazai senmon-iinkai 策梁町文化剘期阴委期会, éd., Sasaguri chōshi. Rekishi-hen 策栗町誌:歴史編, 1982.

4. Pour le nom Taiso-gū, on trouve la graphie 人祖往 dans les documents anciens; mais comme 太祖综 est la graphie la plus répandue, c'est celle que j'utilise.

5. Le nom d'ermitages comme l'Ishii-bō pouvait désigner à la fois la structure religieuse et le spécialiste religieux qui en avait la charge. Ici, le terme Ishii-bō désigne souvent les shugen qui eurent la charge de cet ermitage de génération en génération, et leur tradition. (N.D.T.) 
auteur n'en fait qu'une présentation générale. Yahiro m’avait montré ces archives comme un travail à faire, mais jusque-là le volume considérable de ces documents m'avait toujours fait reculer : cette enquête collective sur Sasaguri a été pour moi l'occasion de me mettre à leur dépouillement, et par là de m'acquitter de la tâche qui m'avait été confiée. C'est là le second motif de la présente étude. Entre-temps, le groupe de volontaires organisé, dans le cadre communal, autour de la lecture, de la transcription et du classement des archives manuscrites de Sasaguri avait pris en photo l'ensemble des pièces, rendant ainsi le travail plus facile.

L'enquête de Yahiro a prouvé l'existence de pratiques cultuelles anciennes sur le mont Wakasugi par la mise au jour de statues bouddhiques et d'objets en grand nombre remontant à l'époque de Heian (784-1185). Bien plus, certains de ces vestiges témoignent de relations avec le continent asiatique, montrant ainsi l'intérêt d'une étude portant sur un site florissant aux époques antiques et médiévales. Néanmoins, personne ne s'y était encore intéressé. Par ailleurs, comme le montre le nom de la divinité qui y est vénérée, Taiso gongen 太祖権現 ${ }^{6}$, les liens avec le shugendō sont évidents. Or, à la différence de divinités shugen comme Kumano gongen 熊野権現 ou Hikosan gongen 彦山権現, dont le culte s'est très largement diffusé dans le pays, les sanctuaires qui sont affiliés à Taiso gongen sont très peu nombreux et situés dans un périmètre étroit, ce qui montre le caractère local de cette divinité. C’est bien tout l'historique de ce culte qu'il s'agit donc de mettre en lumière. L'absence de travaux sur la question tient sans doute, d'une part, au manque de documents anciens à l'exception des histoires des origines et, d'autre part, au peu de recherches effectuées sur les pratiques cultuelles relatives aux montagnes de la région. Ainsi, c'est pour dépasser cette situation que je tenterai ici de faire émerger l'histoire cultuelle du mont Wakasugi et de replacer celle-ci dans le contexte des études sur le shugendō. Tel est mon troisième motif.

Faisant de l'acquisition des pouvoirs son objectif et donnant une importance centrale au fait de « devenir un en ce corps avec le bouddha » (sokushin sokubutsu 即身即仏) par le biais de l'identification à l'univers naturel, le shugendō s'est répandu dans toutes les montagnes du pays. Pourtant, la majorité des travaux de recherche se sont focalisés soit sur les organisations centrales de Yoshino 吉野 et Kumano 熊野 (dans les départements de Nara 奈良県 et de Wakayama 和歌山県), soit sur les grands centres régionaux des Trois monts du Dewa 出羽三山 (département de Yamagata 山形県), des monts Tate 立山 (département de Toyama 富山県), Hiko ou Ishizuchi 石鎚山 (dans Shikoku 四国, département d'Ehime 愛媛県). Le mont Wakasugi ne fut pas le siège d'une grande organisation shugen comme le furent les monts Hiko ou Hōman ; néanmoins, durant sa longue histoire religieuse antérieure à l'époque moderne, il a entretenu des relations avec ces deux derniers en tant que montagne shugen. À l'époque d'Edo (I603-ı868), c'était là que résidait le responsable de l'est

6. Gongen 権現 : gen 現, “ manifestation » et gon 権, «provisoire, circonstancielle ». Il s'agit d'une notion fondamentale du courant shinbutsu shügō 神仏佔合 (《 association » ou « combinaison des dieux et des bouddhas ") de l'époque ancienne assimilant entités bouddhiques, dites " sol originel » (bonji 本地), et divinités locales, dites «traces descendues 》 (sbuijaku 垂迹), qui sont données pour être des manifestations des bouddhas et bodhisattvas adaptées à la société japonaise. (N.D.T.) 


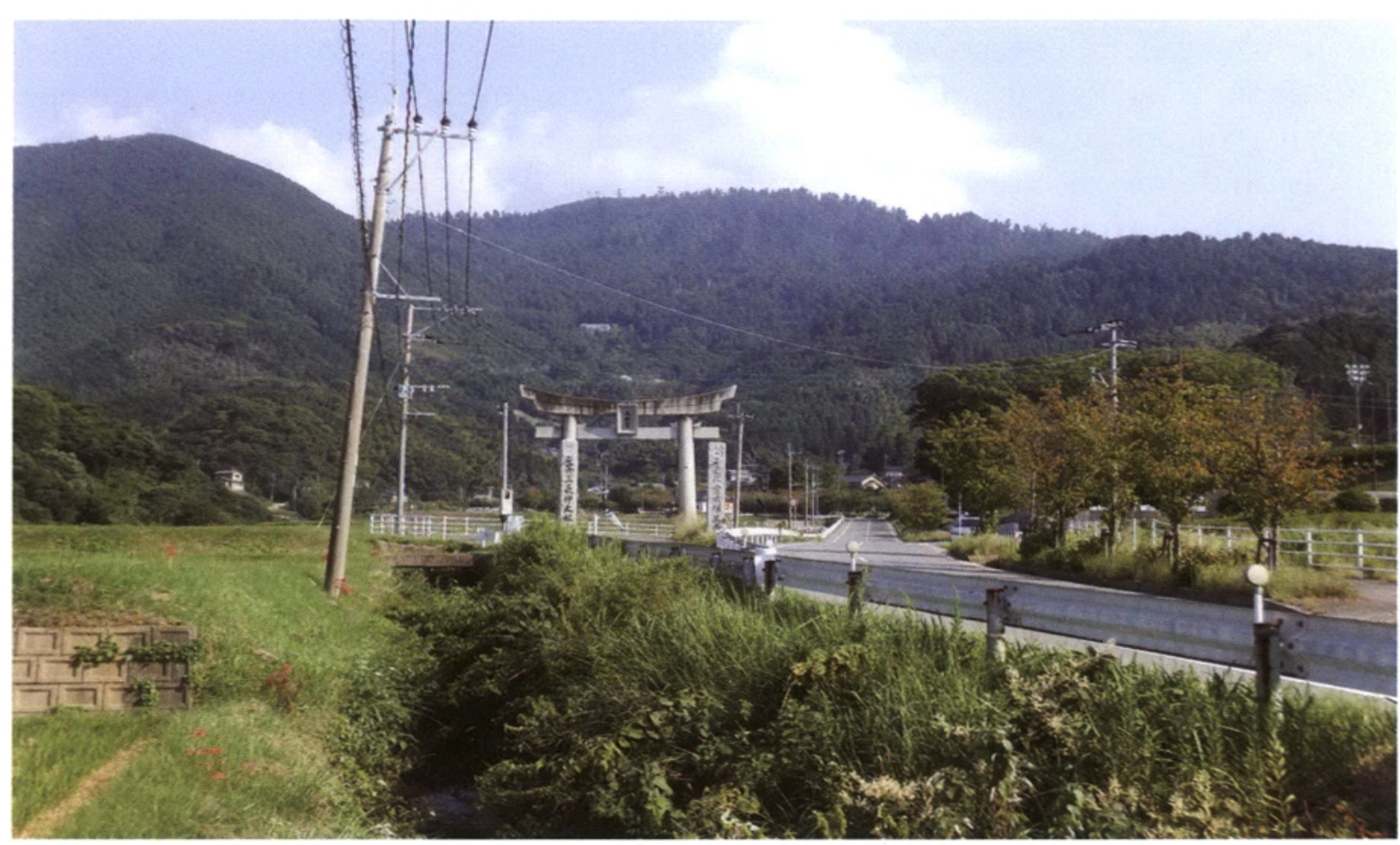

Fig. I : Le mont Wakasugi vu de Sasaguri. Au premier plan, le grand portique. Le sanctuaire Bas, à droite dans le bouquet d'arbres. (Tous les clichés sont de l'auteur.)

(bigashi no furegashira 東の触頭) pour le shugen du mont Hōman et, dans l'un des parcours rituels de cette organisation, le mont Wakasugi jouait un rôle important.

Tout en engageant ici les recherches sur le shugen du mont Wakasugi, cette étude abordera les questions évoquées précédemment sous l'angle de la dynamique du dedans et du dehors. Dans une première partie, l'histoire cultuelle de Wakasugi sera examinée à partir des textes relatifs à cette montagne et des mentions du mont Wakasugi dans les archives d'autres centres religieux. Puis, une analyse des archives de l'Ishii-bō permettra de mettre en lumière les fonctions du spécialiste religieux qui en avait la charge, d'une part en tant qu'affilié à l'organisation sbugen du mont Hōman ayant sous son contrôle tous les yamabushi des cantons de Kasuya et de Munakata 宗像郡 et, d'autre part, en tant que prêtre du sanctuaire Taiso-gū, centre religieux cantonal de Kasuya, qui par les rites répondait aux diverses demandes et attentes des habitants des cantons.

\section{La formation du shugen du mont Wakasugi}

Dans la moitié orientale de la commune de Sasaguri, se déploie du sud au nord un massif montagneux dont les sommets sont les monts Takejō 岳城山 ("Citadelle de montagne »; 38I,3 m), Wakasugi 若杉山 (《 Jeune cryptomère »;678 m) (fig. I), Kome 米八山 (《mont du Riz »; 593,7 m), Unehara 畧原山 (《Champ de sillons »; 662,9 m), Hokotate 鎍立山 ( $($ Dresse-hallebarde »;663,2 m), tous recouverts de forêts. C'est 


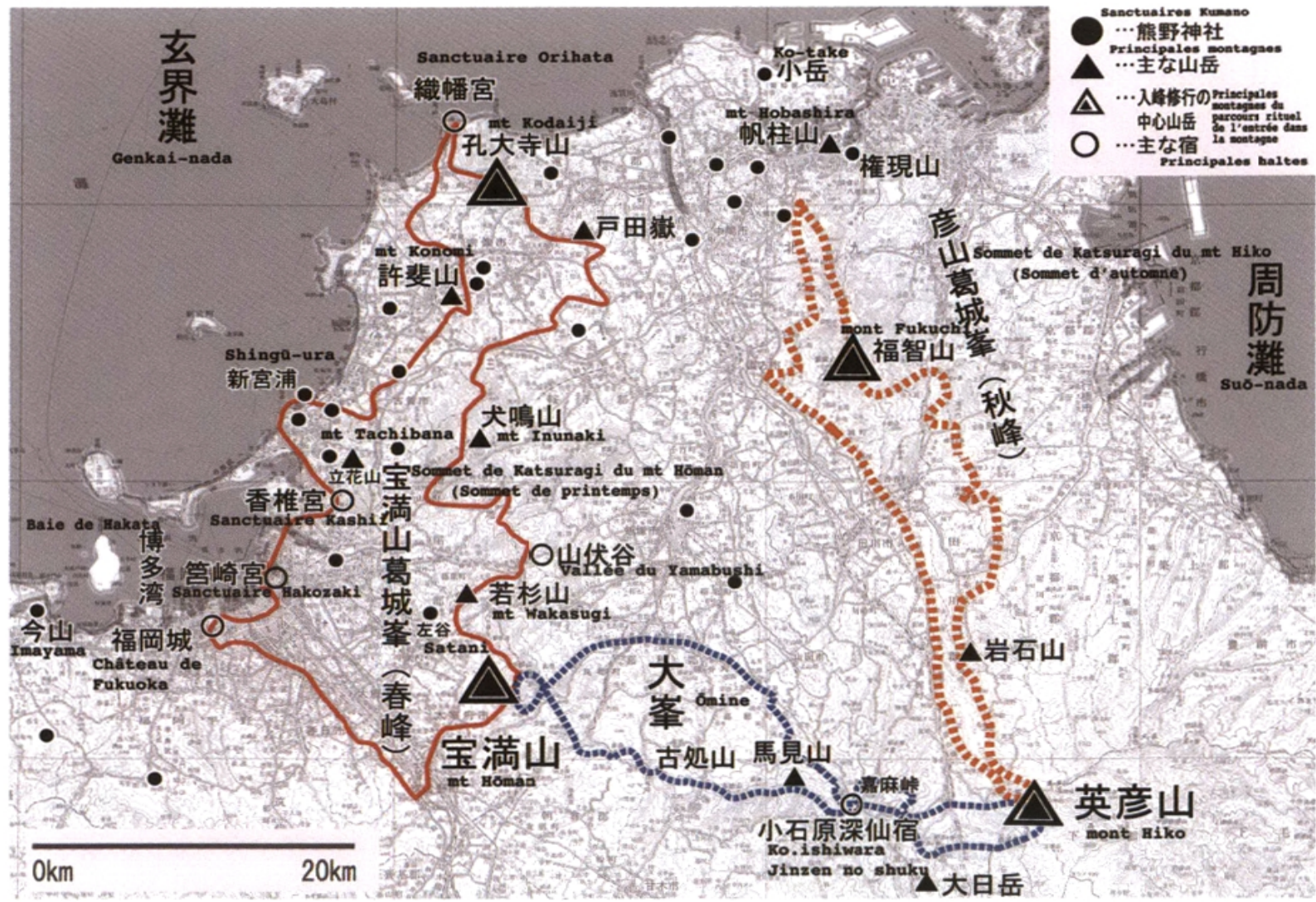

Carte I : Région nord de Kyūshū. Les parcours d'entrée dans la montagne (mine.iri) du shugen des monts Hōman et Hiko (Mori Hiroko 森弘子, Hōmanzan no kankyō-rekisbi gaku teki kenkyū 宝满山の懪境歴史学的研究, 2008, p. 478) et la répartition des sanctuaires de Kumano (d'après Dainippon jingikai Fukuokaken

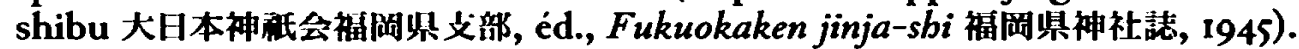

au cœur de ces montagnes que se situe le circuit du nouveau pèlerinage de Shikoku à Sasaguri. C'est également là qu'ont existé des sites shugen importants. Depuis Wakasugi, on gagne le mont Hōman $(829,6 \mathrm{~m})$, centre shugen majeur de la région, en suivant, au sud, la ligne de crêtes qui passe par les monts Oniiwa-tani 鬼岩谷 («Vallée de la roche du démon »; $774 \mathrm{~m}$ ), To.ishi 砥石山 («Pierre à aiguiser ”; $826 \mathrm{~m}$ ), Sangun 三郡山 (《Trois cantons »; 935,9 m), Tokin 頭巾山 (《Calot » 910 m).

Le parcours rituel, appelé « entrée dans la montagne » (mine.iri 峰入り ou nyūbu 入峰), du shugen du mont Hōman se faisait sur deux circuits dont les deux pôles étaient les monts Hōman et Hiko, et qui étaient assimilés à la fois aux deux mandala du bouddhisme ésotérique et aux mine.iri des mont Ōmine 大峯 et Katsuragi 葛城 (Nara), les deux grands modèles de l'entrée dans la montagne (carte I). Ces derniers sont les circuits établis depuis l'Antiquité dans la péninsule de Kii 紀伊半島 par les grandes organisations sbugen centrales de Kumano et Yoshino, qui ont influencé tous les autres groupes shugen du pays. À l'automne, ce parcours rituel se déroulait ici entre le mont Hiko, assimilé au maṇdala de la Matrice (Taizōkai 胎蔵界), et le mont Hōman (maṇdala du Diamant, Kongōkai 金剛界), à mi-distance desquels était située la « halte de Jinzen »(Jinzen no shuku 深仙宿), à Ko.ishiwara 小石原. 
Ce «sommet d'automne» (aki no mine 秋峯) était aussi dénommé 《Ōmine » et avait lieu tous les quatre ans. Le « sommet de printemps » (baru no mine 春粱), qui était organisé une fois par génération de grand supérieur du mont Hōman, était appelé «Katsuragi ». Il partait du mont Hōman pour aller vers le nord jusqu'au mont Kodai-ji 孔大寺山 (499 m, canton de Munakata). Entre ces deux pôles, la halte médiane appelée «Socle central » (chüdai 中台) aurait été anciennement implantée sur le mont Inunaki 犬鳴山 $(583,7 \mathrm{~m})$.

Le mont Wakasugi et l'ensemble du massif montagneux de Sasaguri se trouvaient inclus dans ce parcours rituel du printemps, dit « Katsuragi ». Or, à partir de 1699 (Genroku 元禄 12) ${ }^{7}$, Wakasugi joua un rôle-clé dans cette entrée dans la montagne : en effet, la halte centrale (chüdai) n'ayant pu être installée sur le mont Inunaki, c'est à Sasaguri, au lieu-dit vallée du/des Yamabushi (Yamabushi-dani 山伏谷), au pied nord-est du mont Wakasugi, qu'elle fut définitivement établie en tant que 《halte du mont de la Pierre blanche » (Shira.ishi-dake no shuku 白石獄 の宿). Les yamabushi s'y arrêtaient pour une durée de sept jours de pratiques sur place. Aujourd'hui, cet endroit est englobé dans le parc de Sasaguri planté de cerisiers appelé « nouveau Yoshino»(Shin-Yoshino 新吉野). Au-dessus, se trouve la Roche de l'or jeté (Kane-maki-iwa 金まき岩), liée par une légende au shugen du mont Hiko. Cette roche est située dans l'enceinte du Hōzan-ji 宝山寺, l'un des temples du circuit de pèlerinage de Sasaguri, de même que le $n^{\circ}$ iz de ce même circuit, le Chizuru-ji 千鶴寺, temple shugen. Sur le flanc nord du mont Wakasugi se trouve l'Ishii-bō, temple shugen restauré au début de la période d'Edo sur l'ordre du daimyō 大名 Kuroda Nagamasa 黒田長政 (1568-I623) par Kame.ishi-bō Yüben 龟石坊有弁, lequel était initialement affilié au mont Hōman et en devint alors le représentant pour la partie orientale du canton.

Pour éclairer l'histoire du mont Wakasugi à l'époque d'Edo, il existe de nombreux documents, à commencer par les riches archives de l'Ishii-bō. Mais pour les périodes antérieures, nous ne disposons que d'une inscription de 1325 (Shōchū 正中 2) sur une stèle de l'enceinte du temple Kenshō-ji 建正寺 à Satani 佐谷 (Sue 須恵), situé sur le flanc sud du mont Wakasugi : celle-ci mentionne l'existence d'un temple «Satani-san Kenshō-in affilié au centre Tendai régional Uchi san [c'est-à-dire Hōman] » (Tendai betsu.in Uchi-yama matsuji Satani-san $n i$ okeru Kenshō-in 天台別院有智山末寺於左谷山賢聖院 $)^{8}$. Aussi devons-nous avoir recours aux écrits postérieurs tels que l'histoire des origines du Kenshōhi-ji de

7. On trouve la mention suivante dans le texte Katsuragi būchū taizōkai ki 尊城峯中胎藏界記 (manuscrit conservé au Kanō-in 叶院 à Fukuoka) : «Lors de la restauration de cette entrée dans la montagne en 1699 (Genroku 元䘵 12), à la suite d'un empêchement, la halte a été changée pour celle du mont de la Pierre blanche (Shira.ishi dake 白石獄の宿) ». Mais il n'existe aucun document prouvant l'existence de nyūbu avant cette date.

8. Sur le mont Höman, il existait, de l'époque de Heian à celle de Kamakura, un temple nommé Daisen-ji 大山寺. À l'époque Kamakura, on voit apparaître le nom d'Uchiyama-dera 有智1持. — La graphie du nom du temple Kenshō-ji (ou Kenshö-in) est très variable. "Satani 》 peut également être écrit 左谷 (graphie ancienne) ou 佐谷 (plus récente). (N.D.T.) 
Satani ${ }^{9}$, de Wakasugi ${ }^{10}$ ou encore les historiographies locales de l'époque d'Edo ${ }^{11}$. Quelle lumière peuvent apporter ces documents sur les réalités anciennes du shugen du mont Wakasugi ${ }^{12}$ ?

\section{Le mont Wakasugi et Taiso gongen}

Taiso gongen 大祖権現. - Les divinités du mont Wakasugi sont vénérées dans deux sanctuaires : le sanctuaire Haut (Jōgū 上宮; fig. 2), sur le sommet, et le sanctuaire Bas (Gegū 下宮; fig. 3), à son pied, près des habitations. Ces divinités sont au nombre de sept, ce qui est à l'origine de l'appellation de sanctuaire "aux sept divinités » (shichisha myōjin 七社明神). Le dieu principal est Izanagi ; à sa droite siègent les dieux Hachiman daimyōjin 八幡大明神, Shōmo daimyōjin 聖母大明神, Hōman myōjin 宝满明神, et à sa gauche, Amaterasu ōmikami 天照大神, Shika daimyōjin 志賀大明神 et Sumiyoshi ōkami 住吉大神.

Selon l'Histoire des origines du sanctuaire Taiso du mont Wakasugi du canton de Kasuya en Cbikuzen ${ }^{13}$ (ci-après, Engi) compilée par le savant du fief de Fukuoka 福岡藩, en 1692, Kaibara Furuyoshi 貝原好古, en tant qu'ancêtre du peuple japonais Izanagi 伊猆諾尊, est appelé Taiso 大祖 (《Grand ancêtre 》). Mais d'après la Chronique du sanctuaire Taiso daigongen du canton de Kasuya de la province de Cbikuzen ${ }^{14}$ (ci-après, Güki) écrite par Kame.ishi-bō Yūben en 1597, le mont Wakasugi aurait été fondé en tant que centre cultuel par le moine indien Zenmui Sanzō 善無畏三藏 lorsqu'il arriva de Chine en 718 (Yōrō 養老 2); et c'est Kūkai 空海 (774-835), le fondateur de l'École du Shingon 真言宗, qui, en 808 (Daidō 大同 3), aurait gravi la montagne et aurait été le

9. Satani-san Kenshō-ji engi 左谷山建正寺縁起 (156I, Eiroku 永禄 4), texte écrit par le moine Kenshō-bō Sōshuku 賢正坊宗祝 du Sacani-san Kenshō-in 左谷川婜聖院, avec ajouts de 1644 (Shōhō 正保 I) et 1819 (Bunsei 文政 2), et édité par Yahiro Izumi, dans Kyūshū rekishi shiryōkan, éd., Chikuzen Kasuya. Wakasugi yama no bukkyō iseki, p. 35-37. Le manuscrit est conservé au Musée d'histoire locale de la commune de Sue (Sue-chōritsu rekishi minzoku shiryōkan 須恵 町立歴史民俗資料館).

10. Chronique du sanctuaire Taiso daigongen du canton de Kasuya de la province de Chikuzen, Chiku-no-saki-no-kuni Kasuya-gun Taiso daigongen güki 筑之前州粕屋郡大祖大権現宮記 (1597, Keichō 慶長 2), écrite par Kame.ishi-bō Yūben 亀石坊有弁 ; Histoire des origines du sanctuaire Taiso du mont Wakasugi du canton de Kasuya en Chikuzen et Chikuzen Kasuya-gun Wakasugi-yama Taiso jinja engi 筑前糟屋郡分杉山大祖神社稼起 (1692, Genroku 5), que l'on doit tout deux à Kaibara Yoshifuru 貝原好古 (ces textes ont été réunis par Yahiro Izumi, dans Kyūshū rekishi shiryōkan, éd., Cbikuzen Kasuya. Wakasugi yama no bukkyö iseki, p. 38-44).

II. Kaibara Ekiken 貝原益軒, comp., Cbikuzen no kuni zoku fudo-ki 筑前国続風土記, texte édité par Itō Oshirō 伊藤尾四郎, dans Fukuoka-ken shi shiryō zoku dai yon shū. Chishi ben I 福岡 県史資料続第四輯:地誌編一- ( $\mathrm{I}^{\mathrm{re}}$ éd. I688-1710), I977.

12. Sur le contenu de ces divers documents, voir l'analyse faite par Suzuki Masataka 鈴木正崇 dans ce même volume, "Continuités et transformations de la société locale : le fait coutumier dans le village de Wakasugi », p. 45-63.

13. Cbikuzen Kasuya-gun Wakasugi-yama Taiso jinja engi 筑前糟屋郡分杉山大祖神社縁起 (cf. supra, n. 10).

14. Cbiku-no-saki-no-kuni Kasuya-gun Taiso daigongen güki 筑之前州粕屋郡大祖大権現宮記 (op. cit., p. 37-38 ; cf. supra, n. Io). 


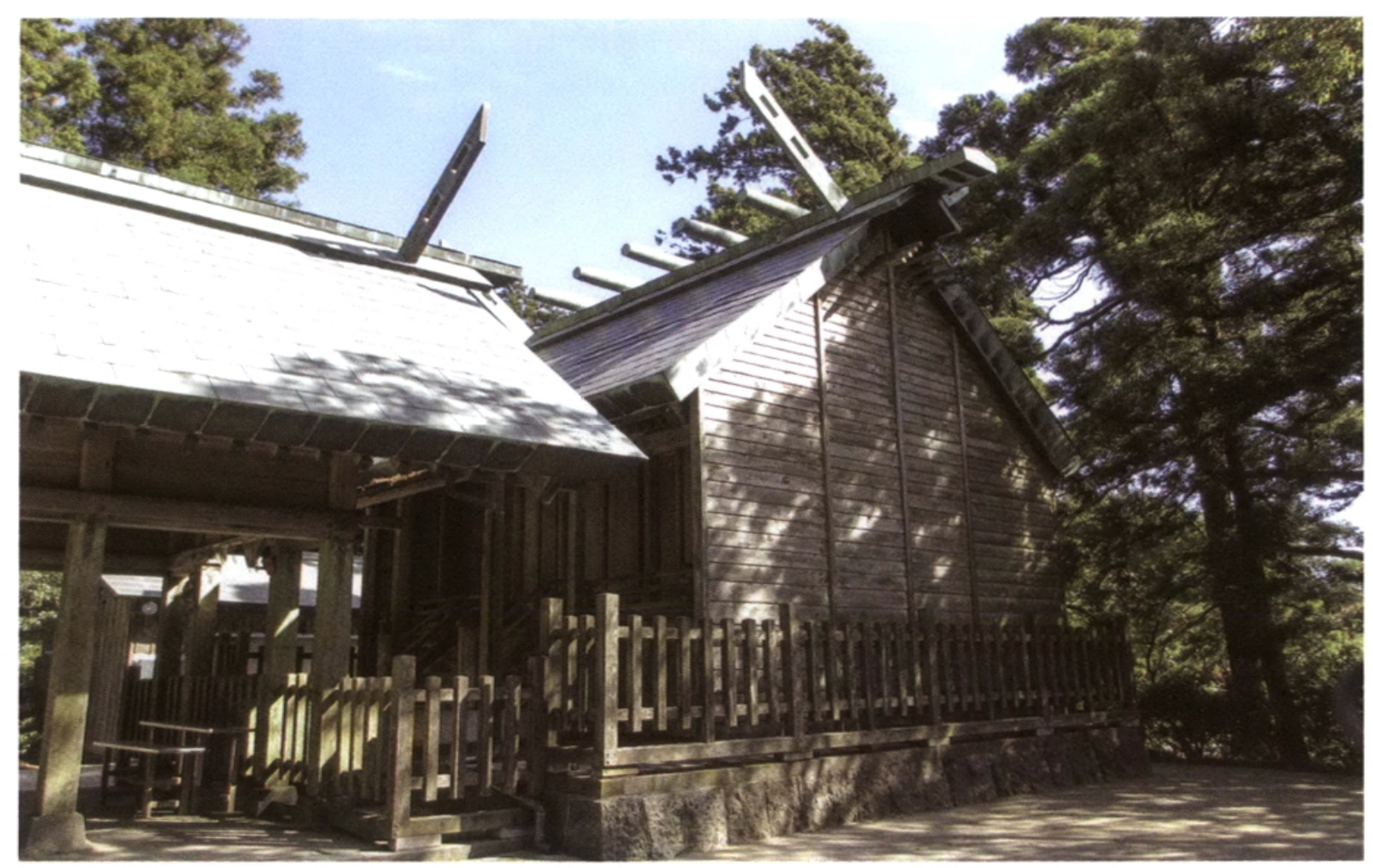

Fig. 2 : Taiso jinja. Le sanctuaire Haut au sommet du mont Wakasugi.

premier à vénérer Zenmui ${ }^{15}$ en tant que " patriarche » de cette école du bouddhisme ésotérique, en l'appelant «Taiso gongen 》大祖権現. La première tradition (Engi) voit donc en Taiso, Izanagi, le dieu qui, avec Izanami son épouse, fut à l'origine de la création de l'univers, de la terre du Japon, de tous les dieux - à commencer par Amaterasu, divinité du soleil et ancêtre mythique de la lignée impériale -, et est considérée par là comme l'ancêtre de tous les êtres et les choses. Pour la seconde $(G \bar{u} k i)$, il s'agit de Zenmui, l'un des patriarches du Shingon.

Dans cette partie septentrionale de Kyūshū, nombreux sont les sanctuaires où sont vénérés les dieux des mythes japonais ${ }^{16}$ : les trois déesses de la mer de Munakata 宗像三女神 à Munakata, les trois dieux Tsutsu-no-o 筒男三神 à Sumiyoshi 住吉, les trois dieux de la mer Watatsumi 綿津見三神 sur l'île de Shika 志賀島 ou l'impératrice Jingū 神功皇后 à Kashii 香椎. Mais partout l'histoire des origines de ces sanctuaires établit des liens entre ces divinités et cette région de Kyūshū. Aussi, dans ce contexte, le culte d'Izanagi sur le mont Wakasugi apparaît-il comme surprenant et hétérogène par rapport à ces traditions locales. En outre, l'appellation gongen témoignant de l'existence d'un rapport étroit entre le shugen et cette montagne, Taiso gongen mérite une attention toute particulière pour notre enquête sur le shugen de Wakasugi.

15. Zenmui Sanzō 善無畏三蔵, le [maître du] Tripițaka Śubhakarasimhha (637-735), moine indien, le cinquième des huit patriarches de l'École ésotérique Shingon.

16. Récits des temps anciens, Kojiki 古事記 (712) et Annales du Japon, Nibon shoki 日本書紀 (720). 


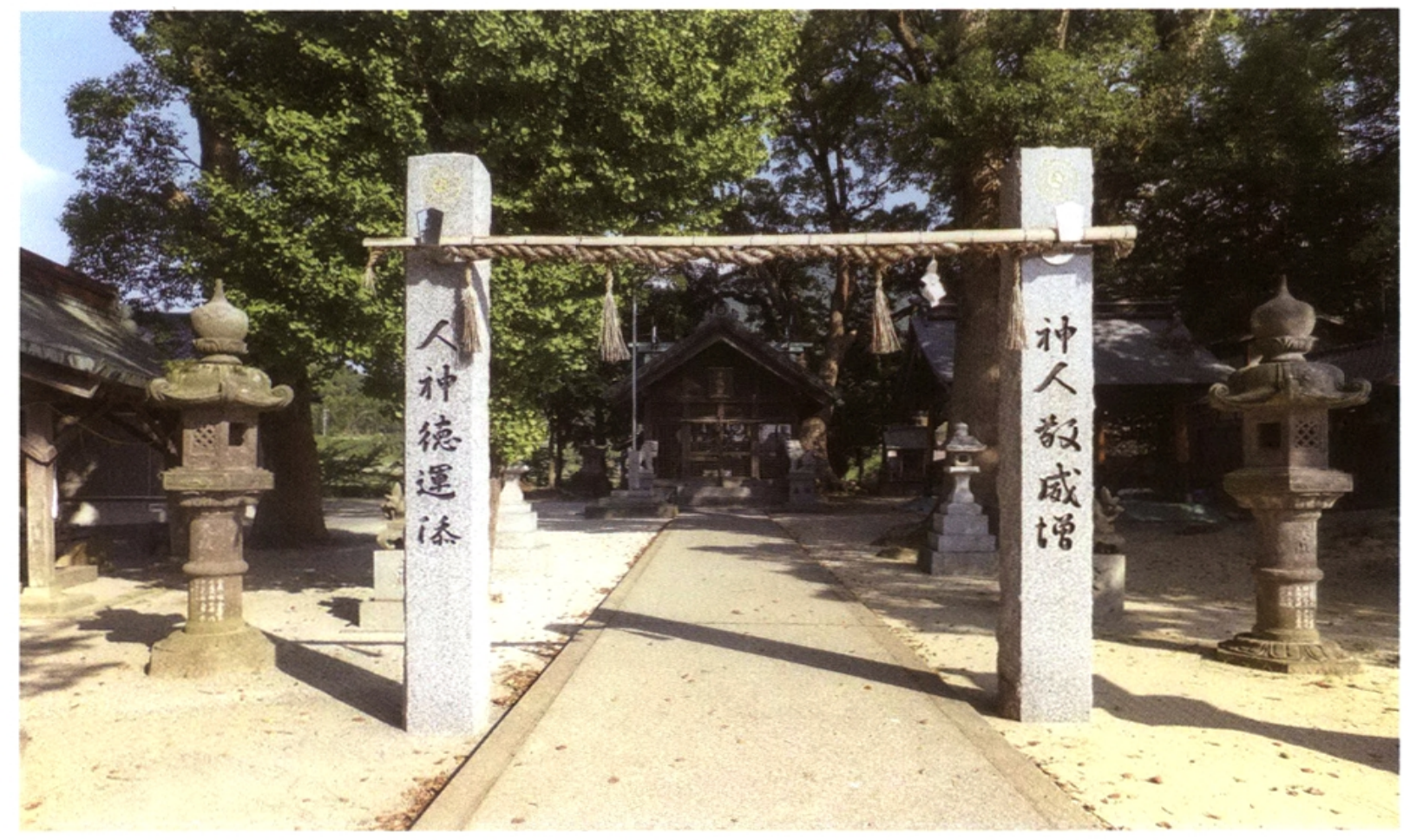

Fig. 3 : Taiso jinja. Le sanctuaire Bas au pied du mont Wakasugi.

L'bistoire du nom Wakasugi. - Selon l'Engi, lors de son départ pour la conquête des royaumes coréens, l'impératrice Jingū aurait demandé sa protection à Izanagi, dieu de cette montagne, et serait partie en mettant dans la manche de son armure une branche du cryptomère sacré de ce sanctuaire. À son retour victorieux, elle aurait planté au sanctuaire de Kashii 香推宮 cette branche qui aurait donné un bel arbre, alors appelé « cryptomère de belle forme » (aya sugi 綾杉), et la montagne aurait reçu le nom de " mont du Cryptomère partagé » (Wakesugi yama 分杉山), par la suite altéré en Wakasugi yama 若杉山 (“ mont du Cryptomère jeune »). L'impératrice aurait ensuite fait construire sur le sommet un sanctuaire tourné vers l'ouest pour anéantir les ennemis étrangers.

Dans les Cbroniques du mont Taiso du canton Omote-Kasuya de Cbikuzen ${ }^{17}$, on retrouve la même version ; cependant, dans l'historiographie locale Cbikuzen no kuni zoku fudo-ki de Kaibara Ekiken, la tradition de la « plantation partagée » est inversée. En remerciement de sa victoire pour laquelle, avant son départ, elle aurait demandé protection à tous les dieux, notamment au dieu Taiso, c'est sur la montagne, où ce dernier était vénéré, qu'à son retour victorieux de Shiragi, l'impératrice aurait

17. Chikuzen no kuni Omote-Kasuya-gun Taiso-zan denki 筑前国表糟屏郡太祖山伝記 (transcription de 1823 , Bunsei 文政 6 ; original sans doute écrit au milieu d'Edo), texte édité par Yahiro Izumi, dans Kyūshū rekishi shiryōkan, éd., Chikuzen Kasuya. Wakasugi yama no bukkyō iseki, p. 44-45 (archives de l'Ishii-bō). 
transplanté une branche qu'elle aurait coupée sur un cryptomère se dressant dans l'enceinte du sanctuaire Kashii : cette montagne aurait ainsi été dénommée "mont du Cryptomère partagé18 ».

Le cryptomère aya est l'arbre sacré du sanctuaire Kashii qui aurait poussé après que Jingū victorieuse l'eut planté à l'emplacement même où elle avait enterré trois trésors. Cet arbre y est un symbole de la puissance guerrière. Les cryptomères résultant de " plantations partagées » après celui que planta l'impératrice Jingū sur le mont Wakasugi auraient ensuite été coupés à la fin du XVI ${ }^{e}$ siècle par le chef du fief de Fukuoka, Kobayakawa Hideaki 小早川秀秋 (1582-1602), pour en faire du bois de construction. Aujourd'hui, le long du « parcours pédestre de la forêt du Yamato » (Yamato no mori $y \bar{u} b o-d \bar{o}$ 大和の森遊歩道) situé sur le mont Wakasugi entre la cascade de Yōrō 養老の滝 et le sanctuaire Haut, on peut voir plusieurs cryptomères géants, dont l'un mesurant 20 mètres de haut est appelé «cryptomère aya ». Mais l'analyse a révélé que l'espèce était différente de celle de l'arbre appelé "cryptomère aya " au sanctuaire Kashii. Il semble qu'autrefois ces cryptomères aient été nombreux et qu'il existait un " champ des cryptomères aya » sur le mont Wakasugi ${ }^{19}$. Quoi qu'il en soit, l'origine de cette montagne est rattachée par les légendes à Jingū et au cryptomère aya du sanctuaire Kashii. Quant aux cinq divinités autres qu'Izanagi et Amaterasu, elles sont mentionnées dans les textes médiévaux relatifs au culte du dieu Hachiman ${ }^{20}$ comme des puissances reliées à Jingū et aux récits de conquête de la presqu'île coréenne.

Taiso gongen dans l'Histoire des origines du grand bodhisattva Munakata ${ }^{21}$. C'est à la fin de l'époque Kamakura (début XIv siècle) que les termes Taiso gongen et mont Wakasugi apparaissent dans les documents écrits. Ainsi l'Histoire des origines du grand bodbisattva Munakata donne, en tant que citation de l'Histoire des origines de Kasbii ${ }^{22}$, les indications suivantes :

Taiso gongen est venu de Chine au Japon en 728 (Jinki 神化 5). Il arriva tout d'abord dans la baie de Nogita 野北浦 du canton Ito 怡土郡 ${ }^{23}$ et entra aussitôt dans le sanctuaire Kashii. À ce moment, Kōra Tamatare 高良玉垂 transmit cet oracle au grand bodhisattva

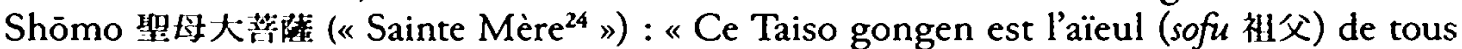
les dieux des 3600 et quelques sanctuaires du Japon ${ }^{25}$. C'est notamment l'ancêtre de la

18. Kaibara Ekiken, comp., Cbikuzen no kuni zoku fudo-ki, p. 403.

19. Sasaguri-chō yakuba 策栗町役場, éd., Kaiteiban Bunkazai meguri. Reibō Wakasugi no korō tachi. Sasaguri-chō no rekishi sanpo 改訂版・文化財めぐり:需峰萑杉の声老たち——笨栗町の歴 史散歩, p. 9-14.

20. Comme le Hacbiman gudō kun 八幡㦙童訓 (en deux versions), texte édité par Hagiwara Tatsuo 萩原龍夫, éd., dans Jisha engi 寺社縁起, coll. Nihon shisō taikei 日本思想大系, vol. 20, 1975, p. 169-205.

21. Munakata daibosatsu go.engi 宗像大菩薩御縁起. Texte édité par Shintō taikei hensankai 神道大系編査会, dans Sbintō taikei, jinja ben, 49, 1979, P. II-14.

22. Kashii go.engi 香椎御縁起 (manuscrit conservé au Musée national de Tōkyō).

23. Aujourd'hui, à Kubochi 久保地 (Keya 芥屋, Itoshima 系鼠梊, près de la falaise de Keya no óto 芥屋大閉, à l'ouest de la ville de Fukuoka), il existe un sanctuaire Taiso qui, selon la tradition locale, existerait depuis le temps des dieux et serait le site où Izanagi effectua ses purifications.

24. Nom donné à l'impératrice Jingu dans les textes de cette époque.

25. Dans le texte original du Kashii go.engi, Taiso est nommé comme le «père »(chichi 父) de tous les dieux. 
neuvième génération de la lignée de Shōmo et de Hachiman ${ }^{26}$, et c'est leur maître. " Le bodhisattva Shōmo, trouvant que l'endroit était trop étroit, et afin que celui-ci puisse résider sur une haute montagne, fit alors une " plantation partagée "(bunshoku 分殖) d'un cryptomère de $\mathrm{Kashii}^{27}$ qu'elle vénéra comme Taiso gongen. C'est là le mont du Cryptomère partagé (Wakasugi 若杉山). Par la suite, Shōmo et Hachiman se rendirent régulièrement en pèlerinage au Taiso gongen.

Dans un oracle, Taiso gongen dit alors :

"Je suis Ōjō-gokuraku satta 往生極楽薩埵 (« le bodhisattva qui [crée le chemin de] la renaissance en Terre pure ») qui a fondé l'École du Shingon et j'ai pour « sol originel » (bonji 本地) le patriarche du Shingon (c'est-à-dire Zenmui). Me manifestant ainsi sous la forme provisoire (gongen) de grande divinité, j’ai pris la décision inébranlable de répandre parmi tous les êtres l'enseignement bouddhique et de le faire prospérer. »C'est pourquoi le général Gōseki (Gōseki shōgun 強石将軍, “Général de la pierre forte ”, c'est-à-dire l'actuel grand bodhisattva Munakata 宗像大菩薩) et Wakasugi Taiso gongen 太祖権現 sont un seul et même dieu ayant deux dénominations.

D’après ce texte, Zenmui Sanzō, Taiso gongen, Gōseki shōgun et le bodhisattva Munakata seraient donc une seule et même entité.

Taiso gongen dans le Recueil des oracles du sanctuaire Hachiman d'Usa ${ }^{28}$. Compilation datant de la même époque que le texte précédent, ce recueil (ci-après, Takusen-sbü) contient, dans le volume 2, la généalogie suivante :

Taiso gongen, nommé aussi Grand Vairocana (Dai-Birushana 大毘盧遮那)

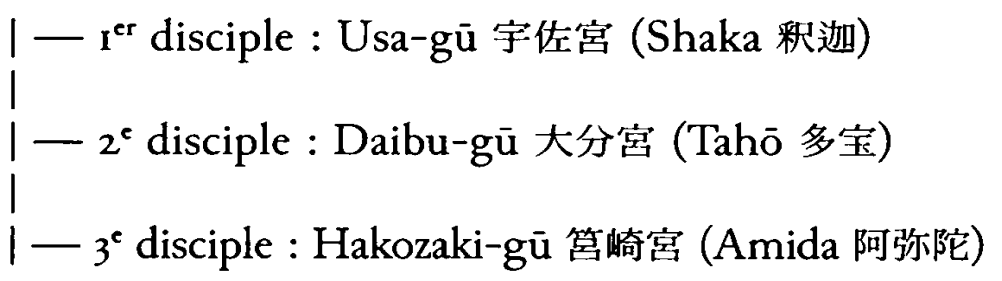

Cette généalogie initiatique identifie donc Taiso gongen au Pan-Boudha, Vairocana, dont les « disciples » sont les divinités de trois grands sanctuaires du nord de Kyūshū, elles-mêmes identifiées aux trois bouddhas Shakyamuni, Tahō et Amida. Le texte ajoute ensuite : "Taiso gongen est Izanagi, le septième des dieux du ciel. Cet esprit divin est Hakusan gongen 白山権現, descendu du ciel dans les années Wadō (708-715) dans le pays d'Echizen 越前 (actuel département de Fukui 福井県). Lorsqu'il revint dans notre pays en 728 (Jinki ऽ) après être allé en Chine, il descendit (littéralement : il mit une part de son âme) sur le sommet de Wakasugi et apporta le salut à tous les êtres de Tsukushi (Kyūshū). "

26. L'empereur Ōjin 応神天皇, fils de l'impératrice Jingū, est vénéré sous le nom du dieu Hachiman.

27. L'arbre sacré du sanctuaire Kashii est le cryptomère aya (aya sugi 綾杉, "cryptomère de belle forme "), Cryptomeria japonica var. araucarioides.

28. Hachiman Usa-gū ontakusen shü 八蟠宇佐宮御託宣集, texte compilé entre 1290 et 1313 (Shōō 正応 3 et Shōwa 正和 2) par Jin.un 神吽, chef des enseignements d'Usa Miroku-ji 宇伎弥 勒寺, et édité par Kodaigaku kyōkai 古代学協会, dans Hachiman Usa-gū ontakusen sbū, jō 八幡宇 佐宮御託宣集, 上, vol. I, 1966, p. 42. 
Le Takusen-shū éclaire ainsi la double relation de la divinité du mont Wakasugi avec le culte de Hachiman d'une part et avec le shugendō d'autre part, puisque le mont Haku 白山, siège de Hakusan gongen, fut aussi l'un des grands centres shugen de l'époque ancienne. En effet, les Chroniques de la grande divinité d'Itsukushima ${ }^{29}$, document en un feuillet écrit à la même période, mentionnent à propos du mont Hōman, également nommé Kamado 䨘門, avec lequel Wakasugi entretient des liens étroits :

Kamado et le mont Haku : une seule et même entité. - Cette divinité est un dieu qui voyage. Maître de l'instauration de la loi bouddhique, elle dispense avant tout la grande compassion. C'est une des filles du roi dragon Shakara 尺迦羅龍王. Sa sœur aînée est la fille dragon de 8 ans et ses sceurs cadettes sont l'impératrice Jingū et Yodo-hime 淀姫 ${ }^{30}$. Se manifestant en tant que Myōri gongen 妙理権現 sur le mont Haku, en pays du nord, pour l'ascèse du sommet ${ }^{31}$, elle accorde ses bienfaits à tous. Ou bien elle descend aussi sur le haut sommet du mont Kamado sous la forme provisoire de la princesse Hōman (Hime Hōman 姫宝満), répandant pour les générations futures ses pouvoirs au prestige renouvelé et radieux. Sa majesté est manifeste dans tout le pays.

Ce dernier extrait, dont on peut considérer qu'il reflète la diffusion du culte du mont $\mathrm{Haku}^{32}$ à Kyūshū, vient ajouter, à la suite des précédents, une autre identification de Taiso gongen (Izanagi) au bodhisattva Hōman et à Hakusan gongen. Tout comme dans l'Histoire des origines du grand bodhisattva Munakata, intervient ici une explication extrêmement complexe des divinités et de leurs relations. C'est une méthode interprétative très utilisée dans les textes médiévaux qui réunissent et amalgament les points de vue du bouddhisme, du shintō et du shugen de l'époque pour combiner les cultes des dieux locaux et des bouddhas. Or l'émergence du Taiso gongen dans un tel contexte discursif montre l'importance alors accordée au mont Wakasugi.

En outre, tous ces documents reflètent le réseau des liens avec le culte et les sanctuaires de Hachiman, dans lequel se situait Taiso gongen. Au sein de la société médiévale qui commençait à se mettre en place dès la fin de l'époque Heian, le sanctuaire Iwashimizu Hachiman 石清水八幡宮 ${ }^{33}$ de la capitale étendit son emprise jusqu’à Kyūshū. Déjà, dans la première moitié du XIe siècle, les sanctuaires dédiés au

29. Itsukushima daimyōjin nikki 笅島人明神日記 (Shyōmyō-ji 称名寺; conservé au Kanazawa bunko 金沢文庫) : ce feuillet $(15,8 \times$ 13,6 cm) de transmission secrète concernant la divinité du sanctuaire Itsukushima (Hiroshima 広島県) et datant de la fin Kamakura a été édité par Tsuda

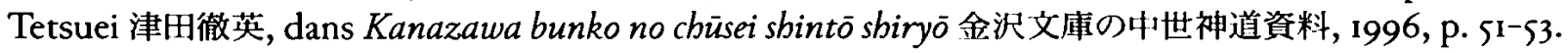

30. Il existe un sanctuaire Yodohime 淀姫神社 à Matsu-ura 松浦, dans le département de Nagasaki. Selon l'histoire des origines de ce sanctuaire, Yodohime serait une sour cadette de l'impératrice Jingū. (N.D.T.)

31. Zen-jō 禅頂 : pratique ascétique, propre au shugen du mont Haku. Myōri gongen est le nom de la divinité de cette montagne. (N.D.T.)

32. À Kubara 久原 de Hisayama 久山町, commune voisine de Sasaguri, se dresse le mont Haku 白山 (dit aussi mont Shura 首羅山), sur lequel des fouilles récentes ont mis au jour des vestiges remontant à une période allant de la fin du XI ${ }^{e}$ au début du XIV siècle, et qui témoignent de la prospérité du culte du mont Haku en cet endroit.

33. Sanctuaire situé à Otoko-yama 男山 de Yawata 八幡 (Kyōto). Gyōkyō 彳亍亍 Daian-ji 大多寺, y importa les divinités d'Usa Hachiman 宇佐八幡 (département d'Ōita 大分県) 
culte de Hachiman (de Hakozaki, Umi, Daibu, Hizen Chiriku Hachiman, Buzen Kawara, Iki Hachiman) ${ }^{34}$ étaient passés sous le contrôle du sanctuaire d'Iwashimizu. En II28 (Daiji 大治 3), l'administrateur de ce dernier (bettó 別当), Kōsei 光清, s'empara de la direction du temple Miroku-ji 宇佐弥勒寺 du sanctuaire d'Usa Hachiman (département d'Ōita 大分眎) et, en II93 (Kenkyū 建久 4), il étendit son emprise sur le sanctuaire Kashii. C'est ainsi qu'à Kyūshū le système de pouvoir religieux local fut réorganisé autour du sanctuaire Iwashimizu Hachiman. Ce fut notamment le cas de tous les temples et sanctuaires de la région côtière du nord de Kyūshū, comme ceux de l'île de Shika, de Munakata, de Sumiyoshi, du mont Rai 雷山 et du mont Hōman, pour lesquels les archives historiques montrent bien que, même des structures religieuses qui n'étaient pas des sanctuaires Hachiman, finirent par être intégrées à ce réseau politico-religieux du culte de Hachiman.

A l'arrière-plan de ce phénomène d'implantation, il y eut les attaques mongoles dans la baie de Hakata 博多湾 à la fin du XIII ${ }^{e}$ siècle $^{35}$. C'est contre ce danger sans précédent, venu de l'extérieur, que fut pleinement instrumentalisée l'idéologie de " Hachiman protecteur du pays ». Dans un tel contexte, le mont Wakasugi, dont l'imposante silhouette domine la baie de Hakata et sert d'amer aux bateaux, joua nécessairement un rôle important.

\section{L'extension du culte de Kumano}

Le sanctuaire de Kumano à Satani 左谷 (“Vallée de gauche »). - Nous avons vu que parmi les sept divinités vénérées au sanctuaire Taiso, cinq d'entre elles (Hachiman, Shōmo, Hōman, Shika et Sumiyoshi) étaient liées au culte de Hachiman. Mais les raisons de la présence d'Izanagi, le dieu principal, et d'Amaterasu n'ont pas encore été éclaircies.

Dans le village Utani 友谷 (《Vallée de droite »), au pied du flanc nord du mont Wakasugi, se dresse le sanctuaire Bas de Taiso (Gegū) appelé aussi « lieu de vénération à distance (du sanctuaire Haut) » (yōbai-sho 遙拝所) ou encore « site du sanctuaire provisoire » (tongū ato 頓宮跡). Sa construction remonte à 1703 (Genroku 16) ${ }^{36}$. Or il existe aussi un autre lieu de vénération à distance du sanctuaire Haut, à Satani. Celui-ci se trouve de l'autre côté, sur le flanc méridional de la montagne : il s'agit d'un sanctuaire de Kumano 熊野神社. Les divinités de ce dernier sont Izanagi 伊邪那 岐神, Hayatama-no-o 速玉男神 et Izanami 伊邪那美神, dont l'histoire, au niveau local,

en 859 (Jōgan 贞観 I). Avec le sanctuaire d'Ise 伊勢神宮 et parfois celui de Kamo 贺茷社 (Kyōto), ce sont les trois plus prestigieux et puissants sanctuaires de l'époque ancienne.

34. Chikuzen Hakozaki-gū 筑前䉥椅葟 (département de Fukuoka), Umi Hachiman-gū 宇美八 幡宮, Daibu-gū 大分宾 (Iizuka-shi 飯塚书, département de Fukuoka), Hizen Chiriku Hachiman-gū 肥前下来八幡宮, Buzen Kawara-sha 豊前香春社, Iki Hachiman-sha 壱岐の八幡社.

35. Les deux tentatives d'invasion de 1274 (Bun.ei 文永 II) et 128I (Kōan 弘安 4) échouèrent à cause de tempêtes survenues au moment de l'arrivée de la fotte ennemie sur la côte japonaise. Ces tcmpĉtcs, qui anćantircnt la flottc mongole, reçurent alors le nom de "vents des dieux " (kamikaze 神風).

36. Kyūshū rekishi shiryōkan 九州歴史資料館, éd., Chikuzen Kasuya. Wakasugi yama no bukkyo iseki 筑前粉屡: 隹杉11の伀教造跡, p. 32 (tableau chronologique). 
s'avère inconnue ${ }^{37}$. Néanmoins, dans l' Histoire des origines $d u$ Satani-san Kenshō-jii ${ }^{38}$, il est mentionné qu'en 708 (Wadō 2), un habitant de cette montagne, Oyamada Kamon no Suke 小山田掃部之助, installa en ces lieux Kumano gongen, dont les trois dieux étaient le dieu Kotosaka-no-o 事解男命 au centre, la déesse Izanami 伊猆苒尊 à gauche, et le dieu Hayatama-no-o 速玉男命 à droite. Il y est aussi précisé que «Les femmes ne peuvent venir en pèlerinage dans ce sanctuaire. Ses pouvoirs de protection pour l'agriculture sont remarquables et celui qui le vénère ne subit pas les calamités des sauterelles, de la sécheresse, des grands vents ou de la famine. » Si les histoires des origines d'Utani (actuel Wakasugi) donnent pour fondateurs de ce sanctuaire Zenmui et Kūkai (lignée Shingon), dans celle de Satani, il s'agit de Saichō 最澄 $(767-822)$, le fondateur de l'École japonaise du Tendai 天台宗. Ceci met en évidence le lien avec le shugen du mont Hōman d'obédience Tendai, où existait également un sanctuaire de Kumano dès avant l'époque de Kamakura ${ }^{39}$.

Dans l'Histoire des origines du Satani-san Kenshō-ji, la fondation de Satani est racontée comme un prodige dû à Saichō et à ce triple sanctuaire de Kumano, et suggère, en arrière-plan, les liens avec le mont Hōman et Munakata :

En 804 (Enryaku 22), avant son départ pour aller chercher l'enseignement bouddhique en Chine, Saichō vint demander protection au temple du mont Hōman (Uchi yamadera 有智山寺) pour la traversée des quatre bateaux des envoyés du Japon avec lesquels il partait. Dans ce but, il y offrit quatre statues du bouddha Yakushi en bois de santal (danzō 望像) ${ }^{40}$. L'année suivante, comme il parcourait le pays en quête des anciens sites, il se rendit d'abord à Munakata pour y vénérer les trois divinités. Alors qu'il traversait le canton, il découvrit un grand arbre d'où sortaient de la lumière et une bonne senteur. Il sculpta dans cet arbre trois statues du bouddha Dainichi. Il nomma la première «Dainichi de la base de l'arbre »; la seconde, «Dainichi du milieu » et la troisième, «Dainichi de la cîme $^{41}$ ». La première fut déposée dans le village Motoki 本木村 du canton de Munakata. Il appela la seconde "Bouddha de droite 》 (Ubutsu 右仏) et la troisième, "Bouddha de gauche" (Sabursu 左仏). Les lieux où les deux dernières statues devaient être déposées furent choisis par des baguettes de divination lancées en l'air (furimikuji 振閪), qui retombèrent l'une à l'ouest (Nakamura du canton de Naka 那珂郡中村) pour le Bouddha de droite, et l'autre, à l'est. À la fin du rite d'ouverture des yeux (kaigen kuyō 開眼供羬) qui dura sept jours, à l'aube, Saichō fit un rêve : un jeune garçon (dōji 童-子) lui apparut, annonçant que le troisième bouddha devait être installé dans une vallée à l'est, et disparut dans cette direction en émettant de la lumière. Saichō nomma cet endroit, situé à dix $r i$ 里 $^{42}$ de distance, le " temple de la Lumière de l'Est " (Tōkō-ji 東光寺),

37. Selon l'historique des sanctuaires du département de Fukuoka : Dainippon jingikai 大日本神祇会, éd., Fukuokaken jinja-shi 福岡県神社誌, 1945, vol. 1, p. 140.

38. Satani-san Kensbö-ji engi (cf. supra, n. 9).

39. Mori Hiroko, Hōman-zan no kankyō-rekishi gaku teki kenkyū, p. 315.

40. Danzō désigne à l'origine des statues bouddhiques en bois d'ébène (Diospyros ebenum), de palissandre (Dalbergia sissoo) ou de santal (Santalum album), mais comme ces bois sont rares au Japon, et qu'ils sont très durs, la plupart de ces statues sont de petites dimensions. Au Japon, on utilise plus généralement le bois de cyprès du Japon (binoki 桧, Chamaecyparis obtusa) et on appelle danzō les statues sans couleur sculptées dans ce bois.

41. Motoki no Dainichi 本木の大H, Nakaki no Dainichi 中木の大曰, Sueki no Dainichi 末机大日.

42. Un ri équivaut environ à quatre kilomètres. 
et y vénéra dans un sanctuaire les trois divinités (san-sha 三社), c'est-à-dire Kumano. Ce prodige fut interprété comme un oracle de ce sanctuaire de Kumano dédié aux trois divinités. Il dressa donc à cet endroit un oratoire où il installa une statue de Kannon aux onze visages, et un autre où il déposa la troisième statue de Danichi (« de la cîme » ou "Bouddha de gauche »). Enfin, il y édifia un troisième oratoire où il installa les bouddhas Amida et Yakushi qu'il sculpta. Amida, Yakushi et Kannon sont les trois « sols originels » des trois dieux de Kumano qui en sont les manifestations provisoires. L'ensemble fut nommé par Saichō «Satani-san Kenshō-ji » 左谷山建正寺 (Kenshō-ji de la montagne de la Vallée de gauche). Les cérémonies de fondation furent accomplies par les religieux du temple du mont Hōman, Uchiyama-dera. Après son retour de Chine, Saichō visita de nouveau Chikushi 筑紫 pour remercier les divinités de l'avoir protégé pendant les années passées dans ce pays. Constatant qu'il n'y avait pas de moines au temple du mont Satani qu'il avait fondé, il en fit venir plusieurs, auxquels il dispensa son enseignement, afin qu'ils assurent ensuite l'entretien de ce temple. Ainsi, dix-huit moines de l'École Hossō 法相宗 de l'Uchiyama-dera se convertirent au Tendai, reçurent son enseignement et se fixèrent en ces lieux.

Aujourd'hui, ce sanctuaire de Kumano à Satani n'est plus qu'un petit sanctuaire du dieu tutélaire local. La question est donc de savoir quelle fut l'importance socioreligieuse de ce Kumano gongen qui est lié à la fondation de Satani. La distance entre Satani et le sommet du mont Wakasugi est beaucoup plus courte que celle existant entre le sanctuaire Bas de Wakasugi et le sommet de la montagne. Mais, étrangement, dans cette histoire des origines de Satani, ni le mont Wakasugi ni Taiso gongen ne sont mentionnés.

Les sanctuaires de Kumano du département de Fukuoka. - Les Trois sanctuaires de Kumano (Kumano san sha 熊野三社) d'origine sont situés dans le sud de la péninsule de Kii, dans le département de Wakayama : Kumano imasu jinja 熊野坐神社 (Hongū 本宮), dont le dieu principal est Ketsumiko (家津御子神); Kumano Hayatama jinja 熊野速玉 神社 (Shingū 新宮), où est vénéré le dieu Hayatama 速玉神; Kumano Musubi/Fusumi jinja 熊野夫須美神社 (Nachi 那智), dont la divinité principale est Musubi 結神 (Fusumino-kami 夫須美神 ou Musubi-no-kami 牟須美神). L'ensemble est couramment appelé les «Trois montagnes de Kumano »(Kumano sanzan 熊野三山), les Trois sanctuaires de Kumano 熊野三社, les Trois Kumano 三熊野 ou encore les Trois gongen de Kumano 熊野三所権現. Depuis l'Antiquité, ce sont des lieux saints privilégiés et représentatifs du shugen. À l'origine, ces trois sanctuaires, qui ont chacun une genèse différente, étaient indépendants les uns des autres, et des divinités distinctes y étaient vénérées. C'est vers le milieu du XI' siècle qu'ils en vinrent à constituer une même configuration cultuelle réunissant les trois divinités, qui devinrent alors objet de culte commun dans les trois sanctuaires. Sous l'influence du shugendō, vers la fin du XII ${ }^{e}$ siècle, neuf autres divinités leur furent ajoutées (les Cinq princes [Gosho oji 五所王子] et les Quatre sanctuaires [Shisho-gū 四所宮]) et ils furent dès lors appelés les Douze gongen de Kumano (Kumano jūnisho gongen 熊野十二所権現). De la fin Heian au début Kamakura, le pèlerinage aux Trois Kumano connut une véritable vogue parmi les empereurs retirés et les aristocrates, ce qui fut à l'origine de la grande prospérité de ceux-ci, grâce aux donations de terres qui leur furent faites un peu partout dans le pays. Au Moyen Âge, ce sont les classes populaires qui se mirent à affluer de toutes les provinces, en groupes conduits par des guides : ceci fut appelé 
le " pèlerinage des fourmis à Kumano » (ari no Kumano mōde 蟻の熊野詣), et fit de ce pôle religieux le "premier des lieux prodigieux du Japon ${ }^{43}$ ». Les recherches ont montré qu'à l'arrière-plan de cette affluence de pèlerins vers Kumano, était à l'œuvre l'action de diffusion de ce culte menée dans tout le pays par des spécialistes de narratifs des prodiges de Kumano, les " maîtres de Kumano » (Kumano oshi 熊野御師) et les « nonnes de Kumano 》 (Kumano bikuni 熊野比丘尼), qui pratiquaient également des collectes de fonds. Ce sont eux qui furent les acteurs majeurs de l'extension du culte de Kumano dans tout le Japon où l'on compte actuellement plus de 3000 sanctuaires portant ce nom.

Pourtant, aujourd'hui, les recherches sur la diffusion locale du culte de Kumano ne sont guère avancées. Aussi m'intéresserai-je ici au processus d'implantation de cette forme cultuelle en examinant l'histoire des sanctuaires de Kumano répartis dans le département de Fukuoka (carte I). La majorité d'entre eux ont pour divinités principales le trio Hayatama-Kotosaka-Izanami. Selon la « Base de données nationale des sanctuaires de Kumano ${ }^{44}$ ", les divinités le plus fréquemment vénérées dans ces sanctuaires sont les suivantes, en ordre décroissant : Izanami (I 436 sanctuaires), Hayatama (897), Izanagi (829), Kotosaka (708), Susanoo 素戔鳴尊 (277); Amaterasu n'arrive qu'au $6^{\mathrm{e}}$ rang (177), puis Kumano gongen (158), Ketsumiko (I2I), Fusumi / Musubi (90) et Kumano Kusuhi 熊野楈樟日命 (67).

L'Histoire des origines des monts Ōmine $e^{45}$, qui relate le mythe des Douze gongen de Kumano, relie ceux-ci à des lieux et des personnages du bouddhisme indien et du shugendō. Kumano gongen y est présenté à la fois comme le cinquième descendant d'Amaterasu et comme le cinquième des rois indiens descendant du roi Jōbon-ō 浄飯王 (sk. Śuddhodana, le père du Bouddha Saákyamuni) du pays de Makada 摩竭陀国 (Magadha). Appelé Jihidaiken 慈悲大顕王, il prit pour épouse la fille d'un descendant de Kashō 迦葉 (sk. Kāśyapa), le disciple du Bouddha. De cette union seraient nés deux enfants, Musubi et Hayatama. Dans les textes shugen du $\mathrm{XV}^{e}$ siècle ${ }^{46}$, ces deux derniers sont présentés comme les géniteurs des Cinq princes de Kumano : l'époux de Musubi est Izanagi et leurs enfants, trois des Cinq princes (Wakamiya onna-ichiōji 若宮女一王子, c'est-à-dire Amaterasu, Zenji-no-miya 禅師宮 et Hijiri-no-miya 聖宮), tandis que l'épouse de Hayatama est Izanami, et

43. Nibon dai ichi dairengensho 日本第一大霊験所; reigen ou reiken correspond aux prodiges dus à l'efficace des divinités qui exaucent les vœux. (N.D.T.)

44. Kumano sanzan kyōgikai 熊野二Il協議会, Zenkoku Kumano jinja dèta bèsu 全国熊野种社 データベース (document non publié).

45. Ómine engi 大峰縁起. Selon les traditions shugen du début Kamakura, le $\mathrm{I}^{\text {er }} \mathrm{du} 8^{\mathrm{e}}$ mois de 1070 (Enkyū 延久 2), ce texte, qui est une compilation des mythes et traditions orales se rapportant à Kumano, Ōmine 大峰 et En no Gyōja, fut déposé au sanctuaire Hongū de Kumano (dit Shōjō-den 証誠殿). Le yamabushi de Kumano, Chōen 長円, se rendit à la capitale pour en faire part à l'empereur retiré Shirakawa 白河 $上$ 皇, qui vit cet engi lors de son pèlerinage à Kumano en I090 (Kanji 寛治 4). À compter de cette date, fut instaurée la coutume de présenter ce texte aux empereurs retirés et aux nobles de la cour qui faisaient le pèlerinage. Cf. Miyake Hitoshi 宮家準, Kumano shugen 熊野修験, 1992, p. 50-73.

46. Shugen shinanshō 修験指南鈔 et Ryōbu mondō bishō 両峰問答秘鈔. Cf. Miyake Hitoshi, Kumano shugen, p. 50-73. 
leurs enfants sont les deux autres princes (Chigo-no-miya 児宮 et Komori-no-miya 子守宮). Un texte plus tardif (I72I, Kyōhō 享保 6) des archives du sanctuaire Hayatama de Shingū, le Kumano sōsō yurai zasshū shō 熊野草創由来雑集抄, assimile Musubi à Izanami, Hayatama à Izanagi, Kotosaka à Asuka gongen 阿須賀権現, le maître du sol de Shingū, et enfin le premier des Cinq princes à Amaterasu ${ }^{47}$. Par ailleurs, on trouve aussi l'identification du dieu Ketsumiko de Hongū au dieu Susanoo, celle de Hayatama de Shingū à Izanagi, de Musubi/ Fusumi de Nachi à Izanami et celle de Wakamiya à Amaterasu ${ }^{48}$.

Si un grand nombre des sanctuaires de Kumano situés en différents endroits du pays ont pour dieu principal Hayatama, c'est-à-dire celui de Shingū, c'est peut-être, selon l'hypothèse de Yamamoto Shigeo 山本殖生, parce que ce sanctuaire se trouve immédiatement sur le bord de la côte du Pacifique et que l'on peut en sortir directement en bateau : ceci aurait ainsi facilité la dynamique de diffusion. Or, comme le montre la carte des sanctuaires de Kumano dans le département de Fukuoka (carte I), ceux-ci se concentrent, d'une part le long de la côte de la mer Genkai-nada 玄界灘 et, d'autre part, dans le bassin fluvial de la rivière Yabe 矢部川, affluent du fleuve Chikugo 筑後川. Il est en particulier tout à fait remarquable que des sanctuaires de Kumano se trouvent sur la ligne côtière des montagnes qui, depuis la mer Genkai-nada, servent d'amers aux bateaux : les monts Hobashira 帆柱山 (“Mât »), Wakamatsu Kotake 若松小岳山, Fukuchi 福智山, Konomi 許斐山, Imajuku-Imayama 今宿今山 et Kayasan 可也山, appelé aussi « Fuji de Chikushi »筑紫富士.

Le sanctuaire Takami 鷹見神社 a été construit sur le mont Hobashira en II94 (Kenkyū 建久 ऽ) par le fondateur de la maison des Asō 麻生, Utsunomiya Kōzukeno-suke Fujiwara Shigenari 宇都宮上野介藤原重業, lorsqu'il édifia une citadelle à cet endroit, afin que les divinités qui y étaient vénérées protègent à la fois cette dernière et la maison des Asō. Pour cet ensemble, il fit don d'une terre de 3000 chō 町 (environ 3 ooo ha) où Kumano gongen (Hayatama, Kotosaka et Susanoo) fut vénéré sous le nom de Takami gongen 高見権現.

Sur le mont Kotake de Wakamatsu se dresse aujourd'hui le sanctuaire Hakusan 白山神社 édifié par Asō Hyōbu-dayū 麻生兵部大輔 qui y importa les dieux du mont Haku d'Utsunomiya 宇都宮 (département de Tochigi 栃木県). Mais antérieurement, il y avait un sanctuaire dédié à Kumano gongen : selon la légende ce gongen serait venu du pays de Makada 摩珂陀国, en Inde, en volant au-dessus de la mer, et ayant trouvé cette montagne splendide, il s'y serait reposé avant de gagner le mont Hiko puis Kumano du pays de $\mathrm{Kii}$ où il se fixa. Les divinités qui y sont vénérées sont Kikuri-hime 菊理媛命 (du mont Haku), Hayatama, Kotosaka et Izanami.

La tradition locale veut que le sanctuaire de Kumano du mont Konomi ait été fondé en 857 (Ten.an 天安 I) pour la protection du pays et l'écrasement des ennemis, avec l'installation sur place des dieux de Hongū à Kumano. Y sont vénérés Hayatama, Kotosaka, Izanami ainsi que les trois déesses de Munakata et la divinité Orihata 織幡神. À l'origine, il était appelé Konomi gongen 許斐権現. La date de

47. Miyake Hitoshi, ibid.

48. Koyama Yasunori 小山靖憲, «Kumano sanzan 》熊野一-山, dans Kumano. Ikai e no tabi 熊野・異界への旅, numéro spécial du Taiyō 別冊太陽, 2002, P. I2. 
fondation en 857 est sujette à caution, mais en tout cas, son existence est confirmée au XII ${ }^{e}$ siècle, car dans les archives de Munakata, on le trouve mentionné en Izo9 (Jōgen 承元 3), en tant que dieu tutélaire local. Au Moyen Âge, son palanquin avait sa place dans la plus grande célébration des Cinq sanctuaires de Munakata (les trois divinités de Munakata, de Konomi gongen et d'Orihata).

L'une des communes limitrophes de Sasaguri s'appelle Shingū 新宮町 et selon l'historiographie régionale de la fin du XviI et du début du XVIII' siècle, le Chikuzen no kuni zoku fudo- $k i^{49}$, ce nom vient de ce que l'on a transféré ici le sanctuaire de Sumiyoshi. Mais dans les archives du sanctuaire Isozaki 磯崎神社 ${ }^{50}$, il est rapporté que le dieu Hayatama de Shingū de la péninsule de Kii est arrivé par la mer jusqu’à la baie de Shingū, où un pécheur l'a ramené dans ses filets puis vénéré sous le nom de grande divinité de Shingū. Il est aujourd'hui dieu tutélaire des deux villages de Shimonofu 下府 et Kaminofu 上府. C'est pourquoi la baie qui s'appelait Minatoura 湊浦 a pris le nom de Shingū-ura 新宮浦. Une autre historiographie régionale, le Chikuzen no kuni zoku fudo-ki shüi 筑前国続風土記拾遺 $^{51}$, précise qu'on a installé la divinité de Sumiyoshi dans Shingū jinja, le sanctuaire tutélaire des deux villages Shimonofu et Kaminofu. Les divinités actuellement vénérées dans le sanctuaire Shingū de Kaminofu sont Kumano Kusubi 熊野椄樟日命, Hayatama, Izanami et Kotosaka.

Dans cette même commune de Shingū, il existe un autre sanctuaire de Kumano situé à Matono 的野 ${ }^{52}$, au nord-est, au pied du mont Tachibana 立花山 $(367 \mathrm{~m})$, très visible de la mer. Ses divinités sont Hayatama, Kotosaka et Izanami. Il a été reconstruit en 1587 par le chef de fief Kobayakawa Takakage 小早川隆景 (1533-1597), après un incendie ; aussi son existence antérieure à cette date est-elle certaine. Au sud de cette même montagne, sur une petite colline, se tient le sanctuaire Kashii qui entretient des liens étroit avec le culte de Jingū et l'histoire des origines du mont Wakasugi.

Selon les mythes du Kojiki et du Nibon shoki, c'est sur le site où avait résidés son époux défunt, l'empereur Chūai 仲哀大皇, que l'impératrice Jingū aurait reçu l'oracle du dieu Sumiyoshi disant : «Va chercher l'or et l'argent de Corée de l'autre côté de la mer. " À ce titre, et en tant que point de départ de l'expédition vers la péninsule coréenne, ce lieu est donc important. Aussi est-ce à cet endroit qu'en 724 (Jinki 神亀 2),

49. Cbikuzen no kuni zoku fudo-ki 筑前国続風土記, la première des historiographies locales de Chikuzen publiées à l'époque d'Edo. Le savant du fief de Fukuoka, Kaibara Ekiken 貝原益軒, reçut l'autorisation de faire cette compilation en I688 (Genroku 元禄 I) alors qu'il avait 59 ans. Il la présenta en 1703 (Genroku 16), à 73 ans, au daimyō Kuroda, puis il y fit des rectifications, ajouta une préface et l'acheva en 1709 (Hōei 宝永 6). L'ensemble a été édité par Itō Oshirō 伊藤 尾四郎 (1869-1949) et publié en 1973, Tōkyō, Meichō shuppan 名著出版; puis reproduit à Tōkyō, Bunken shuppan 文献出版, 2001, P. 430 .

50. Shingū ura yuraisho jōchō 新宮浦由来書上帳.

51. Aoyagi Tanenobu 青柳種信, comp., Chikuzen no kuni zoku fudo-ki shūi 筑前国続風土記 拾遺, dans Chikuzen no kuni zoku fudoki shūi kankō-kai 筑前国続風土記拾遺刊行会, éd., (I ${ }^{\mathrm{r}}$ éd. 1814-1864), vol. 4, p. 1566.

52. Selon la légende, Matono, "Lande des cibles ", doit son nom au fait que c'était le lieu où les guerriers de l'impératrice Jingũ s'entraînaient au tir à l'arc avant le départ pour la conquête des royaumes coréens.

53. Kashii no miya 㹂日宮. 
le pouvoir central construisit le sanctuaire Kashii, en tant que défense religieuse face à la péninsule coréenne, sur le lieu mythique d'où était partie Jingū pour la conquête, dont elle rentra victorieuse sans avoir versé de sang. Aujourd'hui, on pense qu'à cet endroit vivait Tsukushi no kimi Iwai 筑紫君整井, qui possédait un important pouvoir dans la région et entretenait des relations amicales avec la péninsule coréenne ${ }^{54}$. De deux tertres funéraires ${ }^{55}$ datant de la seconde moitié du IV $v^{e}$ siècle sont sortis des miroirs, des poteries avec des armatures métalliques. Quant au mont Tachibana, on peut supposer qu'un sanctuaire y avait été construit avant celui de Kashii.

Les dates données par toutes ces histoires des origines ne sont sans doute pas toujours fiables, mais ce qui est important, c'est qu'elles permettent de constater que, sur les montagnes, dans les baies et dans les villages situés à proximité du mont Wakasugi, existèrent, dès l'époque ancienne, des échanges par le biais des voies maritimes, d'une part, avec les pays extérieurs au Japon et, d'autre part, avec toutes les autres régions du pays. L'extension locale du culte de Kumano est reconnue comme remontant à une période antérieure à la fin du XIre siècle et, comme on peut le voir sur la carte I, il est certain qu'il s'est implanté dans des structures religieuses construites sur toutes les hauteurs et montagnes qui font face à la mer Genkai-nada.

Le mont Wakasugi et le shugen de Kumano. - Si l'on tient compte de ces données régionales pour examiner le rapport qu'entretient l'histoire du mont Wakasugi avec le culte de Kumano, on peut penser que le sanctuaire de Kumano, qui se trouve aujourd'hui à Satani sur le flanc sud du mont Wakasugi, se dressait lui aussi, originellement, sur le sommet. À la différence de Kumano gongen, Hiko gongen ou Konomi gongen, dont le nom même affiche la relation avec le lieu d'origine du culte de ces divinités, le dieu principal de Wakasugi, Izanagi, ne porte ici que celui très particulier de "Taiso gongen ", sans relation avec le lieu ni aucune autre mention. Comme on a pu le voir précédemment, les interprétations concernant les divinités de Kumano sont multiples, très compliquées, et changent selon les époques et les textes. Néanmoins, on peut affirmer qu'Izanagi et Amaterasu dont nous nous occupons ici, bien que se trouvant dans un réseau de relations complexes, possèdent en tout cas des liens étroits avec le culte de Kumano.

Les précédentes analyses permettent de penser que sur le sommet du mont Wakasugi, où depuis une époque ancienne était vénérée une divinité protectrice de la navigation maritime, vint s'implanter le culte de deux dieux de Kumano, Izanagi et Amaterasu. Historiquement, cette implantation a dû se produire au moment où le pèlerinage de Kumano connaissait une grande vogue parmi les empereurs retirés et les milieux de la cour, et où le culte de Kumano commença à se diffuser vers les provinces, soit vers la fin de l'époque Heian ou le début de l'époque Kamakura (fin XII siècle), si l'on tient compte des archives historiques de Kyūshū. Dans un deuxième temps, fut introduit le culte de Hachiman. Nous ignorons quelle était la configuration du groupe des divinités lorsque Kumano gongen était vénéré à Wakasugi, mais on peut penser que c'est lors de leur association avec celles du culte

54. Chō Yōichi 長洋一, «Dazaifu seiritsu zenshi »太萃府成立前史, dans Tamura Enchō 田村 円澄, éd., Kodai wo kangaeru Daizaifu 古代を考劣る大莘付, 1987, p. 28.

55. Tenjin no mori kofun 天神/森古墳 et Kasumi ga oka kofun 香住ヶ丘古垻. 
de Hachiman qu'Izanagi fut mis en avant en tant que fondateur et donc " ancêtre » (taiso 大祖) du pays et du peuple japonais, et qu'il reçut le titre de Taiso gongen. Il devint alors la divinité principale de l'ensemble qu'il formait avec les trois divinités de Hachiman et avec celles qui lui étaient associées, les dieux de Shika et de Sumiyoshi.

Les documents relatifs à Wakasugi sont trop peu nombreux pour faire apparaitre de quelle façon, à l'époque ancienne, se sont articulés les divers cultes extérieurs avec le culte local originel, comment s'est déroulé le processus de dénomination des dieux, ou comment s'est instauré le contrôle politico-religieux des sanctuaires. Mais pour émettre une hypothèse à ce sujet, je prendrai l'exemple des rapports du culte de Hachiman et de celui du mont Hōman, dont les archives éclairent ces processus. Le culte de Hachiman est centré sur trois divinités : le "grand bodhisattva Hachiman " (Hachiman daibosatsu 八幡大菩薩 ${ }^{56}$ ), le « grand bodhisattva Sainte Mère " (Shōmo daibosatsu 聖母大菩薩 ${ }^{57}$ ) et une déesse (Hime-ōkami 姫大神). En pays de Chikuzen, cette troisième entité est identifiée au personnage mythique de Tamayori hime 玉依姫, fille du dieu des mers, elle-même donnée comme étant la divinité du mont Hōman appelée grand bodhisattva Hōman (Hōman daibosatsu 宝満大菩薩). Les premières occurrences se trouvent dans des textes datant de la fin du XIII ${ }^{c}$ et du début du XIve siècle, les Chroniques $d u$ grand bodbisattva Höman du mont Kamado ou le Recueil d'oracles d'Usa ${ }^{59}$. Or, le nom de grand bodhisattva Hōman est apparu à la fin de l'époque de Heian (fin du XII siècle), alors que l'administrateur d'Iwashimizu Hachiman contrôlait aussi l'organisation religieuse du mont Hōman. C'est cette appellation qui a finalement fait passer dans l'usage courant celle de "mont Hōman ", aux dépens de celle de "mont Kamado », nom originel de cette montagne. La triade des trois bodhisattvas Hachiman, Shōmo et Hōman était vénérée dans les trois sanctuaires de Kamado (c'est-à-dire le mont Hōman à Daizaifu), de Hakozaki (Fukuoka) et d'Usa (Usa) ${ }^{60}$. On comprend ainsi que, dans le cadre du culte de Hachiman, la divinité du mont Kamado ait reçu un nouveau nom, grand bodhisattva Hachiman, et une identité la plaçant dans une relation de parenté avec la lignée impériale, en la personne de Jingū dont elle est la sœur aînée,

56. Le grand bodhisattva Hachiman est identifié à l'empereur Ōjin 応神天皇, fils de Jingū. Le nom qui, sur des oracles, a tout d'abord été donné à ce dieu est «bodhisattva roi grand souverain 》 (Daijizai-ō bosatsu 大自在王菩陼) en 78I (Tennō 天応 I) puis, deux ans plus tard, en 783 (Enryaku 延暦 2), "bodhisattva roi grand souverain protecteur du pays à la puissance

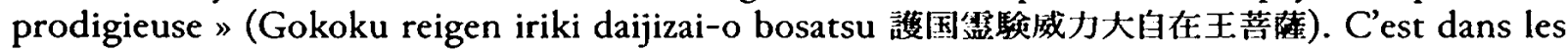
premières années du $1 x^{\epsilon}$ siècle qu'il fut nommé " grand bodhisattva Hachiman " (Hachiman daibosatsu 八鱕大菩隆). Cf. Tödai-ji yōroku 東大寺要録, règlement du 15.12.821, Kōnin 弘併 12 (Zoku-zoku gunsho ruijū 統々群花類従, éd., vol. II, 1969, p. 74).

57. Nom donné à l'impératrice Jingū. La première occurrence de Shōmo daibosatsu date de 1199 : cf. Heikoki 平户記, journal de Taira no Tsunetaka, vol. 32, 1965, p. 6.

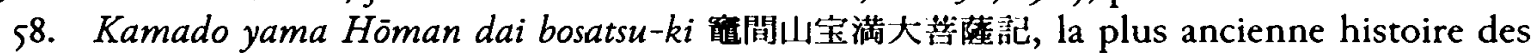
origines du mont Hōman. On peut penser que ce texte a été écrit au début de Kamakura, mais comme l'exemplaire conservé est celui qu'utilisait Kenna 剣阿 (126I-1338), moine du Shōmyō-ji ; la fin Kamakura est en tout cas certaine (manuscrit conservé au Shōmyō-ji 称名寺 à Kanazawa 金沢 à Yokohama). Voir Mori Hiroko, Hōman-zan kankei shiryō-shū 恁満ll関係史料集, Tōkyō, Iwata shoin 岩专院, P. II-I4.

59. Hachiman Usa-gū ontakusen só̄ (cf. supra, n. 28).

6o. Selon le Kamado yama Höman dai bosatsu-ki, p. 14. 
et de Hachiman (l'empereur Ōjin, fils de Jingū) dont elle est de ce fait la tante ${ }^{61}$. On peut donc penser qu'une restructuration similaire de nom et d'identité a pu se produire pour les divinités du mont Wakasugi.

Étant donné que la première apparition du nom Taiso gongen remonte à la fin de Kamakura (fin XII ${ }^{e}$-début XIV $v^{e}$ siècle) et figure dans le Recueil des oracles d'Usa ou dans l'Histoire des origines du grand bodhisattava de Munakata, texte fortement influencé par le culte de Hachiman ${ }^{62}$, on peut penser que l'implantation du culte de Hachiman à Wakasugi date de l'époque des invasions mongoles, vers la fin du XIII $^{c}$ siècle (les deux invasions eurent lieu en 1274 et en I28I), quand le "dedans ", c'est-à-dire le Japon, fut exposé comme jamais il ne l'avait été à un danger venant du "dehors ». Le changement du nom de la montagne, de Wakesugi en Wakasugi, dut également se produire au même moment, puisque l'appellation de Wakasugi apparaît, avec le cryptomère aya de Kashii, sur une trame où elle est liée à l'impératrice Jingū et à son expédition vers la péninsule coréenne. Avant cette date, il se peut que le nom de la montagne ait été «mont Kōyano " (Kōyano dake 神野埜嶽, «Lande du/des dieu(x) », nom qui est mentionné dans le Gūki comme étant celui de l'endroit où Zenmui fonda une première structure cultuelle en arrivant de Chine, obéissant en cela à l'oracle reçu en mer lors de la tempête. Dans l'Engi, ce nom est devenu la "Haute Lande » (Kōyano 高野埜), où Kūkai aurait fondé, dit-on, un ensemble de temples à quelques centaines de mètres au nord du sanctuaire Haut ${ }^{63}$. Mais il faut aussi remarquer que le caractère « dieu " (kami) 神, lu kō dans le Gūki, peut également se lire kuma. Ainsi, l'ancien nom peut être également lu "Kumano dake ».

Les plus anciennes relations connues entre Kyūshū et le haut lieu du shugendō qu'est Kumano apparaissent dans le texte de donations de terres faites au sanctuaire Ima-Kumano 新熊野神社 à Kyōto par l'empereur retiré Go-Shirakawa 後白河法皇, en Iı8I (Yōwa 養和 1). Est mentionné dans ce texte "le mont Hiko de Buzen ». Ce dernier est le centre shugen de Kyūshū qui fut le premier à nouer des liens avec les organisations centrales. Mais comme nous l'avons vu précédemment, il existe une autre route, celle des voies maritimes qui relient elles aussi le nord de Kyūshū au shugen de Kumano. Ces « chemins de la mer " étaient contrôlés par les clans Munakata 宗像族 et Azumi 安䱏族; aussi peut-on se demander si ces derniers n'ont pas été les acteurs de ces liens entre Kumano et Kyūshū $\bar{u}^{64}$. Comme nous avons pu le constater, le cas du sanctuaire de Kumano du mont Konomi montre à la fois l'existence de relations avec le shugen de Kumano (Hongū) et le sanctuaire Munakata.

L'entrée dans la montagne de printemps du shugen du mont Höman et le sanctuaire du Kumano. - Outre les « chemins de la mer », voies de l'extension du culte de

61. Mori Hiroko, Hōman-zan no kankyō-rekishi gaku teki kenkyū, p. 160-176.

62. Hacbiman Usa-gü ontakusen sbū (cf. supra, n. 28), p. 42 et Munakata daibosatsu go.engi, édité par Shintō taikei hensankai, p. I6-17.

63. Le changement des caractères est probablement à rattacher au lien que le mont Wakasugi chercha à établir avec Kūkai qui fonda le mont Kōya 高野山, centre du Shingon.

64. Selon le supérieur du Kongōchō-in 金剛頂院 du mont Wakasugi, aujourd'hui encore, parmi les fidèles du temple, nombreux sont les pêcheurs d'Ai no shima 相島, Shingū 新宮, Kanezaki 鐘崎 et Munakata 宗像. 
Kumano, cette région est caractérisée par la présence des circuits rituels du shugen des monts Hōman et Hiko (carte I). Le plus ancien est celui qui relie le mont Hiko, assimilé au mandala de la Matrice, et le mont Hōman, assimilé au mandala du Diamant. Appelé "Ōmine ", ce circuit était utilisé au printemps et en été à partir du mont Hiko, et en automne à partir du mont Hōman. Ensuite, à partir du $\mathrm{XIV}^{\mathrm{e}}$ siècle, fut ouvert un autre itinéraire, entre le mont Hiko et, au nord, le mont Fukuchi, pour le parcours rituel de l'automne ${ }^{65}$.

Le mont Wakasugi est situé, quant à lui, sur le parcours rituel de printemps du shugen du mont Hōman, appelé « sommet de Katsuragi 》(Katsuragi no mine 葛城峯), qui part du mont Hōman (manḍala du Diamant) et va jusqu'au mont Kodai-ji 孔大寺山 (mandala de la Matrice) de Munakata. Le trajet aller depuis le mont Hōman jusqu'au mont Shura était identifié au « sommet du mandala des neuf assemblées du mandala du Diamant ${ }^{66}$ »; le mont Inunaki en tant que "Socle central » (chüdai 中台) était le " grand mandala des quatre enceintes et trois classes ${ }^{67}$ ». Entre Kiyotaki-dera 清潼寺 (Komono 薦野, ville de Koga 古賀市) et le mont Tsuta 蔦山 d'Akama 赤間 (Munakata), c'était le «sommet des neuf vénérés du mandala de la Matrice ${ }^{68}$ ». Le mont Kōdai-ji était le « lieu de pratique du Sütra du Lotus ${ }^{69}$ ». Le trajet du retour jusqu'au mont Hōman passait le long de la côte par les sanctuaires Orihata 織幢宮 et Munakata, le mont Konomi 許斐山, Shingū, les sanctuaires Kashii et Hakozaki, le centre de Hakata 博多, le château de Fukuoka, et il était assimilé à la « cour extérieure de la lignée du Diamant ${ }^{70}$ » du mandala de la Matrice ; ses étapes représentaient les 28 mansions lunaires $^{71}$ de ce dernier, et elles étaient elles-mêmes assimilées aux 28 chapitres du Sütra du Lotus de l'entrée dans la montagne des monts Katsuragi du Yamato. Au sein de cet ensemble, le mont Wakasugi faisait partie du mandala des neuf assemblées du Diamant. Les entités du mandala qui étaient vénérées sur ce parcours étaient, à Satani, le jouvenceau Taniyama-Vertu des Trésors ${ }^{72}$; dans le sanctuaire Haut, sur le sommet du mont Wakasugi, le jouvenceau Wakasugi-bouddha Hōshō ${ }^{73}$;

65. Mori Hiroko, Höman-zan no kankyō-rekishi gaku teki kenkyū, p. 312.

66. Kongökai kue mandara no mine 金剛界九会曼茶羅の峯. En français, sur les deux mandala ésotériques et toute cette terminologie, voir Bernard Frank, Dieux et Bouddhas au Japon, 2000 ; et sur le parcours rituel du shugen du mont Hōman, voir A. Bouchy, "'Initiatic landscape' and Shugendō mountain-entry ", Proceedings 148, 2011, p. 73-99. (N.D.T.)

67. Sanbu shijū no daimandara 三部四重の大曼茶羅.

68. Taizōkai kyūson no mine 胎藏界九尊の峯.

69. Hokke no dojjö 法華/道場.

70. Dans Ge kongōbu 外金剛院.

71. Nijübasshuku -二十八宿.

72. Taniyama dōji-Hōharamitsu 谷山童子·宝波矍密. Selon les textes relatant les entrées dans la montagne (mine.iri 浲入) du shugen de Höman, à chacune des haltes rituelles — appelées sbuku 宿, comme sur les monts Ōmine du Yamato - étaient vénérées une divinité locale (en tant que suijaku) et une entité bouddhique (bonji de celle-ci), correspondant aux figures des mandala du Diamant et de la Matrice. Ici, la particularité est que les divinités locales sont représentées sous la forme de jouvenceaux (dōji 童子) protecteurs de la montagne où ils sont vénérés, et portant généralement le nom du lieu de la halte.

73. Wakasugi döji-Hōshō butsu 分杉童子·家生仏. 
sur le mont Shira.ishi 白石获, à droite de la vallée des Yamabushi (Yamabushi-dani 山伏谷), le jouvenceau Shira.ishi-Vertu de la $\mathrm{Loi}^{74}$.

Les détails des journées et du parcours ont été consignés par le yamabushi du mont Hōman, Kame.ishi-bō Jushō-in Yūben 刍石坊寿昌院有弁, en I812 (Bunka 文化 I2). Ce texte a ensuite été retranscrit en I860 (Ansei 安政 7) par Ishii-bō Ken.yū 石井坊堅有 (les graphies de son nom varient selon les sources: 賢祐 ou 賢有) de Wakasugi ${ }^{75}$. Ce document ainsi que d'autres laissés par ce dernier nous permettent de connaître ce parcours rituel et c'est grâce à leurs indications que j'ai pu en tracer le circuit sur la carte r.

Selon les Chroniques de l'entrée dans la montagne du mont Kamado de Cbinzei ${ }^{76}$ (ci-après, Nyūbu denki), ce parcours rituel entre le mont Kamado (Hōman) et le mont Kodai-ji aurait été ouvert par En no Gyōja 役行者, le fondateur du shugendō, en 701 (Taihō 大宝 I), sur le modèle de celui des monts Katsuragi 葛城山 du Yamato, " comme 28 lieux saints configurant les Trois Classes Associées (sanbu shügō 三部 習合), représentant les bénéfices des 28 chapitres du Sütra du Lotus. »Puis entre 707 et 896 , l'entrée dans la montagne aurait eu lieu six fois, au cours desquelles aurait été accompli l'ondoiement ${ }^{77}$, rituel initiatique de transmission des arcanes et de consécration. Ce texte, dont le début date de 952 (Tenryaku 天暦 6), a été écrit par plusieurs auteurs successifs. Il y est mentionné que le «sommet de Katsuragi », sous la forme dans laquelle il s'est transmis, a été mis en place en 96I (Ōwa 応和 I). Les passages les plus anciens ne sont sans doute pas des faits historiques, mais on en retient que le shugen du mont Hōman revendique sa filiation initiatique avec En no Gyōja, car le chef du shugen du mont Kamado, Jōkai zasu 鿇戒座主, dont on dit qu'il fut le premier à réaliser ce parcours rituel en $96 \mathrm{I}$, y est présenté comme le détenteur et le continuateur de la transmission d'En no Gyōja ; ensuite, que l'instauration du sommet de Katsuragi est un acte de portée nationale visant à l'obtention de la sécurité, de la paix et de la prospérité de l'empereur et du pays ; et enfin, comme l'indique le nom de "sommet de Katsuragi des liens noués ${ }^{78}$ ", que c'est lors de cette entrée dans la montagne que se déroule le rite de l'ondoiement, lequel confère le rang de chef du shugen (zasu 座主) du mont Kamado : il s'agit donc du rite d'engagement (des «liens noués ») du zasu avec la Loi (ici, l'enseignement initiatique). C'est pourquoi, si les yamabushi qui ont les plus hauts rangs sont seulement nommés, pour le sommet d'automne (Ōmine), " grands guides de la réception du titre » (jushiki daisendatsu 授職大先達), lors de l'entrée dans la montagne du printemps (de Katsuragi), ces mêmes yamabushi portent le titre de "grands guides de la transmission de la loi »

74. Shira.ishi döji-Hōbaramitsu 白石童子·法波羅密.

75. Katsuragi buchü hanaku michi annai 葛城案中花供道案内. Pour tous les textes du shugen du mont Hōman, voir les annexes de Mori Hiroko, Hōman-zan kankei shiryō-shū, dans Hömanzan no kankyō-rekishi gaku teki kenkyū.

76. Chinzei Kamado yama nyūbu denki 鎮西䨩門山入峯伝記 (archives de l'Eifuku-in 永福院, temple affilié au shugen du mont Hōman).

77. Dentō kanjō 伝燈灌頂. Sur l'ondoiement en français, voir Anne Bouchy, "Du légitime et de l'illégitime dans le shugendō ou 'Sang de buddha', 'sang des êtres des montagnes' ? ", dans Anne Bouchy, Guillaume Carré et François Lachaud, éd., Légitimités, légitimations. La construction de l'autorité au Japon, 2005, p. III-I77. (N.D.T.)

78. Katsuragi kechien no mine 葛城結粶之笔. 
ou « grands guides des liens noués » ${ }^{79}$; le chef du shugen de Hōman consacré par cet ondoiement reçoit quant à lui le titre de "grand guide transmetteur de la lumière " (c'est-à-dire de l'enseignement initiatique) (dentō daisendatsu 伝燈大先達). Depuis le premier sommet de Katsuragi de 96I, ce parcours rituel n'a eu lieu qu'une fois par génération de chef shugen, afin d'assurer la consécration de celui-ci au rang de $z a s u$ et de demander la paix pour le pays, la sécurité de l'empereur et du chef du fief. Toutefois, selon ce document, après l'entrée dans la montagne de 1554 (Tenbun 天分 23), le rang de zasu ayant périclité, ce rituel de Katsuragi fut interrompu. Ce n'est que 146 ans plus tard, en 1699 (Genroku 元禄 I2), que ce sommet de printemps fut restauré pour instaurer de la fonction de zasu du Ryōga-in 楞伽院 et pour demander la protection du chef de fief Kuroda Nagamasa.

De nombreux textes historiques ${ }^{80}$ concordants relatent cette entrée dans la montagne de 1699 ; aussi peut-on considérer que c'est là un fait historique certain. Mais les documents étant peu fiables pour celles qui sont antérieures au Moyen Âge, il est possible que cette « restauration du sommet Ōmine » de 1699 ait été en fait le vrai début de ce rituel du shugen de Hōman ${ }^{81}$. Selon ces documents, qui coïncident aussi avec les informations du Nyūbu denki, 80 yamabushi (guides, novices et yamabushi de rangs intermédiaires) participèrent au sommet de 1699. Il s'agissait donc d'une entreprise d'assez grande envergure, qui impliquait l'existence d'une organisation antérieure à cette date pour être réalisable. Ce parcours rituel traverse un massif montagneux où se trouvaient de nombreux temples du Tendai, et où sont conservées, aujourd'hui encore, beaucoup de statues bouddhiques de la période de Heian. Il est possible que ce cheminement ait été conçu pour relier tous ces temples entre eux, en un même réseau dont le mont Hōman constituait le centre. Il faut aussi remarquer, comme le montre la carte I, que ce rituel sbugen se déroulait le long d'un circuit reliant également entre eux les sanctuaires de Kumano.

\section{Le mont Wakasugi, montagne dominant la plaine de Fukuoka}

Les traces des échanges avec l'extérieur. - Sur le mont Wakasugi subsistent de nombreuses statues de l'époque de Heian (784-1185), que ce soit du côté d'Utani, où l'on trouve des statues de Kannon aux mille bras, d'Amida, de Jizō 地蔵, de Fudō myōō 不動明王 et de deux jouvenceaux (ni-dōji 二童子) (fig. 4), ou du côté de Satani, où l'on rencontre des statues de Kannon aux onze visages, de Dainichi, des fragments des deux rois gardiens et autres entités bouddhiques ${ }^{82}$. Et si les statues de l'ésotérisme bouddhique sont nombreuses, cela est dû certainement à la présence du shugen en ces lieux. Il existe

79. 《Grands guides de la transmission de la loi 》 denbō daisendatsu 伝法大先達 ou 《grands guides des liens noués " kechien daisendatsu 結縁大先達.

8o. Notamment, Kawazoe Shōji 川添昭二 et al., éd., Kuroda sbinzoku kafu 黒田新続家譜, vol. 3, 1982, p. I42-I43 ; Hidemura senzō 秀村選三 et al., éd., Hakata-tsu yōroku 博多津要録, 1975, vol. I, p. 225-226 ; Kaibara Ekiken, comp., Chikuzen no kuni zoku fudo-ki, dans Itō Oshirō, éd., Fukuoka-ken sbi shiryō zoku dai yon shü. Chishi ben I 福阙県史資料続第四輯:地誌編一, p. I5O.

8I. Mori Hiroko, Hōman-zan no kankyō-rekishi gaku teki kenkyū, p. $521-531$.

82. Kyūshū rekishi shiryōkan, èd., Chikuzen Kasuya. Wakasugi yama no bukkyō iseki, p. 5-29. 


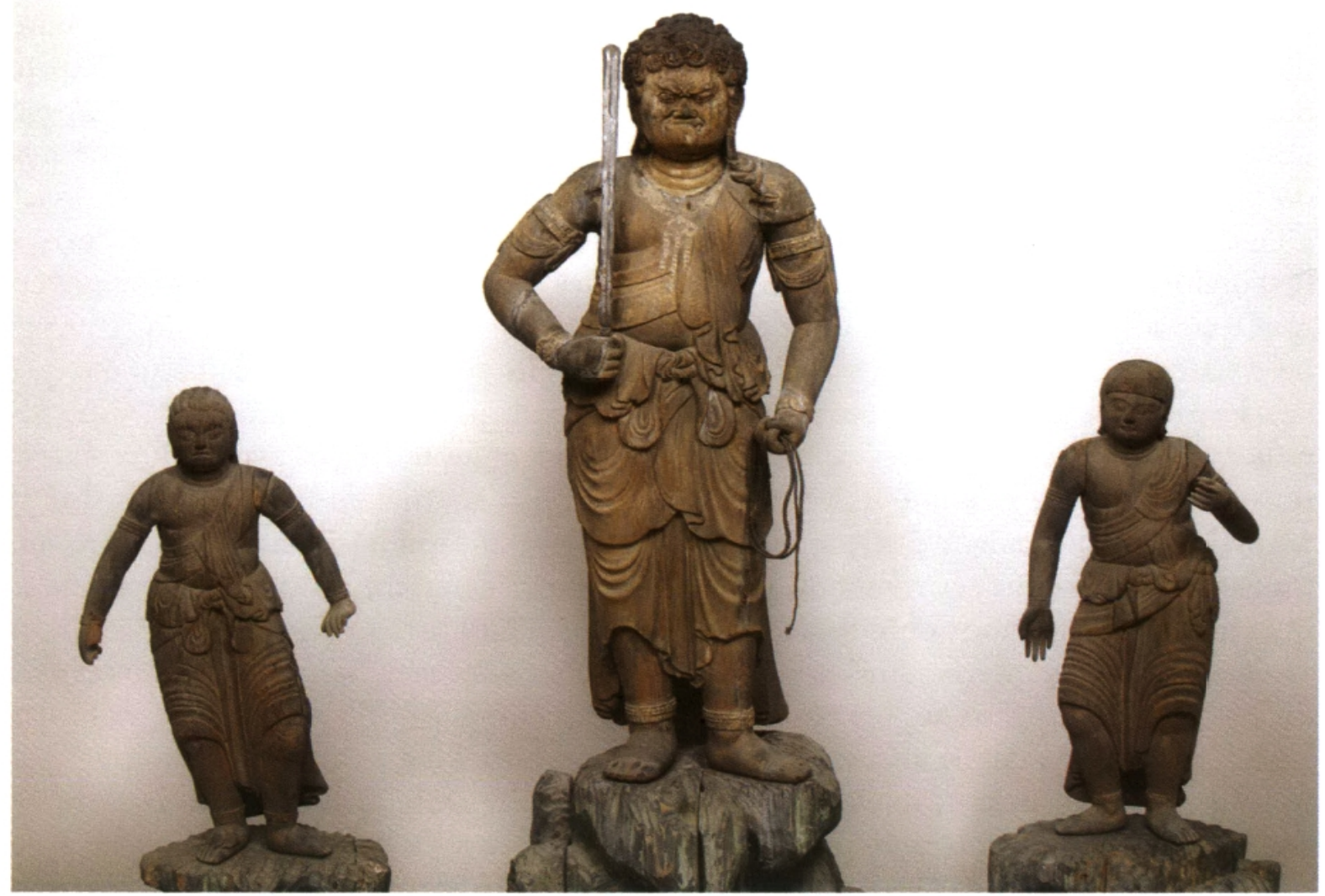

Fig. 4 : Fudō myōō et les deux jouvenceaux (Kongara, Seitaka)

(Ishii-bō, Wakasugi, xII' siècle). (Photo du Centre de documents historiques et de matériaux ethnographiques de Sasaguri 九州柲史資料館)

un autre type de vestiges tout à fait remarquables de cette même époque : ce sont les étuis en métal et en terre (kyōzutsu 経筒), dans lesquels étaient mises les transcriptions des sūtra, et qui étaient ensuite enfouis dans des tertres (kyōzuka 経塚) ${ }^{83}$. À Utani, des étuis de sūtra ont été retrouvés dans un tertre sur le mont Mukai 向/山 (II20, Hōan 保安 I) et en dessous de la cascade de Yōrō (I686, Jōkyō 貞享 3). Ce dernier est conservé à l'Ishii-bō et la transcription du Sūtra du Lotus qu'il contient aurait été, dit-on "écrite avec le sang ${ }^{84}$ ». Il est bien connu que l'un des cinq étuis découverts dans le tertre de sütra à Satani, daté de II2s (Tenji 天治 2), porte l'inscription d'un nom chinois de l'époque Song ${ }^{85}$. Cet étui, qui est aujourd'hui conservé au Musée national de Tōkyō, nous laisse entrevoir l'existence, dans cette région, des pratiques cultuelles de marchands chinois qui faisaient du commerce entre la Chine et le Japon.

Récemment, les recherches historiques sur la plaine de Fukuoka et les massifs montagneux de sa périphérie ont pris en compte la dimension maritime de la région et se sont tout particulièrement intéressées aux échanges entretenus entre l'extérieur

83. Ces sūtra étaient transcrits sur des rouleaux, puis enroulés sur un axe de bois et mis dans des cylindres de métal, de pierre ou de bambou. (N.D.T.)

84. Kessho Hokekyō 血書法華経.

85. Sōjin Hyō Ei (Song-ren Feng Rong) 朱人馮榮. 
du Japon et les temples. La construction de tertres de sūtra et de bâtiments à débuté dans cette région vers la fin du $\mathrm{XI}^{c}$ et le début du $\mathrm{xII}^{c}$ siècle. Selon ces travaux ${ }^{86}$, cette date coïncide avec la fin du Kōrokan 鴻臚館要 ${ }^{7}$ et la véritable fondation de Hakata comme port de commerce extérieur. Libérés de la protection législative et des contraintes douanières, les marchands chinois ont alors recherché le soutien des autorités religieuses privilégiées de l'époque. C'est pourquoi, tout en contribuant aux entreprises de construction de tertres de sütra ou de temples et sanctuaires, ils ont participé, en tant que donateurs, à la gestion de ces structures religieuses. C'est en tenant compte de ce contexte qu'il faut envisager la présence d'étuis de sütra datant de cette époque sur le mont Wakasugi. Et l'histoire nous apprend qu'au même moment, tous les grands temples et sanctuaires de la région, notamment les temples Ōyama-dera 大山寺 du mont Hōman, Anraku-ji 安楽寺 de Dazaifu, les sanctuaires Hakozaki, Kashii et Munakata, protégeaient des marchands chinois en tant que visiteurs (yoryūdo 寄人), que ceux-ci faisaient activement du commerce avec l'extérieur, et que se constitua le quartier des marchands chinois à Hakata (appelé Tōbō 唐房).

Le site montagneux, sur lequel les recherches sur les échanges avec l'extérieur du Japon sont aujourd'hui les plus avancées, est celui du mont Haku 白山 (ou Shura 首羅山, commune de Hisayama). Dans le parcours rituel du sommet de Katsuragi par le shugen de Hōman, ce site est celui qui suit la halte de la vallée des Yamabushi de Sasaguri. On connait déjà depuis longtemps l'existence de la graphie à l'encre d'un nom qui serait chinois (Jō kō, ch. Xu gong 徐工 [probablement au sens d'« artisan $\mathrm{Xu}$ »), et qui figure sur un étui de sütra portant la date ııo9 (Tennin 天仁 2), lequel fut découvert près du sommet de ce mont Haku. Mais, plus récemment, une stèle de style Satsuma et des lions de pierre de style Song, qui se trouvaient sur le site du sanctuaire Hakusan, ont attiré l'attention des chercheurs. Selon Igata Susumu 井形進 ${ }^{88}$, ces sculptures ont été faites en Chine à l'époque Song, au XIII' siècle, et apportées jusqu'au mont Shura; mais l'aire de diffusion de ce type de statuaire reste très limitée. Sur le mont Wakasugi, il en existe également une paire de la même époque (classée patrimoine culturel départemental), ainsi qu'un autre exemplaire de l'époque Muromachi ( $\mathrm{xv}^{e}$ siècle) réalisé sur ce modèle. Dans tout le Japon, seuls dix exemplaires de ces statues sculptées sous les Song ont pu être répertoriés, et, mis à part celles de Kyōto, Okayama 岡山 et Hirado 平戸 (département de Nagasaki 長畸県), elles sont toutes disséminées sur la périphérie de la plaine de Fukuoka

86. Momosaki Yūsuke 桃崎鿆輔, "Kōrokan taisei no hōkai kara chūsei shakai e. Iseki ni

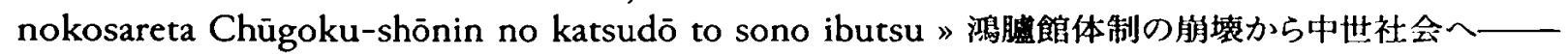
遺跡に遺された中国商人の活動とその遺物, dans Nanakuma shigakkai 七侵史学会, éd., Daijukkai taikei shinpojiumu. Kyüsbū no cbūsei-gaku. Köeki, kaibatsu, sbinkō. Yokō-sbū 第 10 回大会記念シン ポジウム・九州の中世学——交易·開発·信仰:予稿集, 2008, p. 15.

87. Ce centre régissait l'accueil des diplomates étrangers venant du continent asiatique et le commerce d'État avec l'extérieur du pays. C'était l'une des succursales du Bureau des invités étrangers (Bankyaku-sho 菜客所) du Dazaifu 大宰拊, le « gouvernement général » de Kyūshū, qui était lui-même le plus grand office gouvernemental régional de l'époque ancienne.

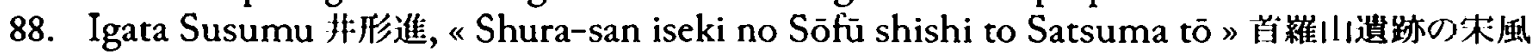
獅子と薩摩塔, dans Hisayama-chō kyōiku iin-kai 久川町教育委買会, éd., Shura san iseki. Fukuoka

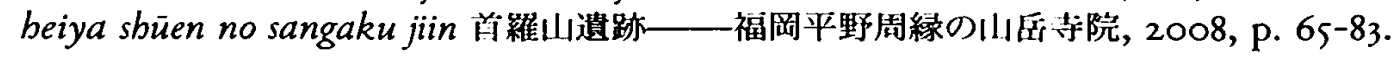




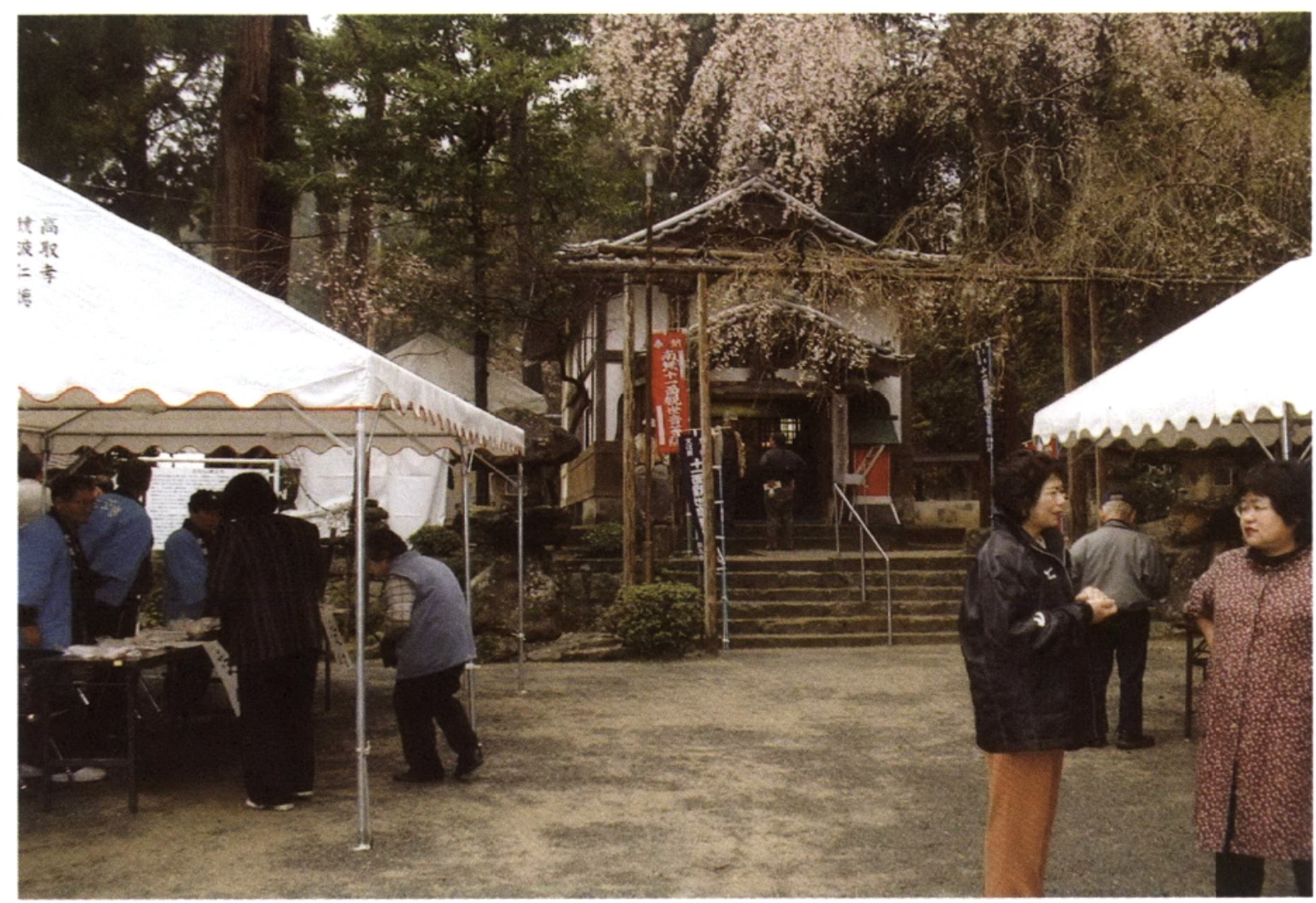

Fig. 5 : L'oratoire de Kannon à Satani (Sue).

(sanctuaire de Munakata, Kanzeon-ji 観世音寺 de Dazaifu, sanctuaire Iimori 飯盛 神社 [ville de Fukuoka], mont Konomi). Les statues du sanctuaire de Munakata résultent d'une donation faite en I20I (Kennin 建仁 I) par Fujiwara Tsukafusa 藤原 支房 et ont été classées 《important bien culturel national ».

La stèle du Lotus de 1325. - Au sud-est de l'oratoire de Kannon 倠音堂 à Satani (fig. 5) se dresse une stèle (patrimoine départemental) de pierre-planche (itabi 板碑) ${ }^{89}$ portant la date 1325 (Shōchū 正中 2), sur laquelle sont gravées les lettres sanskrites représentant les trois bouddhas Dainichi, Shaka, Amida, disposées chacune à l'intérieur d'un cercle; en dessous de ces lettres, sont inscrites les raisons d'édification de cette sculpture. On peut y lire que le moine " récitant du sūtra » (dokuju sbōnin 読誦聖 人), Daijō-bō Myōren 大乗坊妙蓮, ayant fait le vou de réciter dix mille fois le Sütra du Lotus, commença en juillet 1314 au sanctuaire Hakozaki, puis en récita plusieurs milliers au sanctuaire Haut du mont Wakasugi, et acheva son entreprise en 1325 au Kenshō-in de Satani 左谷賢聖院. Et l'on apprend aussi par cette inscription qu’à cette époque, le Kenshō-in était affilié (matsuji 末寺) au temple Uchiyama-dera 有智山寺 du mont Hōman et que celui-ci représentait le

89. Stèle faite d'une seule pierre plate dont la face porte des inscriptions ou des figures gravées dans la masse avec des traits de type sillon (étroits en profondeur, plus larges à la surface) dits yagen bori 薬研娾り, du nom du mortier à remèdes médicinaux qui a cette forme. (N.D.T.) 
Tendai à Kyūshū. Au milieu de la stèle est inscrit le titre «Sūtra du Lotus de la Loi merveilleuse » (Myōbō renge-kyō 妙法蓮華経) ; à sa droite, une stance du chapitre des moyens salvifiques du Sūtra, les noms du prince Shōtoku 聖徳太子 et de Dengyō daishi 伝教大師 (Saichō), et à sa gauche, une stance du Nirvāna-sūtra, les noms de Kōbō daishi 弘法大師 (Kūkai) et de Shōkū 聖空 (c'est-à-dire Shōkū 性空 [9ro$\left.\left.{ }^{1007}\right]^{90}\right)$. Dans l'« Histoire des origines du Kenshō-ji de Satani », ce « récitant du sūtra ", Daijō-bō Myōren, est présenté comme un maître (ajari 阿闍梨, sk. ācārya) d'Uchiyama-dera de Hōman. Il est en outre important de constater que parmi les noms des bouddhas et divinités gravés sur la stèle, se trouve celui de Taiso 太祖. Sur le site de l'ancien sanctuaire Médian (Chūgū 中宮) du mont Hōman, une stèle de pierre naturelle a été dressée en 1318 (Bunpō 2) pour commémorer l'instauration de l'entrée dans la montagne, qui marquerait la véritable fondation du shugen de Hōman. Cette date correspond aussi au moment même où Myōren accomplissait sa récitation du Lotus. Or, selon le Chikuzen no kuni zoku fudo-ki shüi, il y avait à cet endroit la même stèle du Lotus que celle qui fut installée à Satani en $1325^{91}$. Si ces éléments ne permettent pas de connaître les motifs de ce vœu de récitation du Lotus, ni pourquoi Hakozaki et les monts Wakasugi et Hōman ont été choisis pour sa réalisation qui dura dix ans, ils montrent néanmoins l'importance du sanctuaire Taiso du Haut du mont Wakasugi.

Parmi les histoires des origines du mont Wakasugi, celles de Satani expliquent les relations de Saichō et du mont Hōman, mais aucune mention n'est faite ni de l'existence d'Utani, ni de la venue de Kūkai. Quant à l'Engi d'Utani, il précise, au sujet de la fondation des temples de cette montagne, que « sous le règne de l'empereur Shōmu 聖武天皇! (724-749), partout dans le pays ont été construits des “temples de sanctuaires" (miya-dera 營寺) ; sur le mont Wakasugi aussi, le temple Ennen-ji Taiso-san Sanzō-in 延年寺大祖山三蔵院 fut édifié pour administrer le sanctuaire, et ayant prospéré, il fut ensuite séparé dans les deux vallées de Satani et Utani. Le nom d'ensemble d'Utani était Sekisen-ji Tōhoku-in 石泉寺東北院 et celui de Satani Kenshō-ji Seinan-in 建正寺西南院, les deux vallées comptant 300 ermitages de moines ${ }^{92}$ ». Dans le Güki, écrit par Kame.ishi-bō Yūben en I597 (Keichō 慶長 2), il est en outre indiqué que Satani était appelé « mandala de la Matrice » et Utani, "mandala du Diamant ». Engi et Güki mentionnent tous deux que le moine indien Zenmui gravit la montagne dans les années Yōrō 養老 (717-724), de même que Kūkai, qui le fit dans les années Daidō 大同 (806-8Io), et qui résida à Kōyano 高野埜 où il pratiqua des rituels secrets. Le Gūki ajoute à cela la venue de Saichō, qui y aurait construit 120 ermitages, ainsi que des détails assez précis sur Zenmui ; il précise

90. Shōkū était un pratiquant du Sūtra du Lotus (bokke jikyōsha 法華持経者) qui fonda le temple du mont Shosha 書䒓山 à Himeji 婎路 (département de Hyōgo 兵庫県). À Kyūshū, il se rendit, pour pratiquer, sur les monts Kirishima 籍島山 et Seburi 背振山, connus comme lieux saints du shugendō.

91. Aoyagi Tanenobu, comp., Cbikuzen no kuni zoku fudo-ki sbüi, vol. 2, p. 393.

92. On trouve le même texte dans Chikuzen no kuni Omote-Kasuya-gun Taiso san denki 筑前国表糟荎䄮太祖川伝記 (archives Ishii-bō). 
enfin que Kūkai y vénéra Zenmui en tant que patriarche-fondateur sous le nom de Taiso gongen et qu'il y fonda les temples.

Mais ces histoires des origines de Satani et d'Utani differrent sur de nombreux points, et comme il n'existe aucun autre document historique pour vérifier la véracité des faits mentionnés, il est impossible de savoir à partir de quel moment le mont Wakasugi entretint des liens avec le Tendai, le Shingon et le shugen. Toutefois, compte tenu du fait que les noms de Saichō, Kūkai et Shōkū sont inscrits sur la stèle du Lotus de 1325 , on peut dire en tout cas qu'à la fin de l'époque Kamakura, cette montagne entretenait des relations avec le Tendai, le Shingon et le shugen.

C'est sans doute relativement tôt que Satani, qui est le plus proche du mont Hōman, établit des liens avec le shugen de Hōman et reçut l'influence du Tendai. Le domaine des temples de Satani était composé de champs et de rizières qui s'étendaient « au pied de la montagne, à l'est jusqu'à la limite avec Honami 穂波境, à l'ouest jusqu'à Ókawa 大川, au sud jusqu'au mont Shōji 障子岳 et au nord jusqu'à Shira.ishi 白石 $^{\mathbf{9 3}}$ ", c'est-à-dire dans le périmètre où se trouve situé Utani, l'actuel Wakasugi. Aujourd'hui, les temples de Wakasugi, tout comme le pèlerinage de Sasaguri, sont entièrement sous obédience Shingon, mais l'analyse proposée par Yahiro Izumi apporte un éclairage qui mérite attention :

Les deux vallées furent affiliées au Tendai au moins durant l'époque de Heian, et c'est probablement au cours du Moyen Âge qu'Utani se tourna vers le Shingon et qu'on eut recours à l'histoire d'une fondation par Zenmui Sanzō et Kūkai. Le fait que les histoires des origines mentionnent une polémique qui dégénéra en lutte armée n'indique-t-il pas que les deux vallées avaient justement commencé à prendre des voies différentes ${ }^{94}$ ?

Pour résumer, le mont Wakasugi, qui se dresse au bord de la plaine de Fukuoka et fait face à la baie de I Iakata, est la source de toutes les rivières qui se jettent dans le fleuve Tatara 多々良川 irriguant toute cette plaine, et il est un amer pour les bateaux qui entrent dans cette baie. À ce titre, depuis l'époque ancienne, il a certainement été objet d'un culte entretenu par tous ceux qui pratiquaient l'agriculture et la pêche en ces lieux. Nous avons vu comment la formation du culte et des divinités de cette montagne, située sur cette terre ouverte aux échanges avec l'extérieur du pays de façon quasiment unique au Japon, a été façonnée suivant un processus historique, culturel et politique sous-tendu par une dynamique à la fois externe et interne à la région et au pays. J'ai montré comment « Taiso gongen » n'est pas un dieu local, mais a son origine dans le culte de Kumano, arrivé ici de l'extérieur, par la mer, et lui-même enté sur un ancien culte local. On ne peut retenir la date de 708 , avancée par l'histoire des origines de Satani, comme celle de l'introduction historique du culte de Kumano. Mais quoi qu'il en soit, si l'on se réfère aux conditions dans lesquelles ce culte des trois montagnes de Kumano s'est implanté sur toute la périphérie de la plaine de Fukuoka, on peut penser que dès le début de l'époque de Kamakura (fin

93. Selon le Satani-san Kenshō-ji engi, édité par Yahiro Izumi (cf. supra, n. 9), p. 36.

94. Yahiro Izumi, «Wakasugi yama no bukkyō ihin ”, dans Kyūshū rekishi shiryōkan 九州 歷史資料館, éd., Chikuzen Kasuya. Wakasugi yama no bukkyō iseki 筑前粕屋:若杉川の仏教 遺跡, p. 26-27. 
$\mathrm{XII}^{\mathrm{e}}$ siècle), Kumano gongen y était vénéré. Et c'est sur la toile de fond des échanges maritimes avec l'extérieur du pays que, dans un mouvement tendant à en faire une puissance toujours plus performante pour protéger la navigation entre Kyūshū et le continent asiatique, se sont développés l'ésotérisme bouddhique et le shugen. Mais face à l'impact externe considérable que représenta le danger mongol, le culte de Kumano gongen lui-même fusionna avec celui de Hachiman pour donner naissance à Taiso gongen, entité originale de cette montagne qui fut identifiée à Izanagi. Les éléments du dedans, tout en s'imbriquant les uns avec les autres de façon complexe, se sont ainsi ouverts sur le dehors en consolidant cette entité comme une puissance d'une grande force. Et tout ceci attira, en retour, le culte des gens de l'extérieur, notamment des Chinois de l'époque Song. Mais malgré la prospérité ainsi obtenue, à la fin du Moyen Âge, les structures religieuses du mont Wakasugi, prises dans les guerres régionales, s'effondrèrent, et ne reprirent vie qu'avec l'entrée à Utani de Kame.ishi-bō du mont Hōman qui, au début de l'époque d'Edo, fonda le Sekisen-ji Ishii-bō. Or cette époque fut celle de la fermeture du pays et de l'arrêt des échanges avec le continent asiatique. Aussi le culte des divinités du mont Wakasugi ne fut-il plus entretenu que par les populations locales pratiquant l'agriculture dans la plaine du pourtour de cette montagne. Leur efficace n'étant plus sollicitée que pour la protection de l'agriculture et des communautés villageoises, leur culte en vint ainsi à être uniquement tourné vers l'intérieur.

\section{Ishii-bō, shugen de Wakasugi à l'époque d'Edo}

Offensives sur la citadelle de Takatorii et anéantissement de la communauté religieuse de Wakasugi

D'après les histoires des origines. - Selon l'Engi, comme on l'a vu précédemment, les temples et les monastères de Wakasugi prospérèrent dans les vallées de Satani et d'Utani, au point de constituer un ensemble de plusieurs centaines de bâtiments. Mais avec la construction, sur le sommet voisin, le mont Takejō 岳城山 $(382 \mathrm{~m})$, de la citadelle de Takatorii 高鳥居城 par Sugi Okiyuki 杉興行, un vassal du daimyō Ō.uchi 大内 les moines furent mêlés aux combats de cette période médiévale et la totalité des temples et ermitages fut détruite dans des incendies, ce qui fut cause de la dispersion de toute la communauté religieuse. Le Gūki fait remonter cet incendie à la date précise du $3^{\mathrm{e}}$ mois de 1347 (Jōwa 貞和 3), précisant que seuls Bankai 鉸海 法印 du Mandara-in 曼荼羅院 et Jitsuin 実因 de l'Ishii-bō 石井坊 restèrent sur les lieux, où ils vécurent dans des cabanes.

D'après les documents historiques. - Or, selon les recherches compilées dans la monographie historique de Sasaguri ${ }^{95}$, l'histoire de la citadelle de Takatorii est aujourd'hui à peu près connue. La construction aurait été assurée par un vassal de Hōjō Kanetoki 北条兼時 (1264-1295) du bakufu de Kamakura, alors administrateur de

95. Sasaguri-chō bunkazai senmon-iinkai, éd., Sasaguri chöshi. Rekishi-ben, p. 78-79. 
Kyūshū (Chinzei tandai 鎮西探題), Kawazu Yajirō Sadashige 川津弥次郎貞重. Il était alors gouverneur de Chikugo (Chikugo no kami 筑後守), et avait reçu comme terres, dans le canton de Kasuya, les 700 chō (700 ha) de Seto-Kōchi 迫門河内 (c'est-à-dire dix villages représentant la totalité de l'actuel Sasaguri et Ōkuma de Kasuya-machi 粕屋町大隈). Etabli à Onaka 小中 (尾仲), il bâtit cette citadelle, qui resta à sa garde, pour le compte de l'administrateur de Kyūshū. Avec la disparition du bakufu en 1333 , les Kawazu quittèrent la citadelle, qui fut restaurée en I478 (Bunmei 文明 10) par cinq préfets sur l'ordre du daimyō O.uchi Masahiro 大内政弘 (I446-I495), en tant que position fortifiée de Chikuzen. En effet, les Ō.uchi qui gouvernaient le Japon occidental étendirent à cette époque leur domination sur Kyūshū et développèrent à partir de la baie de Hakata un commerce maritime prospère avec la Chine des Ming. Au début du Xvi ${ }^{e}$ siècle, cette citadelle était à la garde de Kōshiro Sadafusa 神代定総, gouverneur de Kii (Kii no kami 紀伊守) et vassal des Ō.uchi, et c'est vers I510 (Eishō 永正 7) que Sugi Okiyuki y fut placé. Sugi Okiyuki et son fils Okikazu 興運 construisirent un bâtiment de garde, mais lors de la révolte de Sue Takafusa 陶隆房 en I55I (Tenbun 天文 20), la citadelle tomba aux mains de l'armée de Sue après le suicide d'Ō.uchi Yoshitaka 大内義隆 (1507-1551). Puis en 1586, alors que Hoshino 星野, un vassal des Kawazu, y résidait, la citadelle tomba de nouveau et fut investie par Tachibana Munetora 立花統虎 ${ }^{96}$. C'est donc probablement au cours de ces nombreux combats locaux de l'époque médiévale que fut prise la communauté religieuse de Wakasugi. Mais reste la question de la date à laquelle eut lieu l'incendie qui détruisit la totalité des bâtiments.

D'après un document de 1352 (Kannō 観応 3) conservé dans les archives du sanctuaire Tenman-gū 天満宮 de Dazaifu' ${ }^{97}$, en 1290 (Shōō 正応 3), sur la liste des donations faites par les grands en pays de Chikuzen, il est précisé que les moines de Wakasugi se sont emparés par la force d'une terre qui avait été donnée à l'Anraku$\mathrm{ji}^{98}$. Par ailleurs, sur l'ancien socle de la statue de Kannon aux mille bras restauré par Moto-Ami 元阿弥 en 1392 (Meitoku 明徳 3), est inscrit le nom du Sekisen-ji 石泉寺. Selon le $G \bar{u} k i$, tous les bâtiments furent détruits et les moines, dispersés par l'incendie de 1347 . Or les documents précédents révèlent qu'au XIV ${ }^{e}$ siècle, cette communauté religieuse était active et prospère au point de faire restaurer la statue de Kannon. Il faut donc plutôt penser que la destruction de cet ensemble monastique eut lieu au XvI ${ }^{\mathrm{e}}$ siècle, lors des luttes entre les provinces (sengoku- $k i$ 戦国期). S'il en est ainsi, cela signifie que la restauration de l'Ishii-bō eut lieu après une période d'abandon qui ne fut pas très longue, après l'époque de prospérité précédente.

96. D'après le dictionnaire des toponymes du département de Fukuoka : cf. Heibon-sha chihō shiryō sentā 平凡社地方資料センター, éd., Fukuoka ken no chimei 福岡県の地名, Nibon rekishi cbimei taikei 日本歴史地名大系 vol. 4I, 2004, s.v. 《Takatorii-jō ato 》高鳥居城跡, p. 460.

97. Anraku-ji ryō chüshinjō utsushi 安楽寺領注進状写 (transcription de 1352, le document original est perdu). Il s'agit de notes sur l'état des terres qui ont été données au domaine du temple Anraku-ji 安楽寺 (actuel sanctuaire Tenman-gū de Dazaifu) ; elles ont été éditées par Kawazoe Shōji 川添昭二, dans Dazaifu. Dazaifu Tenman-gū shiryō 太萃府·太莘府天満宮史料, vol. II, 1979, P. 398-408.

98. 《Taiso-sha Wakasugi yama shuto ōryō nari 》 (大祖社, 若杉山衆徒押領也). 


\section{La reconstruction de l'Isbii-bō}

Ce sont Kuroda Nagamasa et le shugen du mont Hōman qui, au début de l'époque d'Edo, furent les moteurs de la reconstruction de l'Ishii-bō. Selon les archives de l'Ishii-bōo', cet ermitage fut reconstruit au $7^{\mathrm{e}}$ mois de l'année 1597 (Keichō 慶長 2) par Kame.ishi-bō Yūben, affilié au shugen du mont Hōman, sur l'ordre de Kuroda Nagamasa. Mais ce dernier ne prit possession du fief qu'en 1600 (Keichō 5). Dans la Chronique ancienne $d u$ mont Kamado (Kamado san kyü $k i$ 䇫間山旧記) ${ }^{100}$, il est mentionné qu'après l'arrivée de Kuroda en 1600 , ce dernier fit des donations à Hōman, encouragea la culture du thé et gravit plusieurs fois la montagne ; et l'on trouve tout à la fin une mention concernant l'Ishii-bō du mont Taiso (Wakasugi) : Kuroda Nagamasa, ayant emmené avec lui à la chasse Kame.ishi-bō Yūben, lui aurait fait don de terres, rizières et champs pour le temple, qu'il nomma «Ishii-bō » 石井坊 (《ermitage du puits de pierre ») en voyant un puits avec de l'eau pure. Le colophon du Gūki du sanctuaire de Taiso daté du $7^{\epsilon}$ mois de Keichō 2 est signé par son auteur, Kame.ishi-bō Yūben ${ }^{101}$. Dans les transcriptions du Gūki conservées au sanctuaire et à l'Ishii-bō, les colophons précisent que l'auteur Yüben est un moine du temple "Utani-san Tōhoku-in Sekisen-ji102 ». On peut donc penser que cette date de reconstruction a été ici accordée avec celle du Gūki. L'année 1597 est vraisemblablement la date à laquelle Yūben, encore yamabushi du mont Hōman, a écrit le texte de l'histoire des origines du Taiso gongen, et il est probable que la reconstruction par Yüben, sur l'ordre de Kuroda Nagamasa, fut plutôt le résultat d'une demande de l’organisation shugen du mont Hōman auprès de ce dernier.

A Satani, ce sont les habitants du village qui reconstruisirent le sanctuaire et les oratoires du temple. Tout d'abord, un certain Oyamada Kamon 小山田掃部 entra dans ce temple nommé Kenshō-in 賢聖院. Puis, en 1767 (Meiwa 明和 4), grâce à la volonté du chef du shugen du mont Hōman, Ryōga-in Shinga 楞伽院真雅, le temple d'origine, Kenshō-ji 建正寺, fut restauré par le disciple du Nakatani-bō 仲谷坊 appelé Ryōben 良弁, qui en devint le supérieur (Injū-bō 院主坊). Il n'était pas chose rare que des temples disparus soient reconstruits sur l'ordre de l'autorité hiérarchique, qui en déléguait la réalisation à ses subalternes.

Avec le restaurateur Yüben 宥弁 (fig. 6) et ses descendants, la lignée des supérieurs de l'Ishii-bō se perpétua jusqu'à la Restauration de Meiji pendant dix générations : se succédèrent Zenkyō 善教 (mort en I668), Genni 元式 (mort en I70I), Shinkyō 真教 (mort en I718), Ryōben 良弁 (mort en 1718), Kengi 賢義 (mort en 1771), Kenjitsu 賢実

99. Archives Ishii-bō 26.

100. Ce document du Ryōga-in, zasu du mont Hōman, est constitué de deux volumes.

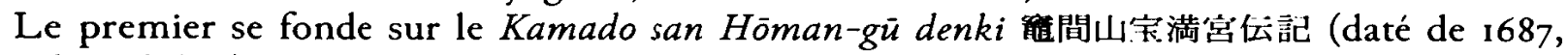
Jōkyō 貞亭 4) auquel ont été joints des katakana, des ajouts et dont certains éléments ont été supprimés. Le deuxième est une chronique des événements survenus entre I599 (Keichō 4) et I680 (Enpō 延宝 8). L'ensemble est actuellement conservé au sanctuaire Kamado 犗間神社) et a été édité par Mori Hiroko, dans Gorai Shigeru 五来重, éd., Shugendō sbiryōshū 修験道史料集 II, Nishi Nibon-hen 西日本編, Sangaku shūkyō-shi kenkyū sōsho 山岳宗教史研究丵書, vol. 18, I984, p. $530-548$ (cf. aussi p. $830-832$ ).

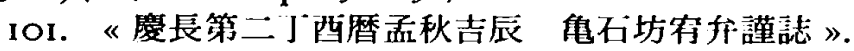

IO2. 《右谷山東北院石泉寺衆徒宥弁謹誌》. 


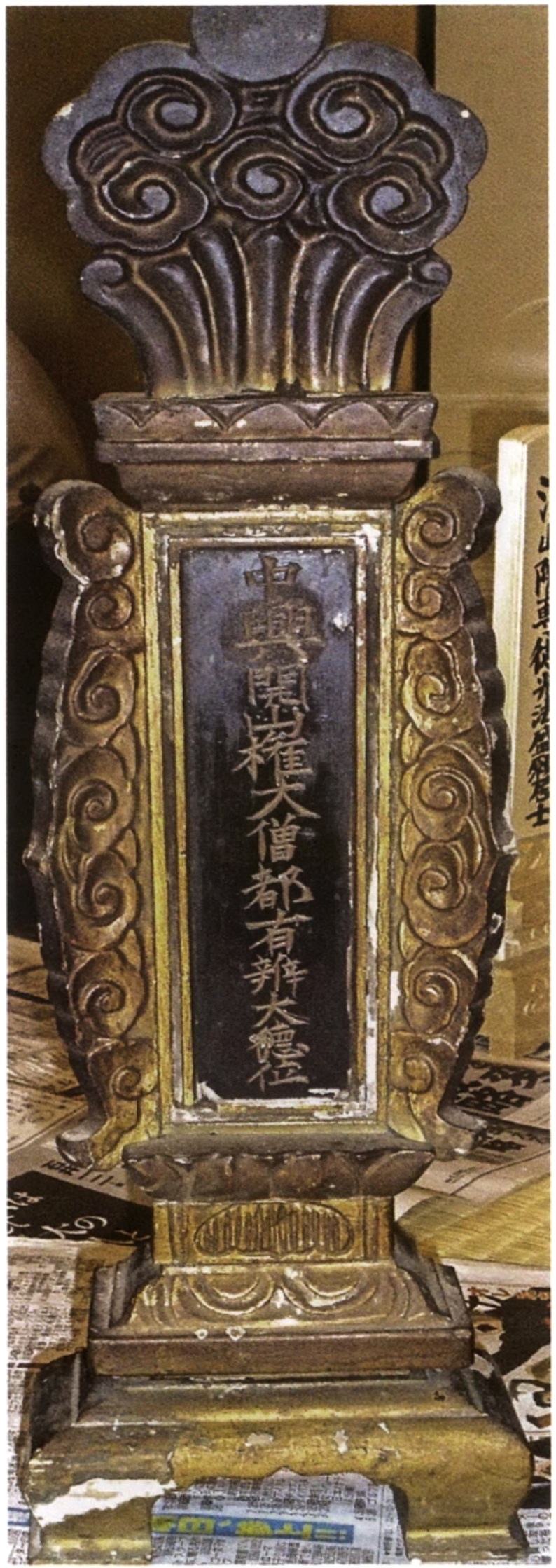

Fig. 6 : Plaquette funéraire d'Ishii-bō Yūben (Ishii-bō, Wakasugi). 
(mort en I804), Kenrin 賢林 (mort en I840) et Kentei 賢貞 (mort en I876) ${ }^{103}$, qui en I855 céda sa charge à son héritier Chijū-in Ken.yū 知十院 賢有.

À cette époque, Ken.yū fut autorisé à porter le costume orange ${ }^{104}$. À la suite de la séparation du culte des dieux et des bouddhas, Ken.yū devint prêtre du sanctuaire Taiso sous le nom d'Ishii Shimizu 石井清水 ${ }^{105}$ et fut placé sous l'autorité de Sakurai Ura gon-gashira Daisuke 桜井浦権頭大輔. Parallèlement, à Satani, l'Injū-bō renonça à sa fonction de prêtre du sanctuaire de Kumano, lequel fut alors confié à l'État, et passa sous l'affiliation shugen de l'ancien chef du Hōman (Ryōga-in), qui avait lui-même pris le nom de Fujii du mont Hōman 宝満山藤井 ${ }^{106}$.

\section{Ishii-bò à l'intérieur de l'organisation sbugen du mont Höman}

Furegashira 触頭 (《chef de secteur »107. - Le shugen du mont Hōman joua un grand rôle dans la restauration des organisations shugen des montagnes de la région de Chikuzen à l'époque d'Edo. À la tête du Hōman se tenait le zasu Ryōga-in, qui contrôlait 25 ermitages de yamabushi dans la montagne ainsi que, selon les époques, 30 à 40 ermitages et temples de shugen résidant chez eux (zaitaku yamabushi 在宅 山伏), situés à l'extérieur du mont Hōman, et composant le bas de la hiérarchie (kumi shita 組下). Cet ensemble constituait l'organisation shugen de Hōman. Deux de ces yamabushi extérieurs étaient chargés d'assurer l'interface entre le bas et le haut de la hiérarchie dont ils transmettaient les ordres en tant que "chefs de secteur » (furegashira 触頭). Le " chef du secteur de l'ouest 》 était le Renjō-in 蓮乗院, et celui de l'est, l'Ishii-bō. Ce dernier avait donc sous son contrôle tous les yamabushi résidant dans les cantons de Kasuya (Omote 表, “Adret », et Ura 裏, “Ubac ») et de Munakata. Un document non daté des archives de l'Ishii-bō, remontant à l'époque d'Edo, indique le nom de ces yamabushi et la composition de leurs familles ${ }^{108}$ :

103. D’après les plaquettes funéraires (ibai 位牌) de la maison Ishii (Wakasugi).

104. Usukaki suri goromo 薄柿摺衣, indiquant son rang dans la hiérarchie shugen (archives Ishii-bō 54).

105. Archives Ishii-bō 57.

106. Archives Ishii-bō 56 .

107. Furegashira 触頚, "chef de secteur ", signifie littéralement : chef (kashira 湏) des ordonnances ou des transmissions (fure 触). Le terme fure désigne originellement une ordonnance, un arrêté, un décret, etc. promulgué ou proclamé. Il est utilisé dans le contexte historique du shugendō en association avec kashira dans le sens de "secteur", pour désigner les yamabushi d'un secteur régional, qui sont placés sous la responsabilité d'un représentant de leur autorité, ici le shugen du mont Hōman, ayant la charge de leur transmettre les ordres, communications, requêtes, etc. émanant de celle-ci. Ce responsable joue aussi le rôle d'interface entre ces yamabushi du bas de la hiérarchie et leurs supérieurs, auprès desquels il les représentent. Dans ce contexte, fure est distinct d'un autre usage de fure, qui désigne à l'époque d'Edo une unité administrative réunissant plusieurs villages. (N.D.T.)

108. Archives Ishii-bō 9i :

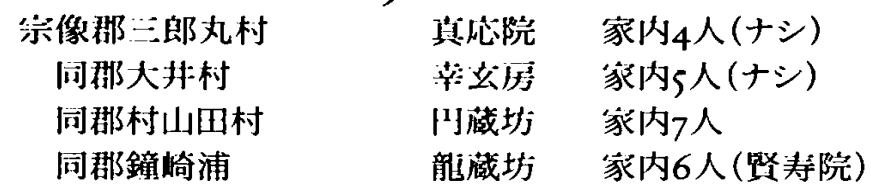


Canton de Munakata :

- Village de Saburō-maru, Shin.ō-in (famille de 4 personnes) [sans] ${ }^{109}$;

- Village d'Ōi, Kōgen-bō (famille de 5 personnes) [sans] ;

- Village de Mura-yamada, Enzō-bō (famille de 7 personnes) ;

- Village de Kanezaki-ura, Ryūzō-bō (famille de 6 personnes) (Kenju-in ${ }^{110}$ ).

Canton de Kasuya-Ubac:

- Village de Minato, Rinkō-in (famille de 3 personnes) (Shingū minato);

- Village de Tachibana-guchi, Taiken-bō (famille de 9 personnes) (Rinshō-in).

Canton de Kasuya-Adret :

- Village de Kubara, Jōen-bō (famille de 7 personnes) [sans] ;

- Village de Satani, Injū-bō (famille de 5 personnes);

- Village de Shiōji, Jōsen-bō (famille de 9 personnes) [sans].

Dans ce même document, les membres de la famille de l'Ishii-bō ne sont pas mentionnés, mais selon un autre (archive 84), leur nombre est de 7, comprenant le maître de l'Ishii-bō, son épouse, leurs enfants et un serviteur.

L'Ishii-bō possédait différents titres et fonctions. Ainsi dans la lettre de nomination de l'Ishii-bō Kentei 賢貞 au rang de " préfet inférieur subsidiaire " (gonshōsōzu 権少僧都) par le Shōgo-in 聖護院 de I835 (Tenpō 天保 6) ${ }^{111}$, on trouve ceci : «Ishii-bō Kentei, Wakasugi-san Ennen-ji du village de Wakasugi, canton de Kasuya-Adret du pays de Chikuzen, administrateur (c'est-à-dire prêtre, gūji 宮司) du Taiso-gū sanctuaire tutélaire de 48 villages du même canton, et affilié au Hōchū-ji du mont Kamado (Hōman) ${ }^{112}{ }^{»}$. Dans une autre lettre de nomination, est mentionné le titre de "chef du secteur » et de "moine ayant une charge au mont Kamado ${ }^{113}$ ». Cette fonction est celle de chef du secteur cantonal de Kasuya.

Yamabushi résidant à leur domicile. - À l'intérieur de l'organisation shugen du mont Hōman, il y avait une grande différence entre les yamabushi vivant sur la montagne, dénommés les « 25 ermitages de Hōman » (Hōman nijügo-bō 宝満二五

$\begin{array}{ccl}\text { 裏糟屋郡湊村 } & \text { 林光院 } & \text { 家内 } 3 \text { 人 (新宮湊) } \\ \text { 同郡立花口村 } & \text { 大賢坊 } & \text { 家内9人(臨昌院) } \\ \text { 表糟屋郡久原村 } & \text { 成円坊 } & \text { 家内 } 7 \text { 人 (ナシ) } \\ \text { 同郡佐谷村 } & \text { 院主坊 } & \text { 家内 } 5 \text { 人 } \\ \text { 同郡四王寺村 } & \text { 成泉坊 } & \text { 家内9人(ナシ) }\end{array}$

ı09. [sans] : signale qu'il n'y a pas d'autre précision à ce nom dans le registre daté de 1790 (Kansei 寛政 2) des temples shugen de Chikuzen affiliés au mont Hōman (cf. Kansei ni-nen Chikuzen matsuji-chō 寛政二年筑前末寺帳, Fukuokaken shi shiryō 福岡県史資料, vol. 7, p. 336337). Dans ce même texte, on trouve également le nom du Enjō-bō 円成坊 dans le village de Shimobaru 下原 du canton de Kasuya-Adret. Il semble que la présence des yamabushi résidant dans les villages ait été peu stable.

Iro. Les titres « - bō » 坊 et 《-in 》 院 correspondent à des rangs dans la hiérarchie shugen, le premier étant le plus bas et le second, son supérieur. Cette hiérarchie est très structurée et complexe, et la montée en grade et en titre repose sur le nombre d'entrées dans la montagne ainsi que sur les années de service et les fonctions remplies à l'intérieur de l'organisation. (N.D.T.)

III. Archives Ishii-bō 44-49.

112. 《隹門山宝仲寺末寺·筑前国表糟屋郡四十八䇢村氏神太祖宮社務別当·同郡分杉村分杉山延 年寺 石井坊堅貞》。

I13. Furegashira 触頭 et Kamado san yakusō 堒門凹役僧. 
坊) et ceux qui habitaient dans les villages avec leur famille, appelés zaitaku yamabushi 在宅山伏 (“yamabushi résidant à son domicile») ou kumi shita 組下 («bas de la hiérarchie »), lesquels devaient respecter les règlements suivants ${ }^{114}$ :

Règlement :

Pratiques d'ascèse ${ }^{115}$ des yamabushi résidant chez eux :

- Lors de la première pratique au mont Kamado (Hōman), sont décernés, de la part de Kyōto (c'est-à-dire du Shōgō-in) le rang de « maître de discipline subsidiaire-bokkyō » 法橋116, ainsi que le droit de porter l'étole nouée de couleur rose avec des pompons blancs, et le vêtement noir.

- Lors des pratiques au mont Hōman en tant que " petit guide » (shōsen 小先) ${ }^{117}$, est décerné le droit de porter l'étole nouée de brocart d'or avec des pompons blancs.

- Le pratiquant doit faire don de 100 biki 疋 d'or.

114. Archives Ishii-bō I08 :

定

一、在宅山伏修行之事

一、於籍門!山二初発執行相勤於京都二権律師法橋桃地結袈乷白房黑衣着用

…、於当山二小先執行相勤金襴地結袈白房着用

一、行者奉納金百足

一、於京都二権少僧都法眼無紋黄色衣御補任申受事

一、役僧分八模様入之黄色衣着用候事

外二京都位御免之事

桃地結袈装銀式両

、一僧低同式両

一、権律師金百疋

一、法橋同百足

一、赤貝緒 銀三両

一、赤地金襇 金壱両

$\alpha$

$\therefore$ 二僧祇 銀三両

、権少僧都 金二百疋

一、法眼同三百疋

一、黄色衣同三耐

$\propto$

$\cdots$ 、三僧祇 銀五両

一、権大僧都金三峏

一、法的同五活

$\alpha$

II5. Yamabushi shugyō 山伏修行, c'est-à-dire l'entrée dans la montagne de printemps, d'été et d'automne.

I16. Concernant l'échelle hiérarchique des moines shugen du Honzan 本山派, c'est-à-dire affiliés au Shōgo-in de Kyōto, voir le tableau établi par Anne Bouchy, "Du légitime et de l'illégitime dans le shugendō ou 'Sang de buddha', 'sang des êtres des montagnes' ? ", dans Anne Bouchy, Guillaume Carré et François Lachaud, èd., Légitimités, légitimations. La construction de l'autorité au Japon, 2005, p. 170-171. (N.D.T.)

I17. Dans Cbinzei Kamado yama nyübu denki 鎮西篗門山入菜伝記 (cf. supra, n. 76), à la date de 1718 (Kyōhō 享保 3), il est mentionné que le grade de shō-sen 小先 (littéralement " petit devant») était autrefois appelé jun-sendatsu 準先達 (《quasi-guide»). Il s'agit d'une dénomination propre au shugen du mont Hōman et ce n'est pas l'abréviation de «petit guide » (shō-sendatsu 少先達). 
- De la part de Kyōto est décerné le rang de "préfet subsidiaire inférieur-bōgen » 法眼 et le droit de porter le vêtement de couleur jaune sans motif.

- Le yamabushi ayant une charge au mont Hōman porte un vêtement jaune à motifs.

- En outre, de la part de Kyōto sont aussi attribués les titres et rangs de l'étole nouée de couleur rose pour un versement de 2 ryō 雨 d'argent.

- [Pour un] moine de première classe (issōgi一僧祇) ${ }^{118}: 2$ ryō d'argent ;

- [Pour un] maître de discipline subsidiaire : Ioo biki d'or ;

- [Pour un] bokkyō : 100 biki d'or ;

- cordon rouge de la conque : 3 ryō d'argent ;

- (étole) rouge de brocart : i ryō d'or.

$--$

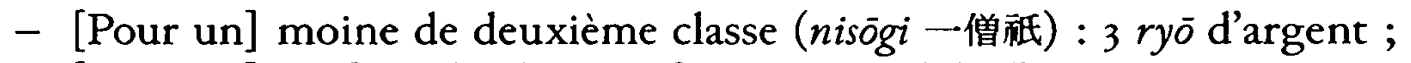

- [Pour un] préfet subsidiaire inférieur : 300 biki d'or ;

- [Pour un] högen : 300 biki d'or ;

- vêtement jaune : 2 ryō d'or.

- [Pour un] moine de troisième classe (sansōgi一僧祇) : 5 ryō d'argent ;

- [Pour un] grand préfet subsidiaire : 3 ryō d'or ;

- [Pour un] hōin : 5 ryō d'or.

Les rangs et titres de yamabushi-moine, tout comme le droit de porter les vêtements et accessoires qui leur correspondaient, étaient demandés au Shōgo-in de Kyōto, quartier général de la branche Honzan du shugendō, par le chef du shugen du mont Hōman, le zasu du Ryōga-in. Ainsi que l'indique ce document, obtenir ces titres et ces droits nécessitait le versement de sommes importantes en espèces. La montée en grade dans la hiérarchie du Hōman commençait dès la première entrée dans la montagne avec l'obtention du titre de « maître de discipline subsidiaire (gonrisshi 権律師)-bokkyō 法橋 ", puis à partir du sommet d'automne, celui de « petit guide » (shösen 小先), anciennement nommé « quasi-guide » (jun-sendatsu 準先達), titre propre à l'organisation du mont Hōman, qui était peut-être l'équivalent de celui de dōgyō 同行 (« qui pratique en commun ») du mont Hiko. Ces quasi-guides étaient ceux qui, parmi les yamabushi des 25 ermitages du Hōman, n'avaient à leur actif qu'un petit nombre d'entrées dans la montagne ; il s'agissait aussi des yamabushi qui résidaient dans les villages avec leur famille. Alors que les yamabushi des 25 ermitages de Hōman montaient en grade, passant du rang de novice acquis lors de la première entrée, à celui de quasi-guide dès la seconde, puis de guide-débutant (sho-sendatsu 初先達) à la quatrième, de grand guide (dai-sendatsu 大先達) à la neuvième, pour arriver à celui de daibokke 大越家 à la trente-sixième entrée, les yamabushi vivant dans les villages demeuraient au rang de quasi-guide. Ainsi, sur le rouleau peint de 1767 (Meiwa 明和 4) ${ }^{119}$ est reproduit le cortège

118. La liste ci-dessous précise les montants que l'on doit verser en espèces pour parvenir à chaque rang et titre, ainsi que pour obtenir le droit de porter les habits associés à ces derniers.

119. Rouleau peint de l'entrée dans la montagne de la branche Hōman, Hōman-ba nyübu emaki 宝満派入峯絵巻, 1767 (Meiwa 4). Ce document conservé au Daien-ji 大円寺 est reproduit 
des yamabushi du mont Hōman lors de l'entrée dans la montagne : ces quasi-guides qui forment un groupe de sept yamabushi à la queue du cortège, portent un vêtement et des jambières blancs, une veste (suzukake 鈴㗭) rouge avec une étole aux pompons blancs. En effet, les yamabushi des villages participaient également à l'entrée dans la montagne en tant que doshi (sic) 度㲾 chargés des tâches logistiques.

Le document 49 des archives de l'Ishii-bō est une autorisation de porter le vêtement brun foncé (mokuranjiki koromo 木闌色衣) dont il est précisé qu'il «n'est pas facile de l'obtenir, mais qu'elle fut accordée grâce à la demande du zasu du Ryōga-in du mont Kamado ». Dans le document 38, le Ryōga-in ordonne à l'Ishii-bō de porter le vêtement brun clair (kobucha suri goromo 昆布茶招衣) lors de l'entrée dans la montagne de Katsuragi (printemps), afin qu'il se distingue des autres branches du shugen, mais il indique qu'une fois terminé son mandat de chef de secteur, ceci est inutile. Cela permet de connaître les positions de l'Ishii-bō et du Ryōga-in, son chef hiérarchique : lors des entrées dans la montagne du Shōgo-in auquel était affilié le shugen du mont Hōman, le Ryōga-in avait le privilège de se trouver aux côtés du palanquin où était monté le grand supérieur du Honzan ${ }^{120}$.

L'entrée dans la montagne de l'Isbii-bō. - Selon le Nyūbu denki, l'Ishii-bō participa à l'entrée dans la montagne d'automne du shugen de Hōman, en tant que quasiguide, en 1718 (Kyōhō 享保 3) et en 1780 (An.ei 安永 9), en la personne de Kenrin 賢林; en I818 (Bunsei 文政 I) et en I830 (Bunsei 13), en celle de Kentei 賢貞; en 1853 (Kaei 嘉永 6), en celle de Ken.yū 賢祐 (ou 賢有). La première entrée de ceux-ci en tant que novices n'est pas consignée, mais dans les archives de l'Ishii-bō, sont conservés plusieurs documents relatant les préparatifs de Ken.yū 賢有, I4 ans, futur supérieur de l'Ishii-bō, pour sa première participation en 1845 (Kōka 弘化 2). Il y est noté que les dons de tous les habitants du canton permirent de réunir les 9 ryō d'or nécessaires pour cette première entrée dans la montagne ${ }^{121}$, dont 3 furent versés au Ryōga-in à titre de « frais de place pour les offrandes 》 (goku age zaryō 御供上げ 座料) ${ }^{122}$. Il lui fallut de plus verser les « frais de calot » (tokin ryō 頭巾料) au guide responsable ${ }^{123}$ de ce sommet, ainsi que les frais de participation à son accompagnateur. A également été conservée la liste de tous les présents qui lui furent offerts par les gens des cantons à cette occasion ${ }^{124}$.

dans Mori Hiroko, Hōman-zan no kankyō-rekishi gaku teki kenkyū, p. 60I-608 ; les shōsen sont représentés p. 607-608 et p. 609.

120. Ce privilège était celui des affiliés proches du Shōgo-in (matsuji-shū 末寺聚) (archives du Shōgo-in, Yosbino san nyūbu no zu 吉野山入荤之図).

121. Archives Ishii-bō 79.

122. Archives Ishii-bō 78 .

123. Sbunin sendatsu 主任先達. Ce titre n'existait pas à l'époque d'Edo, mais est mentionné dans “Yama no himitsu » 山の秘密 (Les secrets de la montagne), article de journal de l'époque Meiji. Il désigne probablement celui qui détenait la plus haute autorité lors des sommets de printemps (denbō dai-sendatsu 伝法大先達) et d'automne (jushoku dai-sendatsu 授職大先達).

124. Archives Ishii-bō 75. Le titre du document porte la date de 1831 (Tenpō 天保 2). Mais il n'y eut pas d'entrée dans la montagne en I83I. En I87ı (Meiji 明治 4), Ken.yū avait 40 ans (archives Ishii-bō 540); aussi peut-on penser qu'il s'agit là d'une erreur et que Tenpō 2 vaut sans doute pour Kōka 弘化 2 (1845), année où Ken.yū avait 14 ans. 
Dès le 15 du $2^{e}$ mois, Ken.yū était déjà monté au mont Hōman pour commencer les pratiques préliminaires chez le guide chef de cette entrée dans la montagne. Puis, à partir du 6 du $3^{\mathrm{e}}$ mois débuta le rite d'« entrée dans la halte du Lion ${ }^{125}$ » : à cette occasion, les novices entrent un à un dans ce lieu d'apprentissage principal et de retraite initiale situé sur le mont Hōman. À partir du $28 \mathrm{du} \varsigma^{\mathrm{c}}$ mois, Ken.yū participa aux pratiques de vénération (raibaigyō 礼拝行) dans la montagne. Le matin du Io du $7^{e}$ mois, à Wakasugi, l'Ishii-bō fit l'annonce de l'« accompagnement » (appelé ici mitate 見立 $\tau^{126}$ ) au groupe des maisons de sa section villageoise ainsi qu'au chef du village (shōya 庄屋), afin que ceux-ci viennent escorter Ken.yū, au matin du II, lorsqu'il quitta le mont Hōman pour s'engager dans le parcours rituel avec le goupe des yamabushi. Pour ce cortège au moment du départ de Ken.yū, des dons furent faits par un groupe de yamabushi de Hōman résidant dans le canton de Munakata (40o mon 文 de frais de sake), par Jōen-bō 成円坊 de l'Injū-bō 院主坊 de Satani (frais de sake et de collation), par le chef de village de Wakasugi, mais aussi par le chef des sections du village, les habitants, le charpentier et le teinturier (frais de collation, nouilles, mets préparés, vinaigre, sake). Parmi les noms des donateurs figure celui de Nagahama 長浜. Or Nagahama est le nom du propriétaire des terres de la vallée des Yamabushi 山伏谷 où le groupe shugen passe huit jours lors du sommet de printemps, dans le lieu d'hébergement construit à cet effet. Il s'agit donc probablement de la même personne.

Et lors du retour de Ken.yū au mont Hōman à la fin de l'entrée dans la montagne, les réjouissances furent encore plus grandioses. L'öjōya 大庄屋 ${ }^{127}$, les représentants de tous les yamabushi de la circonscription contrôlée par l'Ishii-bō, les chefs des villages de Sasaguri, Kana.ide 金出, Onaka et Wakasugi offrirent du sake, des nouilles, des mochi, des gâteaux aux haricots rouges, des légumes, etc. Les boîtes de gâteaux aux haricots rouges offertes par le teinturier de Sasaguri et par un homme d'Oto. inu 乙犬 furent apportées directement jusqu'à la halte du Lion en tant que « cadeau pour le lieu de pratiques » par deux membres de leur famille. Depuis Wakasugi, des dons de vinaigre furent également amenés jusqu'à la halte du Lion et chez le chef du shugen (zasu) du mont Hōman. Le 24 du $8^{c}$ mois, lors du retour de Ken.yū à l'Ishii-bō, celui-ci fut accompagné depuis le mont Hōman par quatre yamabushi de l'Eimon-bō 栄門坊 et du Myōjū-bō 明寿院, ainsi que par l'Injū-bō et l'Enzō-bō, qui l'escortèrent en cortège jusqu'à Wakasugi, tout en soufflant dans la conque chemin faisant. Et un groupe de villageois de Wakasugi, composé par les représentants de toutes les familles sans exception, vint l'accueillir solennellement jusqu'à l'Umi miseya 宇美店屋 (《le magasin d'Umi »). Ils avaient apporté avec eux sake et nourriture, et deux villageois, l'un d'Oto.inu et l'autre de Wakasugi, avaient pris leurs fauchards (naginata 長刀). Ce même jour, un grand banquet fut offert, probablement dans les bâtiments de l'Ishii-bō, à tous les officiels et, le lendemain, à tous les fidèles du sanctuaire Taiso, qui tous apportèrent un nombre considérable

125. Shishi no shuku kake.iri 師子摍馸け入り. La halte du Lion (Shishi no shuku 師子宿) ćtait le principal lieu de pratiques lors des entrées dans la montagne (nyūbu 入峯) du mont Hōman.

126. Mitate signifie ici mi.okuri 見送り (《accompagner du regard le départ de quelqu'un 》).

127. L'ójōya supervise tous les chefs de village d'un canton. 
de présents. Ce texte, signé par les chefs des villages, l'ojōya et les représentants des villages de Hakozaki et Sue, s'achève sur des formules de félicitation et des souhaits de longue vie. Toutes ces marques de sociabilité et de soutien permettent d'évaluer combien étaient grandes l'attente et la confiance envers les pouvoirs du yamabushi chargé des rites de protection pour les habitants des cantons de Kasuya et Munakata.

Lorsqu'en 1849 (Kaei 嘉永 2), le Shōgo-in commémora à Minoo 箕面 (Settsu 掑津, près de l'actuel Ōsaka) le mille cent cinquantième anniversaire de la mort d'En no Gyōja, la présence de tous les yamabushi affiliés fut exigée ; aussi l'Ishii-bō dut-il se rendre jusqu'à Kyōto. À cette occasion, les frais du voyage (7 ryō) furent également assurés par les habitants du canton comme en atteste le rapport fait par le chef du village de Sue et par les deux ojōya de Hakozaki et de Sasaguri, lequel fut adressé au bureau des fonctionnaires des deux cantons de Kasuya et de celui de Munakata ${ }^{128}$.

Enfin, lorsque le chef du shugen du mont Hōman, le Ryōga-in, ordonne à l'Ishii-bō, comme à ses autres affiliés, de participer à l'entrée dans la montagne du Shōgō-in dans les monts Ōmine de la péninsule de Kii 紀伊半島, cette participation est prise en compte dans le calcul du nombre des entrées dans la montagne, qui, on l'a vu, est au fondement de la montée dans la hiérarchie ${ }^{129}$.

L'entrée dans la montagne et les villageois. - Le calendrier ${ }^{130}$ et le parcours (carte I) du sommet de Katsuragi du mont Hōman varient légèrement d'une année à l'autre. Le texte le plus détaillé que nous en ayons est le " Guide de l'offrande des fleurs de l'entrée dans la montagne de Katsuragi131 » datant de I8I2 (Bunka 文化 9). Cette année-là, le groupe des yamabushi quitta la halte du Lion sur le mont Hōman le $22 \mathrm{du} 3^{\mathrm{e}}$ mois, gagnant dans la journée Satani où ils passèrent la nuit dans la vallée de Kannon 観音谷. Le 23, ils gravirent les 25 chō $(2,5 \mathrm{~km})$ jusqu'au sommet du mont Wakasugi où ils dormirent au sanctuaire Haut. Puis, du sanctuaire, ils allèrent jusqu'à l'eau du Vajra (Tokko-sui 独鈷水) et la stèle de Zenmui, d'où ils longèrent la crête de l'Ours, Kuma-ga-o 熊ヶ尾, jusqu'à la vallée des Yamabushi de Gō-no-haru 郷之原 (à un peu plus de $20 \mathrm{cho}$, soit $2 \mathrm{~km}$ ) pour une halte de sept jours. À l'ancienne halte, quelques centaines de mètres avant la vallée des Yamabushi, les participants offrirent des fleurs, et accrochèrent une plaquette signalant le passage du groupe. Le toponyme Gō-no-haru 郷の原 (“Lande du village ») serait en fait une altération de Gyō no haru 行の原, «Lande de la pratique/de l'ascèse ». Quant au nom de la vallée du/des Yamabushi 山伏谷, selon une légende, il viendrait de la mésaventure d'un yamabushi qui aurait été tué à cet endroit par des voleurs voulant s'emparer de l'argent qu'il portait, et dont l'âme se vengerait en produisant des effets dévastateurs ${ }^{132}$. Selon les gens de Gō-no-haru, se trouvent au fond de la vallée des tombes de yamabushi morts au cours des pratiques extrêmes qu'ils y accomplissaient.

128. Archives Ishii-bō 223.

129. Archives Ishii-bō 263.

130. Voir à la fin de cette contribution le tableau I : Calendrier du sommet de printemps (Katsuragi 葛城) du shugen du mont Hōman.

131. Katsuragi buchū banaku michi annai 暮城峯中花供道案内 (archives Ishii-bō 73).

132. Cbikuzen no kuni zoku fudo-ki, chapitre concernant le canton de Kasuya, p. 402. 
Il n'existe aucun bâtiment permanent à cet endroit ; aussi pour que les yamabushi puissent y séjourner sept jours, dès que commence le sommet de printemps, un envoyé du mont Hõman vient-il avertir les habitants des villages afin qu'ils se mettent à construire un abri. Selon les archives du village d'Onaka ${ }^{133}$, " en 1812 , le groupe des yamabushi dirigé par le chef du shugen du mont Hōman (zasu), après avoir passé la nuit au sanctuaire Haut du mont Wakasugi le 22 du $3^{\mathrm{e}}$ mois, entra le 23 dans la vallée des Yamabushi de Gō-no-haru pour y séjourner sept jours. Cette année-là, des hommes de tout le canton, au nombre de 500, avaient construit le lieu d'hébergement en bois, et le chef du fief avait fait don en espèces de 7 kanme d'argent au zasu. Le 29, le groupe quitta Gō-no-haru, fit un rite au sanctuaire de Hagio 萩尾宮, et de là, gagna le village de Kubara 久原村 pour une nuit à la halte de Katsuragi. »

Des précisions sur la construction de l'abri sont données par une pièce des archives de l'Ishii-bō ( $\mathrm{n}^{\circ}$ 129), non datée, intitulée "Outillage pour l'abri de la vallée des Yamabushi »: il y est mentionné que 83 nattes de paille, 3 nattes épaisses et 17 brassées de petits bambous, ainsi que 88 rondins de pin avaient été livrés au chef du village de Wakasugi.

Pendant la halte des sept jours, venait se joindre au groupe un yamabushi de Kuboyama 久保山 du canton voisin Honami 穂波郡, appelé Zenki 前鬼 ${ }^{134}$. Au cours de ces sept jours, trois ou quatre guides débutants se rendaient jusqu'à la demeure des Zenki où se trouvait un oratoire dédié à En no Gyōja, devant lequel ils allaient s'incliner. Ils se rendaient aussi chez les Nagahama, propriétaires de la montagne où ils étaient installés et, en remerciement, ils y faisaient un rite de protection de la maison. La ligne de crête située au-dessus de la vallée des Yamabushi s'appelle "crête de la Pierre blanche » (Shira.ishi-no-o 白石の尾) : c'est la limite entre les trois cantons de Kasuya, Honami et Kurate 鞍手. Un jouvenceau du même nom, Shira.ishi dôji 白石童子, y était vénéré par le shugen de Hōman.

Une fois les pratiques achevées dans la vallée des Yamabushi, le groupe suivait la crête séparant les cantons de Kasuya-Adret et Kurate, descendait jusqu'au village de Haginoo, s'y arrêtait pour un rituel au sanctuaire tutélaire du dieu de la montagne, Ubusuna sanjin no miya 産土山神の宮 (''actuel Ōyamazumi-jinja 大山祇 神社). Aujourd'hui, cette partie montagneuse de Sasaguri est couverte de forêts de cryptomères en dessous desquelles s'étendent des rizières, mais notre enquête auprès des villageois actuels nous a permis de savoir qu'à l'époque d'Edo, ces terres étaient des pâturages ou des espaces à fourrage recouverts d'herbe et sans arbres. Les pentes

133. Conservées au Musée d'histoire locale de Sasaguri, Sasaguri-chō rekishi minzoku shiryō-kan 篠栗町歴史民俗資料館.

134. Zenki 前鬼 et Goki 後鬼 sont deux puissances terribles des monts Ōmine qu'En no Gyōja, le fondateur mythique du shugendō, soumet et transforme en disciples. Dans toutes les montagnes où avait lieu le mine.iri se trouvaient des maisons nommées Zenki et Goki, qui se disaient les successeurs de ces premiers disciples, et dont le rôle était de guider les yamabushi sur lcs scnticrs de montagne. Voir Anne Bouchy, "Du légitime et de l'illégitime dans le shugendō ou 'Sang de buddha', 'sang des êtres des montagnes' ? ", dans Anne Bouchy, Guillaume Carré et François Lachaud, éd., Légitimités, légitimations. La construction de l'autorité au Japon, 2005 , p. $162-167$. (N.D.T.) 
sont assez abruptes ; pourtant le groupe des yamabushi venant de Gō-no-haru devait alors descendre en droite ligne pour remonter ensuite, après l'arrêt au sanctuaire, de l'autre côté de la vallée, par le chemin qui passe devant l'actuel temple Raion-ji 雷音寺 ( $\mathrm{n}^{\circ} 49$ du pèlerinage de Sasaguri), avant de déboucher au col du Côté (Yokotōge 横续). A cette frontière entre le village de Haginoo (Sasaguri) et celui de Kubara (Hisayama), se dressait une stèle du dieu des chemins (dōsojin 道祖神) ${ }^{135}$. De là, ils arrivaient à Kubara, dans la vallée de Katsuragi, d'où ils gagnaient le mont Shura. En I767 (Meiwa 4), ils ne descendirent pas, mais restèrent sur les crêtes et passèrent par les haltes rituelles du mont Katsuragi et de la Lande du saule (Yanagi no hara 柳之原) pour arriver au mont Kumano (dit aussi mont Inunaki 犬鳴山), où ils passèrent la nuit.

\section{Isbii-bō, prêtre du Taiso-gū, sanctuaire cantonal}

L'officiant des rites ${ }^{136}$. - Les documents précédents nous ont donné un aperçu de la place de l'Ishii-bō dans la société locale, et de la façon dont les habitants des cantons et des villages soutenaient matériellement et moralement le yamabushi en charge de l'ermitage de Wakasugi. Le "Registre des rites ${ }^{137}$ " est un autre texte précieux : Kentei 賢貞 ( $9^{\complement}$ génération des supérieurs de l'Ishii-bō ; 18I4-I868, Bunka II-Meiji I) y a consigné pendant un demi-siècle les rites qu'il accomplissait au Taiso-gū, les reconstructions des bâtiments, les fêtes et cérémonies, etc. S'y trouvent détaillés la date, le type de rituel, le demandeur du rite, les participants, les rétributions, éléments qui nous permettent de connaître les réalités des pratiques et les souhaits des villageois ${ }^{138}$. D'après ce texte, les rites fixes de demande d'abondance des récoltes entre le $\mathrm{i}^{\text {er }}$ et le 3 du $\mathrm{i}^{\text {er }}$ mois et ceux de demande de mûrissement du blé au milieu du $3^{\mathbf{c}}$ mois étaient accomplis en présence des fonctionnaires chargés des cantons (gundai 郡代), des ojjōya, des représentants des cantons et des chefs de villages. Les principaux rites occasionnels étaient les demandes de pluie ${ }^{139}$ et de beau temps ${ }^{140}$, et leur occurrence est très fréquente dans le texte. Sont également extrêmement fréquents tous ceux qui ont pour but d'empêcher les ravages par les aléas naturels : rituels pour chasser les maladies et désastres des rizières, pour éloigner les sauterelles, pour arrêter les vents et les typhons en constituent la majorité. Les rituels fixes pour empêcher les désastres causés par les vents, qui sont aussi appelés « fête du vent »(kaza-matsuri 風祭) avaient lieu entre les $7^{c}$ et $8^{c}$ mois et, à cette occasion, se déroulaient des luttes (sumō 角力), des spectacles de marionnettes et de danses. À ce sujet, il reste aussi des documents relatant tous les échanges entre les différents

135. D'après Katsuragi buchū hanaku michi annai (archives Ishii-bō 73).

136. Sur les rites et leur évolution jusqu'à nos jours, voir aussi l'article de Suzuki Masataka 鈴木正禁 dans ce même volume, "Continuités et transformations de la société locale : le fait coutumier dans le village de Wakasugi », p. 63-77.

137. Gokitō bikae kiroku 御行控 記録 (archives Ishii-bō 109).

138. Voir à la fin, le tableau II : “Registre des rites 》, Gokitō bikae kiroku 御新裙 控 記録.

139. Amagoi 雨乞い. Ils sont aussi appelés ici : sböu amagoi 請雨, kōu gitō 降雨祈稆, bibō no daiunrin-bō 秘法()大弉輪法.

I40. Higoi H乞い, également inscrits avec la graphie bigoi 請日,日請, amedome 此雨, kaisei 快晴, seiten gitō 晴犬祈䅺, bibō no tencbi kyō-bō 秘法の天地鏡法. 
protagonistes de cette fête qui témoignent de l'intense contribution et de la participation de tous les habitants du village. En 1836 (Tenpō 天保 7), comme une épidémie s'était répandue parmi les animaux de trait, pendant trois jours et deux nuits, du 9 au II du $4^{e}$ mois, Kentei exécuta un rituel auquel assistèrent les représentants des villages ; des talismans de protection (kake-mamori 掛守) furent envoyés pour les 288I chevaux et bovins de tous les cantons. Ci-dessous sont récapitulés les types de rituels et les dates auxquels ils furent accomplis durant cette période ${ }^{141}$ :

Rite pour une année prospère (bōnen gitō 豊年祈禇) : chaque année $(\mathrm{I} / \mathrm{I}-\mathrm{I} / 3)$.

Rite pour le mûrissement du blé (bakusaku seijuku kitō 麦作成熟祈禇)：chaque année (milieu du $3^{\mathrm{e}}$ mois).

Demande d'ensoleillement (bigoi 請日) : 1819 (6/20-6/22), 1820 (4/3-4/7), $1820(6 / 20-6 / 22), 1825(7 / 16), 1828(8 / 25-8 / 27), 1836(6 / 16-6 / 18), 1837$ (3/26-3/28), I838 (6/2-6/4), I838 (9/18-9/20), 1839 (2/7-2/9), I840 (II /II), $1842(7 / 1-7 / 3)$.

Arrêt de la pluie (amedome/shiu 止雨) : 1824 (3/18-3/20), 1824 (6/28-7/1), 1825 (3/IO-I2), $1825\left(4 / \mathrm{II}^{-4} / \mathrm{13}\right), \mathrm{I} 825(6 / 2-6 / 4), 1825(7 / 7-7 / 9), \mathrm{I} 827(4 / 6-4 / 8)$, I $832(2 / 14-2 / 16), I 837$ (I/I7-I/I9), I837 (2/I3-2/I5), I84I (I/25-I/27), I84I $(7 / 7-7 / 9)$.

Demande de pluie (amagoi/shōu 請雨) : I821 $(6 / 11-6 / 13), 1822(2 / 24-2 / 26)$, $1823(6 / 18-6 / 20), 1823(7 / 27-7 / 29), 1824(5 / 29-6 / 1), 1828(5 / 12-5 / 14), 1832$ $(5 / 28-6 / 1), 1832(8 / 20), 1833(5 / 8-5 / 12), 1834(5 / 25-5 / 27), 1834(7 / 6-7 / 8)$, $1845(5 / 18-5 / 21)$.

Rituel de la roue du grand nuage (rituel secret de demande de pluie) (daiunrin- $b \bar{o}$ 大雲輪法 [雨乞い秘法] ) : $1823(8 / 1-8 / 8), 1834(7 / 26-8 / 3)$.

Chute de pluie du dragon céleste (tenryū kōu 天龍降雨) : 1845 (7/6-7/8).

Anéantissement des fléaux des rizières (densai shōjo 田災銷除) : 1822 (6/28-6/30), $1822(7 / 1-7 / 3)$.

Dispersion des sauterelles (inago sanjo 蝗散除) : $1830(7 / 13-7 / 16), 1839(7 / 1-7 / 3)$, 1839 (7/20-7/24).

Arrêt du vent (kazedome 風留め) : I826 (8), I830 (7/13-7/16), I83I (7/26-7/28), I833 (7/25), I834 (7/22), I835 (7/15), I837 (7/29-7/8), 1841 (8/2), I842 (7/23-7/26).

Élimination des épidémies (ekibyō taisan 疫病退散) : 1843 (7/17-7/19).

Élimination de l'épidémie des chevaux et bovins (gyüba ekibyō taisan 牛馬疫病 退散) : 1836 (4/9-4/11).

Dans ce registre sont consignés les rites officiels que l'Ishii-bō accomplissait ${ }^{142}$, mais en dehors de ceux-ci, il lui était aussi demandé d'effectuer des rituels pour des particuliers, notamment pour les couches faciles, la protection au cours des voyages,

141. Entre parenthèses sont notés les jours et les mois.

I42. À l'exception d'un rituel fait au sanctuaire Taiso pour le chef de village Hōsuke 范助 en 1845 (Kōka 弘化 2) : il s'agissait de demander la guérison d'une maladie (tōbyō beiyu 当病平媔). On peut se demander s'il n'a pas été fait pour tout le village. 


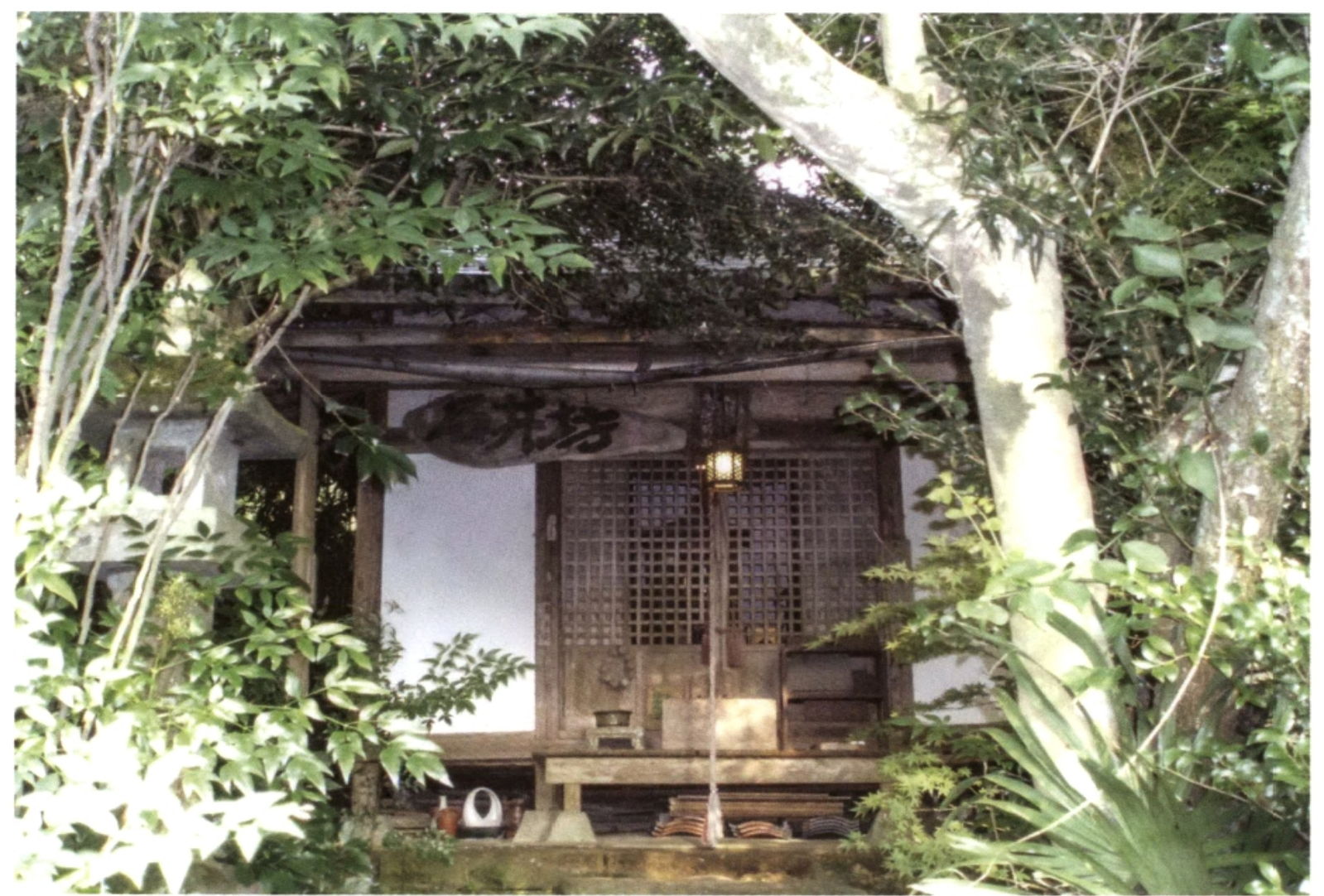

Fig. 7 : L'oratoire des rites du feu de l'Ishii-bō (Wakasugi).

la guérison des maladies, la purification des maisons ou la divination : ceux-ci ont également été notés sur d'autres feuillets où se trouvent des incantations pour la guérison de maladies ${ }^{143}$. Le $6^{\mathrm{e}}$ mois de 1853 (Kaei 嘉永 6), lors de l'arrivée des navires du commodore Perry dans la baie d'Uraga, le Shōgo-in accomplit un rituel exceptionnel, durant l'entrée dans la montagne de Katsuragi, pour l'expulsion des ennemis étrangers, la paix dans le pays et l'Etat, et l'obtention d'un sort favorable pour les armes. Il adressa ensuite à tous ses temples affiliés l'ordre d'en faire autant. Cet ordre fut transmis au chef du shugen du Hōman, le Ryōga-in, qui l'envoya à tous les temples et ermitages de la montagne ainsi qu'à tous les yamabushi des villages $^{144}$. On peut donc penser que l'Ishii-bō obéit à cet ordre.

Les chasses du daimyo. - Le « Registre des rites » contient également des mentions sur les chasses du chef du fief Kuroda. Durant 35 ans, entre 1834 (Tenpō 5 ) et 1868 (Meiji I), elles eurent lieu 2I fois. Le nombre de cerfs et de sangliers abattus est aussi noté. Kuroda Nagahiro 黒田長溥 ( $9^{e}$ génération des daimyō) fut à la tête du fief de I834 à I869; aussi peut-on dire qu'il s'agit là de la totalité des chasses effectuées dans cette période. Toute la superficie du mont Wakasugi était une chasse réservée du fief. Lors de ces chasses, le daimyō passait la nuit chez l'ophtalmologiste du fief,

143. Archives Ishii-bō $95-107$ et 517.

144. Archives Ishii-bō 262, 266. 


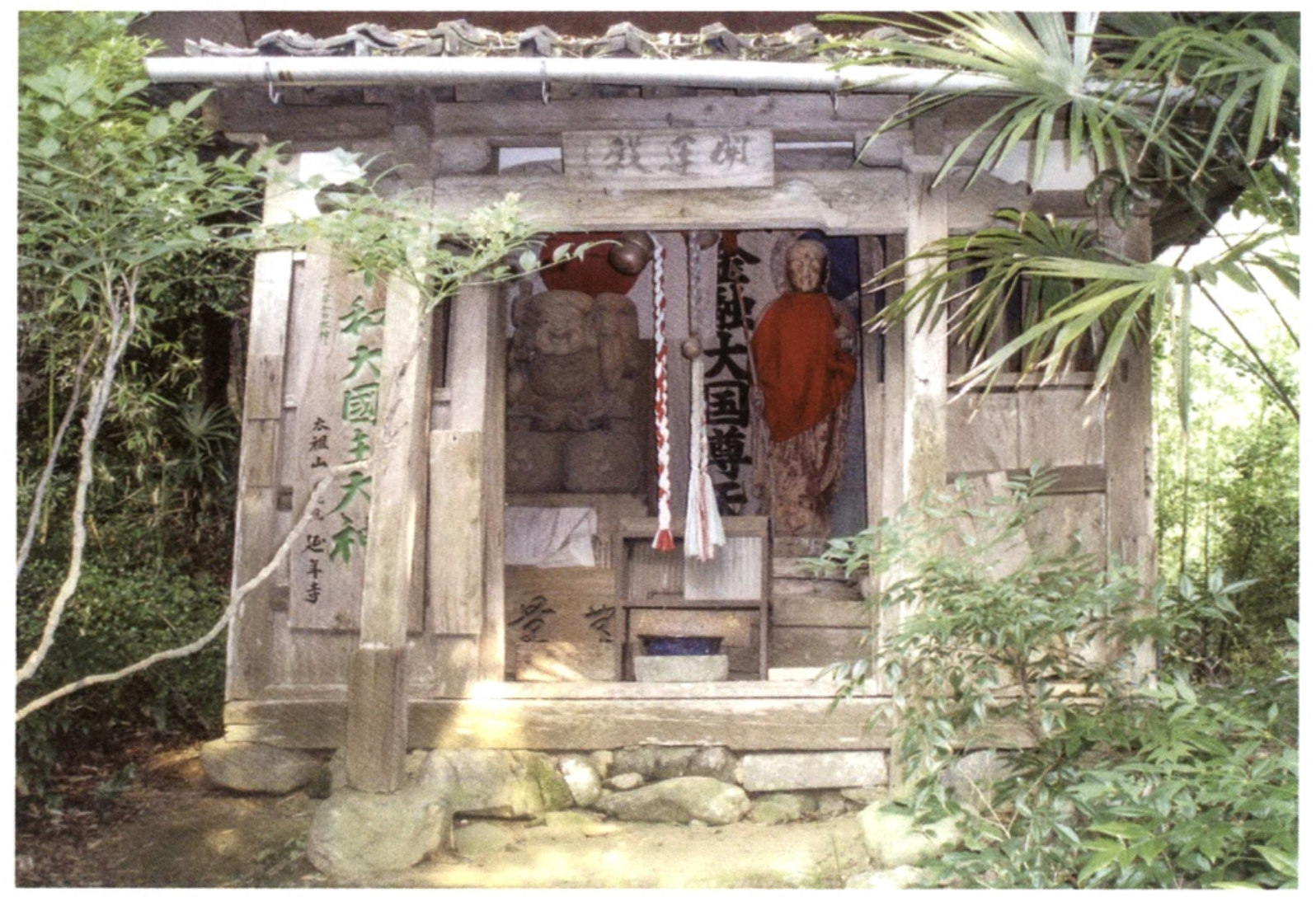

Fig. 8 : L'oratoire de Jizō de l'Ishii-bō (Wakasugi).

un certain Tahara 田原, habitant à Sue, et l'Ishii-bō était son lieu de repos. À cette occasion, l'Ishii-bō faisait un rituel de demande de protection et de beau temps dans la montagne, pour lequel il recevait une rétribution de la part du fief. Ces éléments sont relatés dans les documents que celui-ci échangeait avec le bureau des temples et sanctuaires du fief, et font partie des lettres qui y sont conservées.

Avec la fermeture du pays à l'époque d'Edo, le Taiso-gū s'est donc affirmé comme un sanctuaire villageois et régional, dont les activités principales sont devenues les rites pour la prospérité agricole, et dont les divinités sont surtout vénérées en tant que puissances protectrices de l'agriculture. Dans ce processus, les rituels ésotériques et shugen ont joué un rôle essentiel et n'ont cessé d'être objets de demandes des habitants. L'Ishii-bō, par sa place située au bas de la hiérarchie shugen du Hōman, dépendait du Ryōga-in pour toutes les demandes de montée en grade, que ce dernier transmettait aux hautes autorités shugen du Shōgo-in. Il en allait de même pour toute requête de riz en cas de disette, pour toute demande d'autorisation de couper du bois sur le mont Wakasugi en vue d'effectuer des réparations ou des constructions de bâtiments cultuels. C'est le Ryōga-in qui servait d'intermédiaire entre l'Ishii-bō et le fief à qui elles étaient adressées. Mais dans le même temps, l'Ishii-bō, par sa double fonction de chef de secteur du shugen du mont Hōman pour les trois cantons de Munakata et des deux Kasuya, et aussi de prêtre du Taiso-gū, sanctuaire cantonal vénérant les ancêtres impériaux (sōbyō 宗廟), avait sous son autorité tous 
les yamabushi de ces cantons et bénéficiait d'une grande considération de la part de tous les villages. Cette configuration fait apparaître à quel point les dynamiques du dedans et du dehors interagirent au cours de l'histoire moderne en s'imbriquant de façon complexe.

Avec la Restauration de Meiji et la séparation du bouddhisme et du shintō, s'est close l'histoire des montagnes shugen et de leurs organisations. L'Ishii-bō Ken.yū prit le nom d'Ishii Shimizu et devint le desservant shintō du Taiso-gū. Ce dernier fut promu sanctuaire de village (gösha 郷社) en 1872 (Meiji 5). En 1875, Ishii fut remplacé par le prêtre Muraki Nashi 村木梨, auquel succéda le prêtre Sassa Susugu 佐々雪 en 1876 . Aujourd'hui, les Ishii ont conservé leur habitation à Wakasugi, près de laquelle se dressent toujours l'oratoire pour les rites du feu (goma-dō 護摩堂) (fig. 7) et l'oratoire de Jizō (Jizō-dō 地藏堂) (fig. 8), mais ils ont perdu leur fonction d'officiant religieux du mont Wakasugi. Le Taiso-gū fut élevé en 1896 au rang de sanctuaire départemental (kensha 県社) et, durant quelque temps, c'est le prêtre du sanctuaire de Kashii qui en cumula la charge cultuelle. Toutefois, à partir de 1898 (Meiji 3I), celle-ci fut assurée par Sassa Tamotsu 佐々保, qui la conserva durant 47 ans. Après la guerre, avec l'accord des habitants, elle revint au prêtre Uchikawa 内川. De nos jours, le Taiso-gū est, tout comme le sanctuaire Suwa 諏訪神社 de Sasaguri, placé sous la responsabilité du prêtre Uchikawa Michiomi 内川道臣, et a perdu l'importance qu'il avait lorsqu'il était sanctuaire cantonal vénérant les ancêtres impériaux $(s \bar{o} b y \bar{o})$.

Durant l'époque d'Edo, excepté des rituels exceptionnels comme les rites secrets pour les demandes de pluie, qui avaient lieu au sanctuaire Haut, sur le sommet du mont Wakasugi, presque tous les rites et fêtes étaient célébrés dans le sanctuaire Bas, au pied de la montagne. À l'heure actuelle, l'Association du sommet sacré (Wakasugi Reihō-kai 霊峰会), dont les membres sont les so maisons du village d'origine de Wakasugi, gère le sanctuaire Haut ainsi que la grotte appelée autrefois " grotte des Huit grands rois dragons 》 (Hachidai-Ryūō-kutsu 八大龍王笜), qui est devenue aujourd'hui le «temple du fond »(Oku-no-in 奥の院) du nouveau pèlerinage de Shikoku à Sasaguri. Le sanctuaire Bas est, quant à lui, géré par l'assemblée des fidèles du sanctuaire (ujiko 氏子), dont les membres sont quasiment les mêmes que ceux de l'association précédente. Seuls les célébrations rituelles sont à la charge du prêtre Uchikawa.

Les dieux japonais changent de caractère et de forme sous l'impact de multiples facteurs, dont l'origine se trouve du côté des hommes. Les divinités de Wakasugi ainsi que les modalités de leur culte, prises entre les dynamiques internes et externes des fluctuations sociohistoriques, ont été marquées par des transformations souples. Le shugen qui a contrôlé cette montagne pendant très longtemps semble en avoir disparu à Meiji. Pourtant, les anciens sites sacrés dispersés dans tout cet espace montagneux, sous l'aspect transformé du « nouveau pèlcrinage dc Shikoku à Sasaguri », continuent à être, aujourd'hui encore, des lieux de pratiques et d'ascèse pour un très grand nombre de gens. Parmi ces lieux anciens, le Kongōchō-in 金剛頂院, qui 
fut reconstruit en 1942 sur le site où Kūkai se serait installé à son retour de Chine, et le Chizuru-ji 千鶴寺 de Gö-no-haru, reconstruit en 1954, $\mathrm{n}^{\circ} 12$ du circuit de pèlerinage de Sasaguri où est vénéré Ishitetsu gongen 石鉄権現 (du mont Ishizuchi 石鎳山 de Shikoku), sont deux temples shugen qui témoignent, bien qu'étant sans rapport avec le shugen du mont Hōman, du renouveau du shugendō à Sasaguri : les rites du feu mensuels et les grands rites du feu extérieurs de type shugen qui y ont lieu deux fois par an en sont de très bons exemples. L'espace naturel de la montagne de Wakasugi, où se sont développés autrefois l'ésotérisme et le shugen, reste aujourd'hui comme hier un lieu ouvert aux pratiques et aux pèlerinages. Avec la qualification toute récente de la commune comme site de "thérapie forestière » (shinrin serapi 森林セラピー), des marcheurs sans objectif religieux viennent désormais parcourir ces lieux chargés d'histoire au pied des cryptomères géants, où ils semblent trouver la paix du corps et de l'esprit.

Traduit du japonais par Anne Bouchy 


\section{Bibliographie}

\section{Bouchy, Anne}

2000 "La cascade et l'écritoire. Dynamique de l'histoire du fait religieux et de l'ethnologie du Japon : le cas du shugendō ", BEFEO 87/1, p. 341-366.

2005 «Du légitime et de l'illégitime dans le shugendō ou 'Sang de buddha', 'sang des êtres des montagnes' ? ", dans Anne Bouchy, Guillaume Carré et François Lachaud, éd., Légitimités, légitimations. La construction de l'autorité au Japon, coll. Études thématiques I6, Paris, EFEO, p. III-I77.

2012 "'Initiatic landscape' and Shugendō mountain-entry ", Proceedings I48, Londres, The Japan Society, p. 73-99.

CHō Yōichi 長洋一

1987 《Dazaifu seiritsu zenshi »太宰府成立前史, dans Tamura Enchō 田村円澄, éd., Kodai wo kangaeru Daizaifu 古代を考える大莘府, Tōkyō, Yoshikawa Kōbunkan 吉川弘文館, p. 16-4I.

FRANK, Bernard

2000 Dieux et Bouddhas au Japon, Paris, Odile Jacob.

IgATA Susumu 井形進

2008 《Shura-san iseki no Sōfū shishi to Satsuma tō »首羅山遺跡の宋風獅子と 薩摩塔, dans Hisayama-chō kyōiku iin-kai 久山町教育委員会, éd., Shura san iseki. Fukuoka beiya shüen no sangaku jiin 首羅山遺跡——福岡平野周 縁の山岳寺院, Fukuoka, Hisayama-chō kyōiku iin-kai, p. 65-83.

KoYAMA Yasunori 小山靖憲

2002 《Kumano sanzan》熊野三山, dans Kumano. Ikai e no tabi 熊野:異界への 旅, numéro spécial du Taiyō 別冊太陽, Tōkyō, Heibonsha 平凡社, p. 9-32.

MrYaKe Hitoshi 宮家準

1992 Kumano sbugen 熊野修験, Tōkyō, Yoshikawa Kōbunkan 吉川弘文館.

Momosaki Yūsuke 桃崎祐輔

2008 «Kōrokan taisei no hōkai kara chūsei shakai e. Iseki ni nokosareta Chūgokushōnin no katsudō to sono ibutsu » 鴻臚館体制の崩壊から中世社会へ——遺 跡に遺された中国商人の活動とその遺物, dans Nanakuma shigakkai 七幔史学会, éd., Daijukkai taikei shinpojïumu. Kyūshū no chüsei-gaku. Kōeki, kaibatsu, shinkō. Yokō-shū 第 10 回大会記念シンポジウム:九州の中世学——交易・開発・ 信仰·予稿集, Fukuoka, Nanakuma shigakkai 七隈史学会, p. 5-34.

MORI Hiroko 森弘子

2008 Hōman-zan no kankyō-rekishi gaku teki kenkyū 宝満山の環境歴史学的研究, et ses annexes, Hōman-zan kankei shiryō-shū 宝満山関係史料集, Tōkyō, Iwata shoin 岩田書院.

YAHIRO Izumi 八尋和泉

1986 《Wakasugi yama no bukkyō ihin » 若杉山の仏教遺品, dans Kyūshū rekishi shiryōkan 九州歴史資料館, éd., Cbikuzen Kasuya. Wakasugi yama no bukkyō iseki 筑前粕屋:若杉山の仏教遺跡, Kyūshū no jisha shirīzu 九州の 
寺社シリー.ズ 8, Dazifu 太㚔府 (Fukuoka 福剛), Kyūshū rekishi shiryōkan 九州歴史資料館, P. 26-30.

Monographies locales, compilations

AOYAGI Tanenobu 青柳種信, comp.,

1973 Cbikuzen no kuni zoku fudo-ki shūi 筑前国続風土記拾遺, 5 vol., Chikuzen no kuni zoku fudoki shūi kankō-kai 筑前国続風土記拾遺刊行会, éd., Fukuoka, Yoshida Kimimasa 吉田公正 (compilé 1814-1864).

Dainippon jingikai Fukuoka-ken shibu 大日本神祇会福岡県支部, éd.

1945 Fukuokaken jinja-shi 福岡県神社誌, 3 vol., Fukuoka.

Heibon-sha chihō shiryō sentā 平凡社地方資料センター, éd.

2004 Fukuoka ken no chimei 福岡県の地名, dans Nibon rekishi chimei taikei 日本 歴史地名大系, vol. 4I, Tōkyō, Heibonsha 平凡社.

Hisayama-chō kyōiku iinkai 久山町教育委員会, éd.

2008 Shura san iseki. Fukuoka beiya shüen no sangaku jiin 首羅山遺跡——福岡 平野周縁の山岳寺院, Fukuoka, Hisayama-chō.

KaIBARA Ekiken 貝原益軒, comp.

1977 Cbikuzen no kuni zoku fudo-ki 筑前国続風土記. Édité par Itō Oshirō 伊藤 尾四郎 (1869-1949), dans Fukuoka-ken shi shiryō zoku dai yon shū. Chishi ben I 福岡県史資料続第四輯:地誌編一, Tōkyō, Meichō shuppan 名著出版 (compilé en 1709) ( ${ }^{\text {re }}$ éd. 1943 ; réimpression : Tōkyō, Bunken shuppan 文献出版，2001).

KUMANO sanzan kyōgikai 熊野三山協議会, éd.

Zenkoku Kumano jinja dēta bēsu 全国熊野神社データベース (document non publié).

KYūsHū rekishi shiryōkan 九州歴史資料館, éd.

1986 Chikuzen Kasuya. Wakasugi yama no bukkyō iseki 筑前粕屋:若杉山の仏教遺跡, Kyūshū no jisha shirīzu 九州の寺社シリーズ 8, Dazaifu 大莘府 (Fukuoka).

Sasaguri-chō bunkazai senmon-iinkai 篗栗町文化財専門委員会, éd.

1982 Sasaguri chōsbi. Rekisbi-ben 篠栗町誌:歴史編, Sasaguri 篠栗, Sasaguri-chō yakuba 篠栗町役場.

1990 Sasaguri chōsbi. Minzoku-ben 篠栗町誌:民俗編, Sasaguri 策栗, Sasaguri-chō yakuba 篠栗町役場.

Sasaguri-chō yakuba 策栗町役場, éd.

s.d. Kaiteiban Bunkazai meguri. Reibō Wakasugi no korō tachi. Sasaguri-chō no rekishi sanpo 改訂版・文化財めぐり:霊峰若杉の古老たち一一篠栗町の歴史 散歩, Fukuoka, s.n.

Shingū chōshi hensan iinkai 新宮町誌編集委員会, éd.

1997 Shingū chōshi 新宮町誌, Shingū. 
Documents anciens, documents d'arcbives édités

Anraku-ji ryō chūshinjō utsushi 安楽寺領注進状写 (transcription de 1352, le document original est perdu), notes sur l'état des terres qui ont été données au domaine du temple Anraku-ji 安楽寺 (actuel sanctuaire Tenman-gū de Dazaifu) : Kawazoe Shōji 川添昭二, éd., Dazaifu. Dazaifu Tenman-gū shiryō 太莘拊· 太宰府天満宮史料, vol. II, Fukuoka, Daizaifu Tenman-gū, 1979, p. 398-408.

Cbiku-no-saki-no-kuni Kasuya-gun Taiso daigongen gūki 筑之前州粕屋郡大祖大権現 宮記 : Kyūshū rekishi shiryōkan 九州歴史資料嗆, éd., Cbikuzen Kasuya. Wakasugi yama no bukkyō iseki 筑前粕屋:若杉山の仏教遺跡, 1986, p. 37-38.

Chikuzen Kasuya-gun Wakasugi-yama Taiso jinja engi 筑前糟屋郡分杉山大祖神社縁起, par Kaibara Yoshifuru 貝原好古 : Kyūshū rekishi shiryōkan 九州歴史資 料館, éd., Cbikuzen Kasuya. Wakasugi yama no bukkyō iseki 筑前粕屋 若杉山の仏教遺跡, p. 38-44.

Chikuzen no kuni Omote-Kasuya-gun Taiso san denki 筑前国表糟屋郡太祖山伝記, archives de l'Ishii-bō : Kyūshū rekishi shiryōkan 九州歴史資料館, éd., Chikuzen Kasuya. Wakasugi yama no bukkyō iseki 筑前粕屋:若杉山の仏教遗跡, 1986, p. 44-45. Hacbiman gudō kun 八幡愚童訓 (deux versions différentes) : Hagiwara Tatsuo 萩原 龍夫, éd., dans Jisha engi 寺社縁起, coll. Nihon shisō taikei 日本思想大系 20, Tōkyō, Iwanami shoten 岩波書店, 1975, p. 169-273.

Hacbiman Usa-gū ontakusen shü 八幡宇佐宮御託宣集 (compilé entre 1290-1313, Shōō 正応 3 et Shōwa 正和 2, par Jin.un 神吽, chef des enseignements d'Usa Miroku-ji 宇佐弥勒寺) : Kodaigaku kyōkai 古代学協会, éd., Hachiman Usa-gu ontakusen shū 八幡宇佐宮御託宣集, 2 vol., Shiryō shūi 史料拾遺, Kyōto, Rinsen shoten 臨川書店, 1966-1967.

Hakata-tsu yōroku 博多津要録, Hidemura Senzō 秀村選三 et al., éd., vol. I, Fukuoka, Nishi Nihon kyōkai 西日本文化協会, 1975.

Heikoki 平戸記, journal de Taira no Tsunetaka 平経高 : édité dans la collection Zōho Shiryō taisei 增補史料大成, vol. 32, Kyōto, Rinsen shoten 臨川書占, 1965. Hōman-ba nyūbu emaki 宝満派入峯絵巻 (1767 [Meiwa 4], document conservé au Daien-ji 大円寺) : reproduit dans Mori Hiroko, Höman-zan no kankyōrekishi gaku teki kenkyū, 2008, p. 601-608.

Itsukushima daimyōjin nikki 篆島大明神日記 (Shyōmyō-ji 称名寺 ; conservé au Kanazawa bunko 金沢文庫), feuillet $(15,8 \times 13,6 \mathrm{~cm})$ de transmission secrète concernant la divinité du sanctuaire Itsukushima 簃島神社 (Hiroshima 広島県), datant de la fin Kamakura : Tsuda Tetsuei 津田徹英, éd., Kanazawa bunko no chüsei sbintō sbiryō 金沢文庫の中世神道資料, Yokohama, Kanazawa bunko 金沢文庫, 1996, p. 5I- 53 .

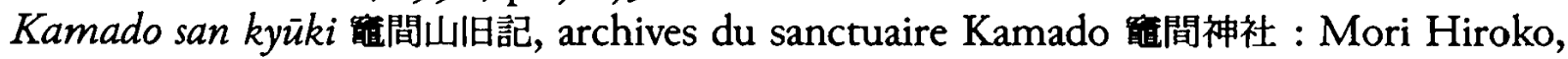
comp., dans Gorai Shigeru 五来重, éd., Shugendō shiryōshū 修験道史料集 II, Nishi Nibon-ben 西日本編, Sangaku shūkyō-shi kenkyū sōsho 山岳宗教史研究綮書, vol. I8, Tōkyō, Meicho shuppan 名著出版, 1984, p. 530-548 (cf. aussi p. 830-832).

Kamado yama Hōman dai bosatsu-ki 篗間山宝満大菩薩記, archives du Kanazawa bunko 金沢文庫 (Shōmyō-ji 称名寺) : Mori Hiroko, Hōman-zan no kankyōrekishi gaku teki kenkyū, éd., Hōman-zan kankei shiryō-sbū, 2008, p. II-I4. 
Kansei ni-nen Chikuzen matsuji-chō 寛政二年筑前末寺帳 : Fukuoka-ken 福岡県, éd., Fukuoka-ken shi sbiryō 福岡県史資料, vol. 7, Fukuoka, Fukuoka-ken, 1937, p. 327-344.

Katsuragi buchū banaku michi annai 葛城峯中花供道案内, archives Ishii-bō 73 : Mori Hiroko, Hōman-zan no kankyō-rekishi gaku teki kenkyū, éd., Hōmanzan kankei shiryō-shiu, 2008, p. 60-67.

Kuroda shinzoku kafu 黒田新続家譜, Kawazoe Shōji 川添昭二 et al., éd., vol. 3, Tōkyō, Bunken shuppan 文献出版, 1982.

Munakata daibosatsu go.engi 宗像大菩薩御縁起 : Shintō taikei hensankai 神道大系編 举会, éd., Shintō taikei, jinja ben, 49, Munakata 神道大系:神社編 49, 宗像, Tōkyō, Shintō taikei hensankai, 1979, p. 6-21.

Satani-san Kenshō-ji engi 左谷山建正寺縁起 (écrit en 1561 [Eiroku 永禄 4] par le moine Kenshō-bō Sōshuku 賢正坊宗祝 du Satani-san Kenshō-in 左谷山賢聖院, auquel des ajouts ont été faits en 1644 (Shōhō 正保 I) et en I819 (Bunsei 文政 2) : le manuscrit est conservé au Musée d'histoire locale de la commune de Sue (Sue-chōritsu rekishi minzoku siryōkan 須恵町立歴史民俗資料館) : Kyūshū rekishi shiryōkan 九州歴史資料館, éd., Chikuzen Kasuya. Wakasugi yama no bukkyōiseki 筑前粕屋:若杉山の仏教遺跡, 1986, p. 35-37.

Tōdai-ji yōroku 東大寺要録 : Zoku-zoku gunsho ruijū 続々群書類従, vol. II, Tōkyō, Zoku-gunsho ruijū kankō-kai 続群書類従刊行会, éd., 1969.

Documents d'archives non édités

Chinzei Kamado yama nyūbu denki 鎮西篗門山入峯伝記, archives de l'Eifuku-in 永福院 (département de Fukuoka), temple affilié au shugen du mont Hōman 宝満山. Gokitō bikae kiroku 御祈禧 控 記録, archives Ishii-bō I09.

Kashii go.engi 香椎御縁起, manuscrit conservé au Musée national de Tōkyō (Tōkyō kokuritsu hakubutsukan 東京国立博物館).

Katsuragi būchū taizōkai ki 葛城峯中胎藏界記, archives du Kanō-in 叶院 à Fukuoka. Shingū ura yuraisho jōchō 新宮浦由来書上帳, archives d'Isozaki jinja 磯崎神社 (Fukuokaken Kasuya-gun Shingū-chō 福岡県糟屋郡新宮町).

Yosbino san nyūbu no zu 吉野山入峯之図, archives du Shōgo-in 聖護院 (Kyōto).

Archives de l'Isbii-bō, citées par numéro d'inventaire

Archives Ishii-bō 26

Archives Ishii-bō 44-49

Archives Ishii-bō 54

Archives Ishii-bō 56

Archives Ishii-bō 57

Archives Ishii-bō 73

Archives Ishii-bō 75

Archives Ishii-bō 78

Archives Ishii-bō 79
Archives Ishii-bō 9I

Archives Ishii-bō 95-107 et 517

Archives Ishii-bō I08

Archives Ishii-bō ro9

Archives Ishii-bō 129

Archives Ishii-bō 223

Archives Ishii-bō 262, 266

Archives Ishii-bō 263

Archives Ishii-bō 540 


\section{Documents annexes}

Tableau I : Calendrier du sommet de printemps (Katsuragi $\mathrm{H}^{\mathrm{H}}$ 城) du shugen du mont Hōman

\begin{tabular}{|c|c|c|c|}
\hline 月日 & 明和 4 年 (1767) & 文化9年 (I8I2) & 安政7年 (1860) \\
\hline $3 \cdot 21$ & & & 宝満出立 $\rightarrow$ 若杉山上宮宿 \\
\hline $3 \cdot 22$ & & $\begin{array}{l}\text { 宝満獅子宿出立 } \rightarrow \text { 石之童子 } \\
\rightarrow \text { 佐谷観音一宿 }\end{array}$ & $\begin{array}{l}\text { 篠栗村郷ノ原山伏谷 } \\
\text { (7日間) }\end{array}$ \\
\hline $3 \cdot 23$ & & $\begin{array}{l}\text { 若杉山(独鈷水·善無畏· } \\
\text { 上宮) }\end{array}$ & \\
\hline $3 \cdot 24$ & $\begin{array}{l}\text { 獅子宿出立 } \rightarrow \text { 石之童子 } \rightarrow \text { 佐 } \\
\text { 谷観音(山上より) }\end{array}$ & $\begin{array}{l}\text { 熊ヶ尾 } \rightarrow \text { 合野原山伏谷 } \\
\text { (29日まで) }\end{array}$ & \\
\hline $3 \cdot 25$ & $\begin{array}{l}\text { 山伏谷馸入 } \\
\text { (晦日まで6日間) }\end{array}$ & & \\
\hline $3 \cdot 28$ & & & $\begin{array}{l}\text { 萩ノ尾山神 } \rightarrow \text { 久原村葛城谷 } \\
\rightarrow \text { 白山観音一宿 }\end{array}$ \\
\hline $3 \cdot 29$ & $\begin{array}{l}\text { 萩尾越 } \rightarrow \text { 葛城山札所 } \rightarrow \text { 柳之 } \\
\text { 原札所 } \rightarrow \text { 熊野峯一宿 }\end{array}$ & $\begin{array}{l}\text { 萩尾村産神山神宮 } \rightarrow \text { 道祖神 } \\
\rightarrow \text { 葛城谷 } \rightarrow \text { 円通窟 } \rightarrow \text { 首羅山 } \\
\rightarrow \text { 久原村観音堂一宿 }\end{array}$ & $\begin{array}{l}\text { 犬鳴山 } \rightarrow \text { 鞍手郡黒丸村清水 } \\
\text { 寺観音一宿 }\end{array}$ \\
\hline $3 \cdot 30$ & & & $\begin{array}{l}\text { 札ヶ峠 } \rightarrow \text { 裏糟屋郡薦野村清 } \\
\text { 滝之薬師 } \rightarrow \text { 不動訔 } \rightarrow \text { 宗像 } \\
\text { 郡本木村 } \rightarrow \text { 鞍手郡山口村 } \rightarrow \\
\text { 上有木村谷底氏神一宿 }\end{array}$ \\
\hline $4 \cdot I$ & $\begin{array}{l}\text { 札ノ峠 } \rightarrow \text { 鞍手·糟屋境 } \rightarrow \\
\text { 脇田山 } \rightarrow \text { 鞍手郡清水寺観 } \\
\text { 音一宿 }\end{array}$ & $\begin{array}{l}\text { 犬鳴道 } \rightarrow \text { 熊野峯 } \rightarrow \text { 尾続 } \rightarrow \text { 伊 } \\
\text { 野峠 } \rightarrow \text { 札ノ峠 } \rightarrow \text { 犬鳴村庄屋 } \\
\rightarrow \text { 清水山鞍手郡黒丸村清水 } \\
\text { 山童子一宿 } \\
(* \text { 以後は鉾ノ峠から清滝に } \\
\text { 下り一宿すべし })\end{array}$ & $\begin{array}{l}\text { 赤木峠 } \rightarrow \text { 大村権現 } \rightarrow \text { 倉久 } \\
\text { 村 } \rightarrow \text { 長谷 } \rightarrow \text { 宗像郡吉留村 } \\
\text { 氏神八所宮一宿 }\end{array}$ \\
\hline $4 \cdot 2$ & $\begin{array}{l}\text { 鉾ノ峠 }(\text { 鞍手·糟屋境 }) \rightarrow \text { 清 } \\
\text { 瀧寺薬師堂 } \rightarrow \text { 荗野一宿 }\end{array}$ & $\begin{array}{l}\text { 錵之峠 } \rightarrow \text { 不動岳 } \rightarrow \text { 宗像郡元 } \\
\text { 木花供原 } \rightarrow \text { 大徳 } \rightarrow \text { 鞍手郡山 } \\
\text { 口村 } \rightarrow \text { 靡山一宿 }\end{array}$ & $\begin{array}{l}\text { 戸田ヶ嶣 } \rightarrow \text { 遠賀郡海老津 } \\
\text { 村 } \rightarrow \text { 野間村薬師 } \rightarrow \text { 高倉宮 } \\
\text { 一宿 }\end{array}$ \\
\hline $4 \cdot 3$ & $\begin{array}{l}\text { 不動岳 }(\text { 薦野の内 }) \rightarrow \text { 花供原 } \\
(\text { 鞍手郡山口の内 }) \rightarrow \text { 靡山 } \\
\text { 牛頭天王一宿 }\end{array}$ & $\begin{array}{l}\text { 本木村 } \rightarrow \text { 赤木峠道祖神 } \rightarrow \text { 大 } \\
\text { 村峠 } \rightarrow \text { 風橋山大村権現 } \rightarrow \text { 地 } \\
\text { 蔵峠 } \rightarrow \text { 長谷村 } \rightarrow \text { 釈迦獄 }(\text { 鞍 } \\
\text { 手·遠賀·宗像三郡境 }) \rightarrow \text { 吉留 } \\
\text { 村八所宮一宿 }\end{array}$ & $\begin{array}{l}\text { 吉木村·三吉·手野·内浦 } \rightarrow \\
\text { 宗像郡池田村一宿 }\end{array}$ \\
\hline $4 \cdot 4$ & $\begin{array}{l}\text { 地蔵獄 }(\text { 鞍手·宗像境 }) \rightarrow \text { 釈 } \\
\text { 迦岳 }(\text { 遠賀·鞍手·宗像境 }) \rightarrow \\
\text { ト夕岳 } \rightarrow \text { 蔦ヶ魰 } \rightarrow \text { 赤間一宿 }\end{array}$ & $\begin{array}{l}\text { 戸田岳 } \rightarrow \text { 高倉宮 } \rightarrow \text { 孔寺権現 } \\
(6 \text { 日まで) }\end{array}$ & $\begin{array}{l}\text { 池田村孔大寺山(二夜三日 } \\
\text { 護摩供、六日朝まで) }\end{array}$ \\
\hline $4 \cdot 5$ & $\begin{array}{l}\text { 孔大寺権現 }(6 \text { 日·7日逗留、 } \\
\text { 8日出立) }\end{array}$ & & \\
\hline $4 \cdot 6$ & & $\begin{array}{l}\text { 孔大寺山碑伝建 } \rightarrow \text { 池田村 } \\
\rightarrow \text { 田野 } \rightarrow \text { 上八 } \rightarrow \text { 鐘崎織幡 } \\
\text { 宮一宿 }\end{array}$ & $\begin{array}{l}\text { 孔大寺山出立 } \rightarrow \text { 池田村 } \rightarrow \\
\text { 田野村 } \rightarrow \text { 上八村 } \rightarrow \text { 鐘崎織 } \\
\text { 幡宮一宿 }\end{array}$ \\
\hline
\end{tabular}




\begin{tabular}{|c|c|c|c|}
\hline $4 \cdot 7$ & & $\begin{array}{l}\text { 不動窟 (吉田村鎮国寺境 } \\
\text { 内) } \rightarrow \text { 田嶋第一宮 }(\text { 宗像宮 }) \rightarrow \\
\text { 東郷村 } \rightarrow \text { 光岡村八幡宮一宿 }\end{array}$ & $\begin{array}{l}\text { 吉田村鎮国寺 } \rightarrow \text { 田嶋宮 } \rightarrow \text { 大 } \\
\text { 井 } \rightarrow \text { 村山田 } \rightarrow \text { 東鄉摩利支 } \\
\text { 天 } \rightarrow \text { 光岡村氏神八幡宮一宿 }\end{array}$ \\
\hline $4 \cdot 8$ & $\begin{array}{l}\text { 孔大寺山出立 } \rightarrow \text { 吉田不動 } \rightarrow \\
\text { 屏風山 } \rightarrow \text { 第一宮 } \rightarrow \text { 光岡八幡 } \\
\rightarrow \text { 許斐山 }\end{array}$ & $\begin{array}{l}\text { 王丸村八幡宮 } \rightarrow \text { 許斐山 } \rightarrow \text { 中 } \\
\text { 宮 } \rightarrow \text { 上宮 } \rightarrow \text { 並村龍ヶ畠 } \rightarrow \\
\text { 笾内村産神若一皇子宮 }(\text { 以前 } \\
\text { は宝満宮)一宿 }\end{array}$ & $\begin{array}{l}\text { 大丸氏神 } \rightarrow \text { 許斐山 } \rightarrow 八 \text { 並 } \\
\text { 村 } \rightarrow \text { 畎町檀ノ原 } \rightarrow \text { 䇥内村 } \\
\text { 氏神一宿 }\end{array}$ \\
\hline $4 \cdot 9$ & $\begin{array}{l}\text { 八並 } \rightarrow \text { 畦町 } \rightarrow \text { 青柳 } \rightarrow \text { 新宮 } \\
\text { 社一宿 }\end{array}$ & $\begin{array}{l}\text { 青柳村 } \rightarrow \text { 訔越山 } \rightarrow \text { 上之符村 } \\
\text { 社 } \rightarrow \text { 鎮護大明神 } \rightarrow \text { 䈆掛弁財 } \\
\text { 天 } \rightarrow \text { 新宮浦 } \rightarrow \text { 三苫 } \rightarrow \text { 和白浜 } \\
\text { 男 } \rightarrow \text { 香椎宮 } \rightarrow \text { 名島弁財天 }\end{array}$ & $\begin{array}{l}\text { 青柳宿 } \rightarrow \text { 获越山 } \rightarrow \text { 上府 } \rightarrow \\
\text { 下府 } \rightarrow \text { 新宮浦 } \rightarrow \text { 三苫村氏 } \\
\text { 神 } \rightarrow \text { 浜男 } \rightarrow \text { 香椎宮 } \rightarrow \text { 名島弁 } \\
\text { 財天一宿 }\end{array}$ \\
\hline $4^{\cdot}$ IO & $\begin{array}{l}\text { 笈掛弁財天 } \rightarrow \text { 香椎宮 } \rightarrow \text { 管崎 } \\
\text { 宮 } \rightarrow \text { 崇福寺 } \rightarrow \text { 博多中市小路 } \\
\text { 地蔵 } \rightarrow \text { 東長寺 } \rightarrow \text { 櫛田宮柴燈 } \\
\text { 護摩供一宿 }\end{array}$ & $\begin{array}{l}\text { 筼崎宮 } \rightarrow \text { 博多魚町地蔵堂 } \\
\rightarrow \text { 東長寺 } \rightarrow \text { 櫛田宮華供大護 } \\
\text { 摩一宿 }\end{array}$ & $\begin{array}{l}\text { 箱崎八幡宮 } \rightarrow \text { 博多諸社勤 } \\
\text { 行 } \rightarrow \text { 櫛田宮一宿 }\end{array}$ \\
\hline $4^{\cdot} \mathrm{II}$ & $\begin{array}{l}\text { 今熊権現 } \rightarrow \text { 城内 }(\text { 弾正扇坂 } \\
\text { 屋敷 } \rightarrow \text { 若一王寺 } \rightarrow \text { 地蔵谷地 } \\
\text { 蔵堂) } \rightarrow \text { 元警固 } \rightarrow \text { 春日社 } \rightarrow \\
\text { 武蔵寺薬師堂一宿 }\end{array}$ & $\begin{array}{l}\text { 今熊権現 } \rightarrow \text { 城内 }(\text { 大日堂 } \rightarrow \text { 扇 } \\
\text { 坂 } \rightarrow \text { 地蔵堂 } \rightarrow \text { 本丸祈祷 } \rightarrow \text { 若 } \\
\text { 一皇子 } \rightarrow \text { 松木坂 } \rightarrow \text { 屋敷 }) \rightarrow \\
\text { 桜峯山勝軍地蔵 } \rightarrow \text { 古小鳥 } \rightarrow \\
\text { 警固大明神 } \rightarrow \text { 一本木 } \rightarrow \text { 高宮 } \\
\text { 村神社一宿 }\end{array}$ & $\begin{array}{l}\text { 城内本丸 } \rightarrow \text { 御舘大護摩 } \rightarrow \text { 裏 } \\
\text { 門 } \rightarrow \text { 古小鳥神社 } \rightarrow \text { 高宮村 } \\
\text { 氏神一宿 }\end{array}$ \\
\hline $4 \cdot I 2$ & 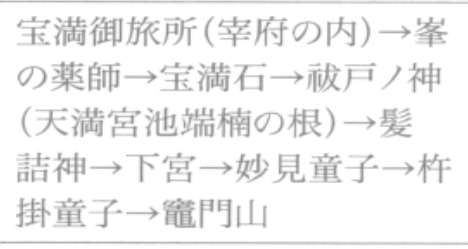 & $\begin{array}{l}\text { 野間村 } \rightarrow \text { 井尻橋 } \rightarrow \text { 春日神社 } \\
\rightarrow \text { 大利村 } \rightarrow \text { 吉松 } \rightarrow \text { 佐野 } \rightarrow \text { 杉 } \\
\text { 塚村 } \rightarrow \text { 武蔵寺 } \rightarrow \text { 湯町 } \rightarrow \text { 二日 } \\
\text { 市 } \rightarrow \text { 峯の薬師一宿 }\end{array}$ & $\begin{array}{l}\text { 麦野松原 } \rightarrow \text { 春日神社 } \rightarrow \text { 武蔵 } \\
\text { 寺薬師 } \rightarrow \text { 天拝山 } \rightarrow \text { 二市 } \rightarrow \\
\text { 峯の薬師一宿 }\end{array}$ \\
\hline \multirow[t]{2}{*}{$4^{\cdot} \mathrm{I} 3$} & $\begin{array}{l}12 \text { 日㷌山、1 5日まで後日 } \\
\text { の執行 }\end{array}$ & $\begin{array}{l}\text { 宝満宮御旅殿 } \rightarrow \text { 五条橋 } \rightarrow \text { 宝 } \\
\text { 満石 } \rightarrow \text { 祓戸神社 } \rightarrow \text { 髪結神 } \rightarrow \\
\text { 宝満下宮 } \rightarrow \text { 妙見社 } \rightarrow \text { 太田社 } \\
\rightarrow \text { 住吉社 } \rightarrow \text { 小田社 } \rightarrow \text { 山王社 } \\
\rightarrow \text { 弁財社 }\end{array}$ & $\begin{array}{l}\text { 太峷府町 } \rightarrow \text { 天満宮 } \rightarrow \text { 延寿 } \\
\text { 王院裏 } \rightarrow \text { 内山村下宮 }\end{array}$ \\
\hline & 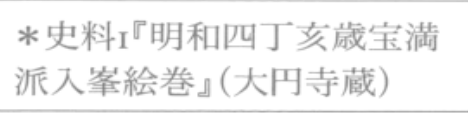 & $\begin{array}{l}\text { *史料 } 2 \text { 『葛城峯中花供道案 } \\
\text { 内』(石井坊文書) }\end{array}$ & $\begin{array}{l}\text { *史料 } 3 \text { 『葛城峯中日割道筋 } \\
\text { 之事』(叶院蔵) }\end{array}$ \\
\hline
\end{tabular}

D'après les documents I, « Rouleau peint de l'entrée dans la montagne de la branche Hōman », Hōman-ba nyübu emaki 宝满派入笔絵巻 de 1767 (Meiwa 4) (Daien-ji 大圆寺) ; 2, "Guide de l'offrande des fleurs de l'entrée dans la montagne

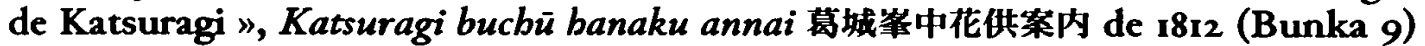
(Archives Ishii-bō 73) ; 3, "Calendrier et itinéraire de l'entrée dans la montagne de Katsuragi ", Katsuragi bucbū biwari michisuji no koto 葛城峯中日割り道筋之事 de I860 (Ansei 7) (Kanae-in 叶院). 
Tableau II : « Registre des rites 》, Gokitō bikae kiroku 御行裙 控 記録 (d'après archives Ishii-bō 109)

\begin{tabular}{|c|c|c|c|c|c|c|c|c|}
\hline & 実施年 & 西暦 & 日時 & 祈䘠の種類 & 願主 & 初穂 & $\begin{array}{l}\text { 祈䘠札 } \\
\text { など }\end{array}$ & 備考 \\
\hline I & 文化 $I I$ & I8I4 & & $\begin{array}{l}\text { 正五九月御 } \\
\text { 祈䘠 }\end{array}$ & $\begin{array}{l}\text { 御新 } \\
\text { 間様 }\end{array}$ & 金IOO㱜 & $\begin{array}{l}\text { 祈䘠札 } \\
\text { 守·鏡餅 } \\
\text { 指上 }\end{array}$ & $\begin{array}{l}\text { 取次松原権七廊・ } \\
\text { 西原三九郎 }\end{array}$ \\
\hline 2 & 文化 12 & $\mathrm{I} 8 \mathrm{I} 5$ & & $\begin{array}{l}\text { 正五九月御 } \\
\text { 祈䘠 }\end{array}$ & $\begin{array}{l}\text { 御新 } \\
\text { 間様 }\end{array}$ & 金IOO㱜 & $\begin{array}{l}\text { 祈䘠札 } \\
\text { 守·鏡餅 } \\
\text { 指上 }\end{array}$ & $\begin{array}{l}\text { 取次松原権七廊・ } \\
\text { 西原三九郎 }\end{array}$ \\
\hline 3 & 文化 ${ }_{13}$ & I8I6 & & $\begin{array}{l}\text { 正五九月御 } \\
\text { 祈䘠 }\end{array}$ & $\begin{array}{l}\text { 御新 } \\
\text { 間様 }\end{array}$ & 金IOO㱜 & $\begin{array}{l}\text { 祈䘠札 } \\
\text { 守·鏡餅 } \\
\text { 指上 }\end{array}$ & $\begin{array}{l}\text { 取次松原権七廊· } \\
\text { 西原三九郎 }\end{array}$ \\
\hline 4 & 文化I4 & I8I7 & & $\begin{array}{l}\text { 正五九月御 } \\
\text { 祈䘠 }\end{array}$ & $\begin{array}{l}\text { 御新 } \\
\text { 間様 }\end{array}$ & 金IOO㱜 & $\begin{array}{l}\text { 祈祷札 } \\
\text { 守·鏡餅 } \\
\text { 指上 }\end{array}$ & $\begin{array}{l}\text { 取次松原権七廊· } \\
\text { 西原三九郎 }\end{array}$ \\
\hline 5 & 文政I & I8I8 & & $\begin{array}{l}\text { 正五九月御 } \\
\text { 祈䘠 }\end{array}$ & $\begin{array}{l}\text { 御新 } \\
\text { 間様 }\end{array}$ & 金IOO疋 & $\begin{array}{l}\text { 祈䘠札 } \\
\text { 守·鏡餅 } \\
\text { 指上 }\end{array}$ & $\begin{array}{l}\text { 取次松原権七廊・ } \\
\text { 西原三九郎 }\end{array}$ \\
\hline 6 & 文政2 & I8I9 & & $\begin{array}{l}\text { 正五九月御 } \\
\text { 祈䘠 }\end{array}$ & $\begin{array}{l}\text { 御新 } \\
\text { 間様 }\end{array}$ & 金IOO㱜 & $\begin{array}{l}\text { 秋より鏡 } \\
\text { 餅お断り }\end{array}$ & $\begin{array}{l}\text { 取次松原権七廊・ } \\
\text { 西原三九郎 }\end{array}$ \\
\hline 7 & 文政3 & 1820 & & $\begin{array}{l}\text { 正五九月御 } \\
\text { 祈䘠 }\end{array}$ & $\begin{array}{l}\text { 御新 } \\
\text { 間様 }\end{array}$ & $\begin{array}{l}\text { 金子I両 } \\
\text { I分 }\end{array}$ & $\begin{array}{l}\text { 祈䘠札守 } \\
\text { は正月だ } \\
\text { け納 }\end{array}$ & $\begin{array}{l}\text { 取次大工町安東 } \\
\text { 十八 }\end{array}$ \\
\hline 8 & 文政4 & $182 \mathrm{I}$ & & $\begin{array}{l}\text { 正五九月御 } \\
\text { 祈䘠 }\end{array}$ & $\begin{array}{l}\text { 御新 } \\
\text { 間様 }\end{array}$ & $\begin{array}{l}\text { 金子I両 } \\
\text { I分 }\end{array}$ & $\begin{array}{l}\text { 祈䘠札 } \\
\text { 守·鏡餅 } \\
\text { 指上 }\end{array}$ & $\begin{array}{l}\text { 取次大工町安東 } \\
\text { 十八 }\end{array}$ \\
\hline 9 & 文政2 & I8I9 & $\begin{array}{l}\text { I } / \mathrm{I} \\
\sim \mathrm{I} / 3\end{array}$ & $\begin{array}{l}\text { 郡中諸種成就 } \\
\text { 祈䘠 }\end{array}$ & $\begin{array}{l}\text { 郡代役 } \\
\text { 所 }\end{array}$ & 5o目 & $\begin{array}{l}\text { 郡中村々 } \\
\text { I枚宛 } \\
59 \text { 枚 }\end{array}$ & $\begin{array}{l}\text { 御役所 I枚·大庄屋 } \\
\text { 3人I枚宛 }\end{array}$ \\
\hline IO & 文政2 & I8I9 & $3 \sim 6$ & 請日祈祷 & 郡中 & 50目 & & $\begin{array}{l}\text { 朝八本勒祈䘠開白 } \\
\text { 法·昼八火天供·夜 } \\
\text { 八仁王経各I座 }\end{array}$ \\
\hline II & 文政3 & 1820 & $\begin{array}{l}4^{/ 3} \\
\sim 4 / 7\end{array}$ & 請日祈祷 & 郡中 & 30目 & & $\begin{array}{l}\text { 郡代竹森安佐右 } \\
\text { 衛門 }\end{array}$ \\
\hline I2 & 文化 ${ }_{\mathrm{I} 3}$ & I8I6 & $\begin{array}{l}\text { 結願 } \\
3 / 18\end{array}$ & 春分祈祷 & 三触 & I触70目 & & $\begin{array}{l}\text { 3触大庄屋外に } 1 \text { 触 } \\
\text { 2人ずつ·郡代竹森 } \\
\text { 武右衛門 }\end{array}$ \\
\hline 13 & 文化 ${ }_{\text {I4 }}$ & I8I7 & & 春分祈祷 & 三触 & I触70目 & & \\
\hline I4 & 文化IS & I8I8 & & 春分祈䘠 & 三触 & I触70目 & & \\
\hline IS & 文政2 & I8I9 & & 春分祈䘠 & 三触 & I触30目 & & $\begin{array}{l}\text { 結願日の参詣相 } \\
\text { 止む }\end{array}$ \\
\hline I6 & 文政3 & 1820 & & $\begin{array}{l}\text { 3月定日之 } \\
\text { 祈䘠 }\end{array}$ & 三触 & 1触30目 & & $\begin{array}{l}\text { 江辻触分 } 4 \text { 月 } 3 \text { 日に } \\
\text { 神納 }\end{array}$ \\
\hline
\end{tabular}




\begin{tabular}{|c|c|c|c|c|c|c|c|c|}
\hline 17 & 文政3 & I820 & $\begin{array}{l}6 / 20 \\
\sim 6 / 22\end{array}$ & $\begin{array}{l}\text { 日乞祈䘠二夜 } \\
\text { 三日 }\end{array}$ & 御上 & 6銭50目 & & 郡代役所より神納 \\
\hline I8 & 文政4 & $\mathrm{I} 82 \mathrm{I}$ & $\begin{array}{l}\text { I/I } \\
\sim \text { I/3 }\end{array}$ & 豊年祈䘠 & $\begin{array}{l}\text { 郡代 } \\
\text { 役所 }\end{array}$ & 銀30目 & & $\begin{array}{l}\text { 郡代小嶋源五右衛 } \\
\text { 門·笹岡辰四郎 }\end{array}$ \\
\hline I9 & 文政4 & I82I & $\begin{array}{l}6 / \text { II } \\
\sim 6 / \text { I3 }\end{array}$ & $\begin{array}{l}\text { 請雨祈䘠三日 } \\
\text { 三夜 }\end{array}$ & $\begin{array}{l}\text { 郡代 } \\
\text { 役所 }\end{array}$ & 50目 & & $\begin{array}{l}\text { 郡代小嶋源五右禕 } \\
\text { 門·笹岡辰四郎- } \\
\text { I触 } 2 \text { 人宛庄屋出勤 }\end{array}$ \\
\hline 20 & 文政5 & 1822 & $\begin{array}{l}2 / 24 \\
\sim 2 / 26\end{array}$ & $\begin{array}{l}\text { 降雨祈䘠二夜 } \\
\text { 三日 }\end{array}$ & $\begin{array}{l}\text { 郡代 } \\
\text { 役所 }\end{array}$ & 6銭50目 & & $\begin{array}{l}\text { 郡代小嶋源五右衛 } \\
\text { 門·梶原市太郎 }\end{array}$ \\
\hline $2 I$ & 文政5 & 1822 & $\begin{array}{l}\text { I } / \mathrm{I} \\
\sim \mathrm{I} / 3\end{array}$ & $\begin{array}{l}\text { 豊年祈䘠二夜 } \\
\text { 三日 }\end{array}$ & $\begin{array}{l}\text { 郡代 } \\
\text { 役所 }\end{array}$ & 銀I5多 & & $\begin{array}{l}\text { 倹約二付初穂減。 } \\
\text { 郡代小嶋源五右衛 } \\
\text { 門·梶原市太郎 }\end{array}$ \\
\hline 22 & 文政5 & 1822 & & 豊年祈䘠 & $\begin{array}{l}\text { 郡代 } \\
\text { 役所 }\end{array}$ & 銀I5多 & & $\begin{array}{l}\text { 郡代小嶋源五右衛 } \\
\text { 門·梶原市太郎 }\end{array}$ \\
\hline 23 & 文政5 & 1822 & 3月 & 麦作成熟新䘠 & 三触 & I触30目 & & $\begin{array}{l}\text { 江辻庄屋惣代和田 } \\
\text { 津波黒3月15日参詣 }\end{array}$ \\
\hline 24 & 文政5 & 1822 & $\begin{array}{l}6 / 28 \sim \\
\text { 晦日 }\end{array}$ & 田災銷除一座 & 江辻触 & 50目 & & 大庄屋卯平 \\
\hline 25 & 文政5 & 1822 & $7 / 1 \sim 3$ & $\begin{array}{l}\text { 田災銷除祈䘠 } \\
\text { 一座 }\end{array}$ & $\begin{array}{l}\text { 郡代 } \\
\text { 役所 }\end{array}$ & 50 目 & & $\begin{array}{l}\text { 郡代小嶋源五右衛 } \\
\text { 門·梶原市太郎 }\end{array}$ \\
\hline 26 & 文政6 & 1823 & $3 / 15$ & $\begin{array}{l}\text { 麦作成熟新䘠 } \\
\text { 二夜三日 }\end{array}$ & 三触 & I触30目 & & $\begin{array}{l}\text { I触より2人宛惣代 } \\
\text { 庄屋参詣・大庄屋 } \\
\text { 卯平 }\end{array}$ \\
\hline 27 & 文政6 & 1823 & $\begin{array}{l}6 / 18 \\
\sim 6 / 20\end{array}$ & 請雨祈䘠 & 御上 & 6銭50目 & $\begin{array}{l}\text { 20日雨 } \\
\text { 7ル21日二大 } \\
\text { 雨7ル }\end{array}$ & $\begin{array}{l}\text { 郡代小嶋源五右衛 } \\
\text { 門·梶原市太郎 }\end{array}$ \\
\hline 28 & 文政6 & I823 & $\begin{array}{l}7 / 27 \\
\sim 7 / 29\end{array}$ & 請雨祈䘠 & & 50目 & & $\begin{array}{l}\text { 大庄屋卯平・小嶋 } \\
\text { 源五右衛門・梶原 } \\
\text { 市太郎 }\end{array}$ \\
\hline 29 & 文政6 & 1823 & $\begin{array}{l}8 / \mathrm{I} \\
\sim 8 / 8\end{array}$ & 大雲輪法一座 & 郡中 & & $\begin{array}{l}\text { 7日7ツ頃よ } \\
\text { り少雨、 } \\
\text { 8日の暮 } \\
\text { 頃より大 } \\
\text { 洪水郡中 } \\
\text { 喜悦 }\end{array}$ & $\begin{array}{l}\text { 発起 郡代小嶋· } \\
\text { 梶原・大庄屋卯平 }\end{array}$ \\
\hline 30 & 文政6 & 1823 & 9/10 & & 郡中 & $\begin{array}{l}\text { I人宛6銭 } \\
35 \text { 多 }\end{array}$ & & $\begin{array}{l}\text { I日に付夫 } 2 \text { 人宛り } \\
\text { 詰方 }\end{array}$ \\
\hline $3 I$ & 文政7 & 1824 & $\begin{array}{l}\mathrm{I} / \mathrm{I} \\
\sim_{\mathrm{I}} / 3\end{array}$ & 豊年祈䘠 & $\begin{array}{l}\text { 郡代 } \\
\text { 役所 }\end{array}$ & 銀I5多目 & & \\
\hline 32 & 文政7 & I824 & $3 / 15$ & $\begin{array}{l}\text { 麦作成熟新䘠 } \\
\text { 二夜三日 }\end{array}$ & 三触 & I触30目 & & 惣代·庄屋参詣 \\
\hline 33 & 文政7 & I824 & $\begin{array}{l}3 / 18 \\
\sim 3 / 20\end{array}$ & 止雨祈䘠一座 & $\begin{array}{l}\text { 郡代·大 } \\
\text { 庄屋 }\end{array}$ & 50目 & & $\begin{array}{l}\text { 郡代小嶋源五右衛 } \\
\text { 門·三木権六·大庄 } \\
\text { 屋卯平 }\end{array}$ \\
\hline
\end{tabular}




\begin{tabular}{|c|c|c|c|c|c|c|c|c|}
\hline 34 & 文政7 & I824 & $\begin{array}{l}5 / 29 \\
\sim 6 / 1\end{array}$ & 請雨祈䘠 & $\begin{array}{l}\text { 郡代·大 } \\
\text { 庄屋 }\end{array}$ & 50目 & & $\begin{array}{l}\text { 郡代小嶋源五右衛 } \\
\text { 門·三木権六・大庄 } \\
\text { 屋卯平 }\end{array}$ \\
\hline 35 & 文政7 & 1824 & $\begin{array}{l}6 / 28 \\
\sim 7 / \mathrm{I}\end{array}$ & 止雨祈䘠 & $\begin{array}{l}\text { 郡代·大 } \\
\text { 庄屋·郡 } \\
\text { 中惣代 }\end{array}$ & 50目 & & \\
\hline 36 & 文政8 & 1825 & $\begin{array}{l}\text { 正月元 } \\
\text { 旦 } 3\end{array}$ & $\begin{array}{l}\text { 豊年諸種成就 } \\
\text { 祈䘠 }\end{array}$ & $\begin{array}{l}\text { 郡代·大 } \\
\text { 庄屋 }\end{array}$ & 銀15多 & & $\begin{array}{l}\text { 郡代小嶋源五右衛 } \\
\text { 門·大庄屋卯平 }\end{array}$ \\
\hline 37 & 文政8 & 1825 & $\begin{array}{l}3 / 10 \\
\sim 12\end{array}$ & 止雨祈䘠 & $\begin{array}{l}\text { 郡代·大 } \\
\text { 庄屋 }\end{array}$ & 6銭50目 & & $\begin{array}{l}\text { 郡代小嶋源五右衛 } \\
\text { 門·大庄屋卯平 }\end{array}$ \\
\hline 38 & 文政8 & 1825 & $3 / 15$ & \begin{tabular}{|l} 
麦作成熟祈 \\
䘠一座三日 \\
三夜
\end{tabular} & 三触 & I触30目 & & $\begin{array}{l}\text { 郡中惣代庄屋·大 } \\
\text { 隈村条七·名子村 } \\
\text { 源七 }\end{array}$ \\
\hline 39 & 文政8 & 1825 & $\begin{array}{l}4 / \mathrm{II} \\
\sim_{\mathrm{I} 3}\end{array}$ & 止雨祈䘠一座 & $\begin{array}{l}\text { 郡代·大 } \\
\text { 庄屋 }\end{array}$ & 6銭50目 & & $\begin{array}{l}\text { 小嶋源五右衛門· } \\
\text { 大庄屋卯平 }\end{array}$ \\
\hline 40 & 文政8 & 1825 & $6 / 2 \sim 4$ & 止雨祈䘠一座 & $\begin{array}{l}\text { 惣代庄 } \\
\text { 屋·郡代· } \\
\text { 大庄屋 }\end{array}$ & 6銭50目 & & $\begin{array}{l}\text { 上山田村条次郎· } \\
\text { 下山田村利平・小 } \\
\text { 嶋源五右衛門·大 } \\
\text { 庄屋卯平 }\end{array}$ \\
\hline $4 \mathrm{I}$ & 文政8 & 1825 & $7 / 7 \sim 9$ & 止雨祈䘠一座 & $\begin{array}{l}\text { 郡代·大 } \\
\text { 庄屋 }\end{array}$ & 6銭50目 & & \begin{tabular}{|l} 
郡代小嶋源五右衛 \\
門·大庄屋卯平
\end{tabular} \\
\hline 42 & 文政8 & 1825 & $7 / 16$ & $\begin{array}{l}\text { 請日祈䘠御礼 } \\
\text { 参詣 }\end{array}$ & 三触 & 6銭50目 & & $\begin{array}{l}\text { 大庄屋卯平・尾仲 } \\
\text { 村庄屋安七·江辻 } \\
\text { 触庄屋江辻村惣次 } \\
\text { 郎·旅石触㗙代·須 } \\
\text { 恵村庄屋清市·須 } \\
\text { 恵村庄屋賀藏 }\end{array}$ \\
\hline 43 & 文政9 & 1826 & $\begin{array}{l}\text { 正月元 } \\
\text { 旦 }\end{array}$ & 豊年祈䘠 & 大庄屋 & 銀30目 & & 大庄屋卯平 \\
\hline 44 & 文政9 & 1826 & $3 / 14$ & $\begin{array}{l}\text { 恒例の祭礼· } \\
\text { 麦作祈䘠 }\end{array}$ & 大庄屋 & I触30目 & & $\begin{array}{l}\text { 江辻触・戸原触・ } \\
\text { 旅石触 }\end{array}$ \\
\hline 45 & 文政8 & 1825 & 9月建立 & 永代常夜燈 & $\begin{array}{l}\text { 大庄屋 } \\
\text { 発起 }\end{array}$ & $\begin{array}{l}\text { I触米I俵 } \\
\text { 目録 } \\
\text { 入り }\end{array}$ & $\begin{array}{l}\text { 出席者や } \\
\text { 持参品、 } \\
\text { 石工の詳 } \\
\text { 細あり }\end{array}$ & $\begin{array}{l}\text { 発起·郡司·大庄 } \\
\text { 屋·旅石村·江辻 } \\
\text { 村·戸原村 }\end{array}$ \\
\hline 46 & 文政8 & 1825 & $8 / 25$ & $\begin{array}{l}\text { 〔上宮渡殿盗 } \\
\text { 人の件〕 }\end{array}$ & & & $\begin{array}{l}\text { 破損品明 } \\
\text { 細有り }\end{array}$ & $\begin{array}{l}\text { 植木村百姓源助· } \\
\text { 庄屋藤次郎・組頭 } \\
\text { 勘吉 }\end{array}$ \\
\hline 47 & 文政IO & 1827 & $\begin{array}{l}3 / 14 \\
\sim 16\end{array}$ & $\begin{array}{l}\text { 麦作成熟祈䘠 } \\
\text { 一座 }\end{array}$ & $\begin{array}{l}\text { 郡中·惣 } \\
\text { 代庄屋 }\end{array}$ & I触30目 & & 恒例祭礼 \\
\hline 48 & 文政IO & 1827 & $4 / 6 \sim 8$ & 止雨祈䘠一座 & $\begin{array}{l}\text { 郡司·大 } \\
\text { 庄屋 }\end{array}$ & 50目 & & \\
\hline 49 & 文政9 & 1826 & 8月 & 操り風留祈願 & \begin{tabular}{|l} 
郡代·大 \\
庄屋
\end{tabular} & 15 多 & & $\begin{array}{l}\text { 願成就 } 4 \text { 月 } 8 \text { 日 } \\
\text { 役所より一人出る }\end{array}$ \\
\hline
\end{tabular}




\begin{tabular}{|c|c|c|c|c|c|c|c|}
\hline 50 & 文政IO & 1827 & $10 / 24$ & $\begin{array}{l}\text { 〔本尊大山祇 } \\
\text { 命勧請の件〕 } \\
\text { 乙戊 }\end{array}$ & $\begin{array}{l}\text { 博多大 } \\
\text { 浜町立 } \\
\text { 石又右 } \\
\text { 衛門 }\end{array}$ & & $\begin{array}{l}\text { 勧請にあたって石 } \\
\text { 筒一宇 }\end{array}$ \\
\hline $5 \mathrm{I}$ & 文政II & 1828 & $\begin{array}{l}\text { 正月元 } \\
\text { 旦 } 3\end{array}$ & 豊年祈䘠一座 & $\begin{array}{l}\text { 郡司·大 } \\
\text { 庄屋 }\end{array}$ & & \\
\hline 52 & 文政II & 1828 & $\begin{array}{l}3 / 14 \\
\sim 16\end{array}$ & 麦作成熟新䘠 & $\begin{array}{l}\text { 郡司·大 } \\
\text { 庄屋·惣 } \\
\text { 代庄屋 }\end{array}$ & I触30目 & 三月祭礼 \\
\hline 53 & 文政II & 1828 & $4 / 21$ & $\begin{array}{l}\text { 〔護摩堂萱替 } \\
\text { の件〕 }\end{array}$ & 当村中 & \begin{tabular}{|l} 
軒別萱 \\
一荷
\end{tabular} & 庄屋 \\
\hline 54 & 文政II & 1828 & $\begin{array}{l}5 / 12 \\
\sim 14\end{array}$ & 請雨祈䘠一座 & $\begin{array}{l}\text { 郡代·大 } \\
\text { 庄屋 }\end{array}$ & 6銭50目 & $\begin{array}{l}\text { 5月中II日用水少し } \\
\text { 13日少雨 14日 } \\
\text { 夕少雨 }\end{array}$ \\
\hline 55 & 文政II & 1828 & $\begin{array}{l}8 / 25 \\
\sim 27\end{array}$ & $\begin{array}{l}\text { 四海安穩一 } \\
\text { 天晴静祈祷 } \\
\text { 一座 }\end{array}$ & $\begin{array}{l}\text { 郡代·大 } \\
\text { 庄屋 }\end{array}$ & 6銭50目 & $\begin{array}{l}\text { 後述8月9日24日台 } \\
\text { 風の記述 }\end{array}$ \\
\hline 56 & 文政I2 & 1829 & $\begin{array}{l}\text { 正月元 } \\
\text { 旦 } 3 \\
\end{array}$ & 豊年祈䘠一座 & $\begin{array}{l}\text { 郡代·大 } \\
\text { 庄屋 }\end{array}$ & 銀30目 & \\
\hline 57 & 文政I2 & 1829 & $\begin{array}{l}3 / 9 \\
10 / 17 \\
\end{array}$ & \begin{tabular}{|l} 
豊年祭祈䘠 \\
一座
\end{tabular} & 郡代 & I触50目 & $\begin{array}{l}\text { 御本地供·習合護 } \\
\text { 摩供·満願護摩供 }\end{array}$ \\
\hline 58 & 文政13 & 1830 & $\begin{array}{l}\text { 正月元 } \\
\text { 旦 } 3\end{array}$ & 豊年祈䘠一座 & $\begin{array}{l}\text { 郡代·大 } \\
\text { 庄屋 }\end{array}$ & 銀30目 & \\
\hline 59 & 文政13 & 1830 & $\mathrm{I} 4 \sim \mathrm{I} 6$ & \begin{tabular}{l|} 
麦作成就祭礼 \\
祈祷
\end{tabular} & $\begin{array}{l}\text { 江辻触 } \\
\text { 怱代 }\end{array}$ & I触30目 & \\
\hline 60 & 文政13 & 1830 & & & & & $\begin{array}{l}\text { 戸原村·土井村·汀 } \\
\text { 辻村 庄屋転役 }\end{array}$ \\
\hline 6I & 文政I2 & 1829 & $9 / 15$ & $\begin{array}{l}\text { 〔破損修繥成 } \\
\text { 就の件〕 }\end{array}$ & & & $\begin{array}{l}\text { 上宮石殿·鳥居額 } \\
\text { (正福禅寺仙厓和 } \\
\text { 尚筆) やり替え } \\
\text { 郡代 }\end{array}$ \\
\hline 62 & 文政13 & 1830 & $2 / 16$ & $\begin{array}{l}\text { 〔破損修繕成 } \\
\text { 就の件〕 }\end{array}$ & & & $\begin{array}{l}\text { 下宮拝殿石壇 久 } \\
\text { 原村今任氏入役 } \\
\text { 6銭60目二建ル 寄 } \\
\text { 付主庄屋 }\end{array}$ \\
\hline 63 & 文政13 & 1830 & $\begin{array}{l}7 / 13 \\
\sim 16\end{array}$ & $\begin{array}{l}\text { 蝗散除治風 } \\
\text { 祈䘠 }\end{array}$ & $\begin{array}{l}\text { 郡代·大 } \\
\text { 庄屋 }\end{array}$ & 6銭60目 & \\
\hline 64 & 文政13 & 1830 & $8 / 28$ & $\begin{array}{l}\text { 〔上宮渡殿建 } \\
\text { 替の件〕 }\end{array}$ & & & $\begin{array}{l}\text { 郡代大塚六内代 } \\
\text { 正遷座入用控 }\end{array}$ \\
\hline 65 & 天保2 & 1831 & $\begin{array}{l}\text { 正月元 } \\
\text { 旦 } 3\end{array}$ & 豊年諸種成就 & $\begin{array}{l}\text { 郡代·大 } \\
\text { 庄屋 }\end{array}$ & 銀30目 & \\
\hline 66 & 天保2 & I83I & $\begin{array}{l}2 / 20 \\
\sim 22\end{array}$ & 止雨祈䘠 & $\begin{array}{l}\text { 郡代·大 } \\
\text { 庄屋 }\end{array}$ & 6銭50目 & \\
\hline
\end{tabular}




\begin{tabular}{|c|c|c|c|c|c|c|c|c|}
\hline 67 & 天保2 & I83I & $\begin{array}{l}7 / 26 \\
\sim 28\end{array}$ & $\begin{array}{l}\text { 治風防災新 } \\
\text { 䘠二夜三日 } \\
\text { 執行 }\end{array}$ & $\begin{array}{l}\text { 郡代·大 } \\
\text { 庄屋 }\end{array}$ & $\begin{array}{l}\text { 3触より } \\
\text { 6銭8o目 } \\
\text { 新酒素麺 }\end{array}$ & & $\begin{array}{l}\text { 27日大庄屋中惣 } \\
\text { 代参詣 }\end{array}$ \\
\hline 68 & 天保3 & 1832 & $\begin{array}{l}\text { 正月元 } \\
\text { 旦 } 3\end{array}$ & 豊年祈䘠 & 郡代 & 30目 & & \\
\hline 69 & 天保3 & 1832 & $\begin{array}{l}2 / 14 \\
\sim 16\end{array}$ & 止雨祈䘠 & $\begin{array}{l}\text { 郡代·大 } \\
\text { 庄屋 }\end{array}$ & 6銭50目 & & $\begin{array}{l}\text { 15日より天気に相 } \\
\text { 成り }\end{array}$ \\
\hline 70 & 天保3 & 1832 & $\begin{array}{l}5 / 28 \\
\sim 6 / 1\end{array}$ & 降雨祈䘠 & $\begin{array}{l}\text { 郡代·大 } \\
\text { 庄屋 }\end{array}$ & 50目 & $\begin{array}{l}\text { 満座2日 } \\
\text { 降雨 }\end{array}$ & \\
\hline $7 \mathrm{I}$ & 天保3 & 1832 & $8 / 20$ & 請雨御祝䘠 & & 金2歩 & $\begin{array}{l}\text { 6月大早 } \\
\text { 魅7月2I日 } \\
\text { 大雨 }\end{array}$ & 大雲輪 \\
\hline 72 & 天保3 & 1832 & 9月 & $\begin{array}{l}\text { 〔下宮拝殿覆 } \\
\text { 替の件〕 }\end{array}$ & & & & 郡代·大庄屋 \\
\hline 73 & 天保3 & 1832 & 9月 & $\begin{array}{l}\text { 〔下宮神殿覆 } \\
\text { 替·上段内陳 } \\
\text { の件他〕 }\end{array}$ & & & & \\
\hline 74 & 天保3 & 1832 & $10 / 9$ & $\begin{array}{l}\text { 〔正遷座 } \\
\text { の件〕 }\end{array}$ & & & & 郡代·大庄屋 \\
\hline 75 & 天保4 & 1833 & $\begin{array}{l}\text { 正月元 } \\
\text { 旦 } 3\end{array}$ & $\begin{array}{l}\text { 豊年諸種成就 } \\
\text { 祈䘠 }\end{array}$ & 郡代 & 銀30目 & & \\
\hline 76 & 天保4 & 1833 & ${ }_{5} / 8 \sim_{12}$ & 請雨祈䘠 & 郡代 & 6銭50目 & $\begin{array}{l}\text { 5日田植え } \\
\text { 延引 I2 } \\
\text { 日夕方大 } \\
\text { 雨13日 }\end{array}$ & $\begin{array}{l}\text { 上宮登山、大庄屋 } \\
\text { 同行 }\end{array}$ \\
\hline 77 & 天保4 & 1833 & $7 / 25$ & 治風防災祈䘠 & $\begin{array}{l}\text { 大庄屋· } \\
\text { 庄屋 }\end{array}$ & 50 目 & & \\
\hline 78 & 天保5 & I834 & $\begin{array}{l}\text { 正月元 } \\
\text { 旦 } 3\end{array}$ & 豊年諸種成就 & \begin{tabular}{|l} 
戸原触 \\
㥎代
\end{tabular} & 6銭50目 & & \\
\hline 79 & 天保5 & 1834 & $3 / 14$ & 麦作祈祷 & $\begin{array}{l}\text { 郡代·大 } \\
\text { 庄屋·笹 } \\
\text { 栗触 }\end{array}$ & $\begin{array}{l}3 \text { 触6銭 } \\
90 \text { 目 }\end{array}$ & & 恒例 \\
\hline 80 & 天保5 & 1834 & $3 / 26$ & $\begin{array}{l}\text { 〔侍従樣の御 } \\
\text { 山诵〕 }\end{array}$ & & & & \begin{tabular}{|c|} 
当坊をにて小休 \\
29日㷌城
\end{tabular} \\
\hline $8 \mathrm{I}$ & 天保5 & 1834 & $\begin{array}{l}5 / 25 \\
\sim 27\end{array}$ & 請雨祈䘠 & $\begin{array}{l}\text { 郡代·大 } \\
\text { 庄屋 }\end{array}$ & 6銭50目 & $\begin{array}{l}27 \cdot 28 \text { 日夕 } \\
\text { から降雨 }\end{array}$ & \\
\hline 82 & 天保5 & I834 & $7 / 6 \sim 8$ & 降雨祈䘠 & $\begin{array}{l}\text { 大庄屋· } \\
\text { 庄屋惣 } \\
\text { 代 }\end{array}$ & 50目 & & $\begin{array}{l}\text { 笹栗大庄屋の退役 } \\
\text { と着任 }\end{array}$ \\
\hline 83 & 天保5 & I834 & $7 / 22$ & 風祭角力奉納 & $\begin{array}{l}\text { 郡中·大 } \\
\text { 庄屋 }\end{array}$ & 銀20目 & & 下宮＼cjkstart郡中寄せ \\
\hline
\end{tabular}




\begin{tabular}{|c|c|c|c|c|c|c|c|c|}
\hline 84 & 天保 5 & I834 & $\begin{array}{l}7 / 26 \\
\sim 8 / 3\end{array}$ & 大雲輪零一座 & $\begin{array}{l}\text { 大庄屋· } \\
\text { 御山奉 } \\
\text { 行·同手 } \\
\text { 傳役 }\end{array}$ & $\begin{array}{l}\text { I坊50目 } \\
\text { 当社60目 } \\
5 \text { 分 }\end{array}$ & & $\begin{array}{l}\text { 祈䘠中庄屋中昼夜 } \\
\text { 詰方交代 }\end{array}$ \\
\hline 85 & 天保5 & I834 & 8月 & $\begin{array}{l}\text { 〔神額一面献 } \\
\text { 納の件〕 }\end{array}$ & \begin{tabular}{|l} 
山奉行 \\
角又四 \\
郎信祇 \\
ほか
\end{tabular} & & $\begin{array}{l}\text { 社木を } \\
\text { もつて製 } \\
\text { 作 }\end{array}$ & $\begin{array}{l}\text { 二川幸之進筆·祭 } \\
\text { 典奉仕触下山伏 }\end{array}$ \\
\hline 86 & 天保6 & 1835 & $\begin{array}{l}\text { 正月元 } \\
\text { 旦 } 3 \\
\end{array}$ & $\begin{array}{l}\text { 豊年諸種祈䘠 } \\
\text { 一座 }\end{array}$ & $\begin{array}{l}\text { 郡代·大 } \\
\text { 庄屋 }\end{array}$ & 銀30目 & & \\
\hline 87 & 天保6 & I835 & $2 / 6 \sim 8$ & 豊年祈䘠一座 & $\begin{array}{l}\text { 郡代·大 } \\
\text { 庄屋 }\end{array}$ & $\begin{array}{l}\text { 金100㱜 } \\
50 \text { 目 }\end{array}$ & & \\
\hline 88 & 天保6 & 1835 & $\begin{array}{l}3 / 14 \\
\sim 16 \\
\end{array}$ & 麦作成就祈䘠 & 大庄屋 & I触30目 & & \\
\hline 89 & 天保6 & 1835 & $7 / 15$ & 稲供祈䘠一座 & 大庄屋 & 50目 & & $\begin{array}{l}\text { 治風防災 角力 } \\
\text { 郡中斩 }\end{array}$ \\
\hline 90 & 天保7 & 1836 & $\begin{array}{l}\text { 正月元 } \\
\text { 旦 } 3\end{array}$ & 豊年祈䘠一座 & $\begin{array}{l}\text { 郡奉行· } \\
\text { 大庄屋 }\end{array}$ & 銀30目 & & \\
\hline 9I & 天保7 & 1836 & $\begin{array}{l}3 / 14 \\
\sim 16\end{array}$ & 麦作成就新䘠 & $\begin{array}{l}\text { 郡奉行· } \\
\text { 制代 } \\
\text { 庄屋 }\end{array}$ & I触30目 & & \\
\hline 92 & 天保7 & 1836 & $\begin{array}{l}6 / 16 \\
\sim_{18}\end{array}$ & 晴天祈䘠一座 & \begin{tabular}{|l} 
篠栗触 \\
大庄屋 \\
\end{tabular} & 正銭30目 & & 下宮参籠 \\
\hline 93 & 天保7 & 1836 & $7 / 5 \sim 10$ & $\begin{array}{l}\text { 太祖宮 一天 } \\
\text { 晴䍀 五穀豊 } \\
\text { 登 国護珠法 } \\
\text { 執行之事 }\end{array}$ & $\begin{array}{l}\text { 寺社奉 } \\
\text { 行·大 } \\
\text { 庄屋 }\end{array}$ & 正銀3枚 & & \\
\hline 94 & 天保7 & 1836 & 4/9 $\sim_{\text {II }}$ & $\begin{array}{l}\text { 牛馬病流行 } \\
\text { 二付二夜三日 } \\
\text { 祈䘠 }\end{array}$ & & IOO目 & $\begin{array}{l}\text { 牛馬掛 } \\
\text { 守り(郡中 } \\
\text { 牛馬 } \\
\text { 288I疋) }\end{array}$ & 祈䘠中惣代参詣 \\
\hline 95 & 天保8 & 1837 & $\begin{array}{l}\text { 正月元 } \\
\text { 旦 } 3\end{array}$ & 豊年祈䘠 & $\begin{array}{l}\text { 郡奉行· } \\
\text { 大庄屋 }\end{array}$ & 正銭50目 & & \\
\hline 96 & 天保8 & 1837 & $\begin{array}{l}\text { 正月 } 17 \\
\text { 日 } \sim_{19}\end{array}$ & $\begin{array}{l}\text { 止雨祈䘠麦作 } \\
\text { 豊熟 }\end{array}$ & 奉行 & 正銭50目 & & 始終正月雨天 \\
\hline 97 & 天保8 & I837 & $\begin{array}{l}2 / 13 \\
\sim 15\end{array}$ & 止雨祈䘠一座 & 郡奉行 & 正銭50目 & & $\begin{array}{l}\text { 麦作豊熟為 2月始 } \\
\text { 終雨天 }\end{array}$ \\
\hline 98 & 天保8 & I837 & $3 / 14$ & $\begin{array}{l}\text { 太祖宮祭礼御 } \\
\text { 祈祷 }\end{array}$ & $\begin{array}{l}\text { 大庄屋· } \\
\text { 惣代庄屋 }\end{array}$ & I触金I歩 & & \\
\hline 99 & 天保8 & 1837 & $\begin{array}{l}3 / 26 \sim \\
\text { 晦日 }\end{array}$ & $\begin{array}{l}\text { 〔太祖宮祭礼 } \\
\text { 祈䘠料・天地 } \\
\text { 鏡法天気快晴 } \\
\text { 麦作豊熟祈䘠 } \\
\text { 札の件〕 }\end{array}$ & $\begin{array}{l}\text { 郡奉行・ } \\
\text { 大庄屋 }\end{array}$ & 6銭150目 & & \\
\hline
\end{tabular}




\begin{tabular}{|c|c|c|c|c|c|c|c|}
\hline IOO & 天保8 & I837 & $\begin{array}{l}7 / 29 \\
\sim 8 / \mathrm{I}\end{array}$ & 治風防災祈䘠 & & & 下宮角力郡中寄せ \\
\hline IOI & 天保8 & 1837 & 8月 & $\begin{array}{l}\text { 〔上宮石垣修 } \\
\text { 復の件〕 }\end{array}$ & $\begin{array}{l}\text { 郡司·大 } \\
\text { 庄屋 }\end{array}$ & & \\
\hline 102 & 天保9 & 1838 & $\begin{array}{l}\text { 正月元 } \\
\text { 旦 } 3\end{array}$ & 豊年祈䘠一座 & $\begin{array}{l}\text { 郡奉行・ } \\
\text { 大庄屋 }\end{array}$ & 銀30目 & 郡中より \\
\hline IO3 & 天保9 & 1838 & $3 / 23$ & $\begin{array}{l}\text { 〔筑前大守少 } \\
\text { 将様の山猟〕 }\end{array}$ & & & 当坊に休泊 \\
\hline IO4 & 天保9 & 1838 & $\begin{array}{l}4 / 13 \\
\sim 14\end{array}$ & $\begin{array}{l}\text { 太祖宮祭礼麦 } \\
\text { 作寸志祈祷 }\end{array}$ & $\begin{array}{l}\text { 郡中大 } \\
\text { 庄屋·惣 } \\
\text { 代庄屋 }\end{array}$ & I触金I歩 & 御見舞素麺35抱 \\
\hline IOS & 天保9 & 1838 & $6 / 2 \sim 4$ & $\begin{array}{l}\text { 太祖宮天気快 } \\
\text { 晴五穀成就祈 } \\
\text { 䘠一座 }\end{array}$ & $\begin{array}{l}\text { 郡司·大 } \\
\text { 庄屋 }\end{array}$ & 正銭30目 & \\
\hline 106 & 天保9 & 1838 & $\begin{array}{l}9 / 18 \\
\sim 20\end{array}$ & $\begin{array}{l}\text { 太祖宮天気快 } \\
\text { 晴五穀豊穣祈 } \\
\text { 䘠二夜三日 }\end{array}$ & $\begin{array}{l}\text { 郡奉行· } \\
\text { 大庄屋 }\end{array}$ & 正銭50目 & \\
\hline 107 & 天保IO & I839 & $\begin{array}{l}\text { 正月元 } \\
\text { 旦 } 3\end{array}$ & 豊年祈䘠一座 & $\begin{array}{l}\text { 郡司·大 } \\
\text { 庄屋 }\end{array}$ & 正金2歩 & \\
\hline 108 & 天保IO & I839 & $2 / 7 \sim 9$ & $\begin{array}{l}\text { 太祖宮天気快 } \\
\text { 晴五穀成就祈 } \\
\text { 䘠一座 }\end{array}$ & $\begin{array}{l}\text { 郡司•大 } \\
\text { 庄屋 }\end{array}$ & 銭 50 目 & $\begin{array}{l}\text { 正月中始終雨天 } \\
\text { 郡中惣代庄屋参詣 }\end{array}$ \\
\hline I09 & 天保IO & 1839 & $3 / 14$ & $\begin{array}{l}\text { 太祖宮祭祀麦 } \\
\text { 作豊饒祈祷 } \\
\text { 一座 }\end{array}$ & $\begin{array}{l}\text { 郡司· } \\
\text { 三触 }\end{array}$ & 金三歩 & 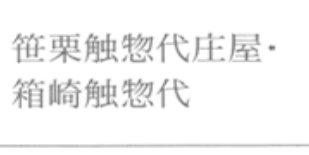 \\
\hline IIO & 天保IO & 1839 & $7 / 1 \sim 3$ & $\begin{array}{l}\text { 太祖宮蝗退散 } \\
\text { 祈䘠一座 }\end{array}$ & $\begin{array}{l}\text { 大庄屋· } \\
\text { 触中庄 } \\
\text { 屋·組頭 }\end{array}$ & 正銀I枚 & 目録入 \\
\hline III & 天保IO & 1839 & $\begin{array}{l}7 / 22 \\
\sim 24\end{array}$ & $\begin{array}{l}\text { 太祖宮蝗退散 } \\
\text { 祈䘠一座 }\end{array}$ & $\begin{array}{l}\text { 三触より } \\
\text { 総代庄 } \\
\text { 屋2人 }\end{array}$ & & $\begin{array}{l}\text { 3触より怱代庄屋二 } \\
\text { 人宛参詣 }\end{array}$ \\
\hline II2 & 天保IO & 1839 & $8 / 2 I$ & $\begin{array}{l}\text { 太祖宮於社内 } \\
\text { 角力一座 }\end{array}$ & $\begin{array}{l}\text { 郡奉行· } \\
\text { 大庄屋 }\end{array}$ & 正銭30目 & $\begin{array}{l}\text { 郡中夥敷参詣角力 } \\
\text { 行事参り }\end{array}$ \\
\hline II3 & 天保II & 1840 & $\begin{array}{l}\text { 正月元 } \\
\text { 旦 } 3\end{array}$ & 豊年祈䘠全座 & $\begin{array}{l}\text { 郡奉行· } \\
\text { 大庄屋 }\end{array}$ & 金2歩 & \\
\hline II4 & 天保II & 1840 & $\mathrm{II} / \mathrm{II}$ & $\begin{array}{l}\text { 太祖宮天気快 } \\
\text { 晴麦作豊登 }\end{array}$ & $\begin{array}{l}\text { 惣代庄 } \\
\text { 屋·当触 }\end{array}$ & & \\
\hline IIS & 天保I2 & I84I & $\begin{array}{l}\text { 正月元 } \\
\text { 旦 } 3\end{array}$ & 豊年祈䘠一座 & $\begin{array}{l}\text { 触·大 } \\
\text { 庄屋 }\end{array}$ & 金2歩 & \\
\hline II6 & 明和元 & $\begin{array}{r}1764 \\
(s i c)^{*}\end{array}$ & 8月 & $\begin{array}{l}\text { 当山為鎮守山 } \\
\text { 神勧請の件 }\end{array}$ & & & $\begin{array}{c}\text { 上須恵村皿山開起 } \\
\text { 安亮院賢儀代 }\end{array}$ \\
\hline II7 & 天保I2 & I84I & $\begin{array}{l}\text { 正月 } 25 \\
\sim 27\end{array}$ & 止雨祈祷一座 & 惣代 & 50目 & 始終雨天 \\
\hline
\end{tabular}

* Ajout d'une autre main à cette ligne. 


\begin{tabular}{|c|c|c|c|c|c|c|c|}
\hline II8 & 天保I2 & I84I & $4 / 26$ & 参籠祈願成就 & 大庄屋 & 金I歩 & \\
\hline 119 & 天保I2 & I84I & $7 / 7 \sim 9$ & 止雨祈䘠一座 & $\begin{array}{l}\text { 大庄屋· } \\
\text { 惣代 } \\
\text { 庄屋 }\end{array}$ & 50目 & \\
\hline 120 & 天保I2 & I84I & $8 / 2$ & $\begin{array}{l}\text { 太祖宮秋作祭 } \\
\text { 治風防災角力 } \\
\text { 奉納 }\end{array}$ & 大庄屋 & 30目 & \\
\hline I2I & 天保I2 & I84I & $5 / 28$ & $\begin{array}{l}\text { 太祖宮本地供 } \\
\text { 一座 }\end{array}$ & 大庄屋 & 30目 & $\begin{array}{l}\text { 和田大隈両村庄屋 } \\
\text { 病気二付平癒 }\end{array}$ \\
\hline 122 & 天保I2 & I84I & $\mathrm{II} / 20$ & $\begin{array}{l}\text { 〔殿様山狩 } \\
\text { の件〕 }\end{array}$ & & & $\begin{array}{l}\text { 当坊に御休泊 鹿 } \\
\text { 猪凡そ7ツ打留 }\end{array}$ \\
\hline 123 & 天保I3 & 1842 & 正月25 & $\begin{array}{l}\text { 〔殿様山猟 } \\
\text { の件〕 }\end{array}$ & & & $\begin{array}{l}\text { 当坊に御休泊 鹿 } \\
\text { 猪凡そ6\%打留 }\end{array}$ \\
\hline I24 & 天保I3 & 1842 & $\begin{array}{l}\text { 正月元 } \\
\text { 旦 } 3\end{array}$ & 豊年祈䘠一座 & $\begin{array}{l}\text { 郡司· } \\
\text { 惣代 }\end{array}$ & 金2歩 & \\
\hline 125 & 天保I3 & 1842 & $3 / 14$ & $\begin{array}{l}\text { 太祖宮祭礼麦 } \\
\text { 作豊饒祈祷 } \\
\text { 一座 } \\
\end{array}$ & $\begin{array}{l}\text { 郡中·大 } \\
\text { 庄屋 }\end{array}$ & 金3歩 & \\
\hline 126 & 天保I3 & 1842 & $7 / 1 \sim 3$ & $\begin{array}{l}\text { 太祖宮天気快 } \\
\text { 晴祈䘠 }\end{array}$ & \begin{tabular}{|l} 
郡司·大 \\
庄屋
\end{tabular} & 銭50目 & $\begin{array}{l}\text { 7/3触中庄屋参詣 } \\
\text { 御見舞素麺30抱 }\end{array}$ \\
\hline 127 & 天保I3 & 1842 & $\begin{array}{l}7 / 23 \\
\sim 26\end{array}$ & \begin{tabular}{|l|} 
太祖宮治風防 \\
災五穀成就護 \\
国珠法全座 \\
\end{tabular} & $\begin{array}{l}\text { 郡司·大 } \\
\text { 庄屋 }\end{array}$ & 金2歩 & $\begin{array}{l}\text { 目録在中 下宮に } \\
\text { 於いて昼夜触中庄 } \\
\text { 屋6人交代修法 }\end{array}$ \\
\hline 128 & 天保I4 & I843 & $\begin{array}{l}\text { 正月元 } \\
\text { 旦〜3 }\end{array}$ & 豊年祈䘠一座 & \begin{tabular}{|l} 
郡司·惣 \\
代庄屋
\end{tabular} & 金2歩 & \\
\hline 129 & 天保I4 & 1843 & $3 / 14$ & $\begin{array}{l}\text { 太祖宮祭礼麦 } \\
\text { 作成就祈䘠 } \\
\text { 一座 } \\
\end{array}$ & 大庄屋 & 3触金3歩 & \\
\hline 130 & 天保I4 & 1843 & & $\begin{array}{l}\text { 決願上宮二テ } \\
\text { 修法 }\end{array}$ & & 50目 & \\
\hline I3I & 天保I4 & I843 & $5 / 2 \sim 4$ & $\begin{array}{l}\text { 太祖宮天気快 } \\
\text { 晴祈䘠一座 }\end{array}$ & \begin{tabular}{|l|} 
郡司·大 \\
庄屋
\end{tabular} & & 3触中庄屋交代 \\
\hline 132 & 天保I4 & 1843 & $\begin{array}{l}7 / 17 \\
\sim 19\end{array}$ & \begin{tabular}{|l|} 
太祖宮疫病退 \\
散祈䘠全座二 \\
夜三日
\end{tabular} & 庄屋 & $\begin{array}{l}\text { 米I俵御 } \\
\text { 見舞素麺 } \\
\text { I2抱 }\end{array}$ & 若杉村中 \\
\hline 133 & 天保I5 & I844 & $\begin{array}{l}\text { 正月元 } \\
\text { 旦 } 3\end{array}$ & $\begin{array}{l}\text { 太祖宮豊年祈 } \\
\text { 䘠一座 }\end{array}$ & & 金1歩 & 倹約二付 I 歩丈滅成 \\
\hline 134 & 天保I4 & 1843 & $11 / 5$ & $\begin{array}{l}\text { 天気快晴并山 } \\
\text { 猟満足祈䘠 }\end{array}$ & & 銀4多3歩 & $\begin{array}{c}\text { 殿样当山遊猟の件 } \\
\text { 往来并休泊 同 } \\
\text { 日日和 翌日雨降 }\end{array}$ \\
\hline 135 & 天保I5 & 1844 & $2 / 5$ & $\begin{array}{l}\text { 天気快晴并山 } \\
\text { 猟満足祈䘠 }\end{array}$ & & 銀4多3步 & $\begin{array}{l}\text { 殿様当山猟の件 } \\
\text { 往来并休泊 猪打 } \\
\text { 留 5日日和吉 } \\
\text { 6日朝飯後降雨 }\end{array}$ \\
\hline
\end{tabular}




\begin{tabular}{|c|c|c|c|c|c|c|c|}
\hline 136 & & & & 〔鉄砲の件〕 & & & $\begin{array}{l}\text { 若杉村が鉄砲を持 } \\
\text { つことを許され、明 } \\
\text { 和6年5月20日に達 } \\
\text { せられ、明和7年7月 } \\
\text { 7日停止となる。 }\end{array}$ \\
\hline I37 & 天保I5 & I844 & $2 / 28$ & $\begin{array}{l}\text { 太祖宮天気快 } \\
\text { 晴麦作成就祈 } \\
\text { 䘠一座 } \\
\end{array}$ & $\begin{array}{l}\text { 郡司·大 } \\
\text { 庄屋 }\end{array}$ & 50目 & \\
\hline 138 & 弘化2 & 1845 & $3 / 14$ & $\begin{array}{l}\text { 太祖宮祭祀麦 } \\
\text { 作豊饒祈祷 } \\
\text { 一座 } \\
\end{array}$ & $\begin{array}{l}\text { 郡司·大 } \\
\text { 庄屋 }\end{array}$ & 金3歩 & \\
\hline 139 & 弘化 2 & 1845 & $\begin{array}{l}5 / 18 \\
\sim 21 \\
\end{array}$ & $\begin{array}{l}\text { 太祖宮降雨 } \\
\text { 祈䘠 }\end{array}$ & $\begin{array}{l}\text { 郡司·惣 } \\
\text { 代庄屋 }\end{array}$ & 6銭50目 & \\
\hline 140 & 弘化2 & 1845 & $7 / 6 \sim 8$ & $\begin{array}{l}\text { 太祖宮天龍降 } \\
\text { 雨祈䘠一座 }\end{array}$ & $\begin{array}{l}\text { 郡代·大 } \\
\text { 庄屋 }\end{array}$ & 金2歩 & $\begin{array}{l}\text { 祈䘠間庄屋衆交代 } \\
\text { 祈䘠入用品々郡中 } \\
\text { より 目録 }\end{array}$ \\
\hline I4I & 弘化2 & 1845 & $8 / 26$ & \begin{tabular}{|l|} 
於太祖宮庄 \\
屋芳助為当病 \\
平癒
\end{tabular} & 大庄屋 & 金I歩 & 日籠願成就 \\
\hline 142 & 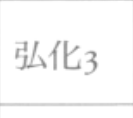 & I846 & $\begin{array}{l}\text { 正月元 } \\
\text { 旦 } 3\end{array}$ & $\begin{array}{l}\text { 豊年諸種新䘠 } \\
\text { 一座 }\end{array}$ & 郡司 & 金I歩 & \\
\hline 143 & 弘化 $_{3}$ & I846 & $\begin{array}{l}\text { 正月 } \\
27 \text { 日 }\end{array}$ & $\begin{array}{l}\text { 〔御上山㺌 } \\
\text { の件〕 }\end{array}$ & $\begin{array}{l}\text { 杉山文 } \\
\text { 右左 } \\
\text { 衛門 } \\
\end{array}$ & 300銅 & 鹿猪凡17㱜打留 \\
\hline I44 & 弘化4 & I847 & II/I9 & $\begin{array}{l}\text { 〔御上山唡 } \\
\text { の件〕 }\end{array}$ & & 450 多 & 御休泊 \\
\hline 145 & 弘化 5 & I 848 & $\begin{array}{l}\text { 正月 } \\
\text { I2日 }\end{array}$ & $\begin{array}{l}\text { 〔御上山猟 } \\
\text { の件〕 }\end{array}$ & & 450 多 & 御休泊 鹿猪I8㱜 \\
\hline 146 & 嘉永3 & 1850 & $\begin{array}{l}\text { 正月 } \\
\text { 26日 }\end{array}$ & $\begin{array}{l}\text { 〔殿様御山猟 } \\
\text { の件〕 }\end{array}$ & & 500 多 & \begin{tabular}{|l} 
御小休 鹿猪 \\
25 㱜 天気快晴山 \\
猟満足
\end{tabular} \\
\hline I47 & 嘉永 5 & 1852 & $4 / \mathrm{II}$ & $\begin{array}{l}\text { 〔正遷宮寄進 } \\
\text { の件〕 }\end{array}$ & & & $\begin{array}{l}\text { 御旗二流御紋付 } \\
\text { 施主庄屋 }\end{array}$ \\
\hline 148 & 嘉永 5 & 1852 & 4月 & 〔寄進の件〕 & & & 高銚灯6張御紋 \\
\hline I49 & 嘉永5 & 1852 & $4 / 18$ & $\begin{array}{l}\text { 〔正遷宮寄進 } \\
\text { の件〕 }\end{array}$ & 大庄屋 & & \begin{tabular}{|c} 
御社用薄り IO枚 \\
大庄屋
\end{tabular} \\
\hline 150 & $\begin{array}{l}\text { 嘉永6 } \\
7\end{array}$ & $\begin{array}{l}1853 \\
54\end{array}$ & $10 / I$ & $\begin{array}{l}\text { 〔殿様御山猟 } \\
\text { の件〕 }\end{array}$ & & 金I朱 & $\begin{array}{l}\text { 写 御小休 鹿猪 } \\
\text { 22疋 I日天気吉 } \\
\text { 2日大雨降 }\end{array}$ \\
\hline ISI & & & $\mathrm{II} / 2$ & $\begin{array}{l}\text { 〔殿様御山絾 } \\
\text { の件〕 }\end{array}$ & $\begin{array}{l}\text { 受持白 } \\
\text { 水専六 }\end{array}$ & 金2朱 & ミカン 50献上 \\
\hline 152 & 安政3 & 1856 & $2 / 9$ & $\begin{array}{l}\text { 〔殿樣御山猟 } \\
\text { の件〕 }\end{array}$ & 奥頭取 & 金500㱜 & $\begin{array}{l}\text { 鹿猪30疋打留 } \\
\text { 天気快晴山上安全 }\end{array}$ \\
\hline
\end{tabular}




\begin{tabular}{|c|c|c|c|c|c|c|c|}
\hline 153 & 安政4 & 1857 & $\begin{array}{l}\text { 正月 } \\
27 \text { 日 }\end{array}$ & $\begin{array}{l}\text { 〔若殿様御山 } \\
\text { 椫の件〕 }\end{array}$ & $\begin{array}{l}\text { 奧頭取 } \\
\text { •格式 } \\
\text { 頭取 }\end{array}$ & 金2米 & $\begin{array}{l}\text { 猪鹿33㱜打留 } \\
\text { 天気快晴山上安全 }\end{array}$ \\
\hline I54 & 嘉永7 & 1854 & 3月 & 本尊勧請 & 大庄屋 & & $\begin{array}{l}\text { 祭礼踊り・浄瑠璃奉 } \\
\text { 納許可·演目等 }\end{array}$ \\
\hline 155 & 安政5 & 1858 & $4 / 6$ & $\begin{array}{l}\text { 祭祀踊二座 } \\
\text { 興行 }\end{array}$ & 郡代 & & $\begin{array}{l}\text { 冨士見·行 } \\
\text { 大功記 }\end{array}$ \\
\hline 156 & 文久 3 & 1863 & 3月 & 祭祀踊 & 郡代 & & $\begin{array}{l}\text { 小野東風 昼一座 } \\
\text { 夜入一座 }\end{array}$ \\
\hline 157 & 安政5 & 1858 & $2 / 10$ & $\begin{array}{l}\text { 〔殿様御山絾 } \\
\text { の件〕 }\end{array}$ & & 2朱 & $\begin{array}{c}\text { 御休泊 鹿猪35㱜 } \\
\text { 山上安全天気吉 }\end{array}$ \\
\hline 158 & 安政6 & 1859 & $2 / 7$ & $\begin{array}{l}\text { 〔殿様御山猟 } \\
\text { の件〕 }\end{array}$ & & 2朱 & $\begin{array}{c}\text { 御休泊 鹿猪30疋 } \\
\text { 山上安全天気吉 }\end{array}$ \\
\hline 159 & 元治 2 & 1865 & $\begin{array}{l}4 / 13 \\
\sim \text { I4 }\end{array}$ & 祭礼踊二座 & 郡奉行 & & $\begin{array}{l}\text { 13日忠信講釈 } \\
\text { I4日悪源太平次 } \\
\text { 合戦 }\end{array}$ \\
\hline 160 & 元治元 & 1864 & $\begin{array}{l}3 / 29 \\
\sim 4 / 1 \\
\end{array}$ & 祭礼踊二座 & 郡奉行 & & \\
\hline I6I & 慶応3 & 1867 & $3 / 13$ & 祭祀踊奉納 & $\begin{array}{l}\text { 郡奉行· } \\
\text { 大庄屋 }\end{array}$ & & ウスユキ \\
\hline 162 & 慶應3 & 1867 & $3 / 16$ & 祭礼踊一座 & $\begin{array}{l}\text { 郡奉行· } \\
\text { 大庄屋 }\end{array}$ & & ケイセヒハンゴンコ \\
\hline 163 & 慶應3 & I867 & $4 / 3$ & $\begin{array}{l}\text { 〔殿様御山編 } \\
\text { の件〕 }\end{array}$ & & 金2朱 & 御休泊 鹿猪 24 疋 \\
\hline 164 & 慶應3 & 1867 & $10 / 5$ & $\begin{array}{l}\text { 〔少将様御山 } \\
\text { 猟の件〕 }\end{array}$ & & 2朱 & 鹿猪29疋 \\
\hline 165 & 明治 2 & 1869 & $3 / 14$ & $\begin{array}{l}\text { 太祖宮祭祀踊 } \\
\text { 一座 }\end{array}$ & 触口 & & 祭祀 $4 / 3$ \\
\hline 166 & 明治2 & I869 & $2 / 10$ & $\begin{array}{l}\text { 〔少将様御猟 } \\
\text { の件〕 }\end{array}$ & & 金2朱 & 御休泊 猪鹿20㱜 \\
\hline 167 & 明治3 & 1870 & $3 / 22$ & $\begin{array}{l}\text { 〔知事様御山 } \\
\text { 絾の件〕 }\end{array}$ & & 金2朱 & 御休泊 \\
\hline 168 & 明治3 & 1870 & 2月 & $\begin{array}{l}\text { 〔智事樣御山 } \\
\text { 猟の件〕 }\end{array}$ & & $\begin{array}{l}\text { 金子 } \\
\text { I } 200 \text { 㱜 }\end{array}$ & $\begin{array}{l}\text { 鹿9㱜打留 褒賞 } \\
\text { 金子I } 200 \text { 㱜 }\end{array}$ \\
\hline 169 & 安政7 & I860 & $\begin{array}{l}\text { 正月25 } \\
\text { 日 }\end{array}$ & $\begin{array}{l}\text { 殿様御山猟 } \\
\text { の件 }\end{array}$ & & 850 多 & $\begin{array}{c}\text { 天気快晴山上安全 } \\
\text { 鹿猪15㱜打留 }\end{array}$ \\
\hline 170 & 安政7 & I860 & $3 / 17$ & 同御山猟 & & 850 多 & 鹿猪25㱜 \\
\hline I7I & 安政7 & I860 & 3月 & $\begin{array}{l}\text { 神納猿田彦 } \\
\text { 二面・鋒 }\end{array}$ & \begin{tabular}{|l|}
\multicolumn{1}{|c|}{ 福城 } \\
士施主 \\
牧坂 \\
吉作 \\
\end{tabular} & & \\
\hline 172 & 文久2 & 1862 & 7月 & $\begin{array}{l}\text { 大鼓張替 } \\
\text { 代札 }\end{array}$ & 村中 & 90目 & \\
\hline
\end{tabular}




\begin{tabular}{|c|c|c|c|c|c|c|}
\hline I73 & 文久元 & I86I & $12 / 9$ & $\begin{array}{l}\text { 〔御山猟 } \\
\text { の件〕 }\end{array}$ & 2 朱 & $\begin{array}{l}\text { 中将様侍従様 } \\
\text { 鹿I7㱜打留 }\end{array}$ \\
\hline I74 & 文久2 & 1862 & $12 / 17$ & \begin{tabular}{|l} 
〔御山猟 \\
の件〕
\end{tabular} & 2朱 & $\begin{array}{l}\text { 御休泊 侍従様 } \\
\text { 鹿十正打留 }\end{array}$ \\
\hline 175 & 文久3 & 1863 & 正月 13 日 & $\begin{array}{l}\text { 〔御山猟 } \\
\text { の件〕 }\end{array}$ & 2 朱 & $\begin{array}{l}\text { 侍従様 御休泊 } \\
\text { 鹿I2疋 猪2正 }\end{array}$ \\
\hline 176 & 元治元 & I864 & $1 \mathrm{II} / 5$ & $\begin{array}{l}\text { 〔御山猟 } \\
\text { の件〕 }\end{array}$ & 2朱 & $\begin{array}{l}\text { 御両殿様御休泊 } \\
\text { 鹿猪 } 52 \text { 㱜 }\end{array}$ \\
\hline I77 & 元治 2 & 1865 & $2 / 10$ & $\begin{array}{l}\text { 〔御山猟 } \\
\text { の件】 }\end{array}$ & 2 朱 & $\begin{array}{l}\text { 侍従様 御休泊 } \\
\text { 鹿猪42疋 }\end{array}$ \\
\hline I 778 & 明治元 & I868 & $8 / 19$ & $\begin{array}{l}\text { 〔御山猟 } \\
\text { の件〕 }\end{array}$ & 2朱 & $\begin{array}{l}\text { 少将樣御休泊 } \\
\text { 鹿37㱜打留 }\end{array}$ \\
\hline 179 & 明治元 & I868 & II / II & $\begin{array}{l}\text { 〔御山猟 } \\
\text { の件〕 }\end{array}$ & 2朱 & $\begin{array}{ll}\text { 少将様 御休泊 } \\
\text { 鹿35㱜 }\end{array}$ \\
\hline
\end{tabular}




\section{Résumé en japonais/日本語要旨}

九州と東アジアの歴史にみる若杉山、太祖宮と修験

北部九州は地理的に朝鮮半島・中国大陸と最も近く、古代、対外交涉を受け持つ役所と して「大莘付」が㯰かれた。現在九州最大の都市「福岡市」は、大宰府の港「博多」を都 市的発展の母胎としている。若杉山は、太宰拊の宝満山から北へ連なる三郡山系の一峰で あり、海のソトからこの地へ入ってくるとき、港町博多の奥、正面に秀麗な姿を見せる山 である。この山の神「太祖権現」は、ウチなる土着の神ではなく、海を渡ってソトから入 ってきた神である。この神はさらに大きなソトである蒙古という敵に対して、八幡信仰と 融合し、この山オリジナルな伊帮諾尊＝太祖権現へと変貌した。ウチなるものは複雑に絡 み合いながらソトに向かってより強大な力を発揮しようとしたのである。

中世末の戦乱により疲弊した若杉山には、江戸時代初期、宝淦山から亀石坊が入り石泉 寺石井坊を復興した。石井坊は宝満山の一山組織では、宝満二十五坊の下位に位直する組 下山伏であった。しかし一方では、宝満修験の東の触頭として、宗像・両粕屋郡の山伏を 配下に置くとともに、糟屋郡の宗㗅「太祖宮」の宮司（別当）として、郡中村々の尊崇を 集めた。石井坊をとりまくウチとソトの力学は複雑である。

本論文は若杉山に展開した修験が、山の立地故に負ったウチとソトの力学を資料によっ て分析する。 